\title{
Joining of carbon fibre reinforced polymer (CFRP) composites and aluminium alloys-A review
}

\author{
A. Pramanik ${ }^{1 *}$, A.K. Basak ${ }^{2}$, Y. Dong ${ }^{1}$, P. K. Sarker ${ }^{3}$, M. S. Uddin ${ }^{4}$, G. Littlefair ${ }^{5}$, A.R. \\ Dixit $^{6}$, S. Chattopadhyaya ${ }^{6}$ \\ ${ }^{1}$ Department of Mechanical Engineering, Curtin University, Bentley, WA, Australia \\ ${ }^{2}$ Adelaide Microscopy, the University of Adelaide, Adelaide, SA, Australia \\ ${ }^{3}$ Department of Civil Engineering, Curtin University, Bentley, WA, Australia \\ ${ }^{4}$ School of Engineering, University of South Australia, Mawson Lakes, SA 5095, Australia \\ ${ }^{5}$ School of Engineering, Deakin University, Waurn Ponds, VIC, Australia \\ ${ }^{6}$ Department of Mechanical Engineering, Indian School of Mines, Dhanbad-826004, \\ Jharkhand, India.
}

\begin{abstract}
This paper investigates comprehensive knowledge regarding joining CFRP and aluminium alloys in available literature in terms of available methods, bonding processing and mechanism and properties. The methods employed comprise the use of adhesive, self-piercing rivet, bolt, clinching and welding to join only CFRP and aluminium alloys. The non-thermal joining methods received great attention though the welding process has high potential in joining these materials. Except adhesive bonding and welding, other joining methods require the penetration of metallic pins through joining parts and therefore, surface preparation is unimportant. No model is found to predict the properties of jointed structures, which makes it difficult to select one over another in applications. The choice of bonding methods depends primarily on the specific applications. The load-bearing mechanism of bolted joints is predominantly the friction that is the first stage resistance. Hybrid joints performance is enhanced by combining rivets, clinch or bolts with adhesives.
\end{abstract}

Keywords: carbon fibre reinforced polymer (CFRP) composites, aluminium alloys, joining.

\section{Introduction}

Carbon fibre reinforced polymer (CFRP) is one of the most important materials for structural applications, particularly in aviation industries owing to its high strength to weight ratio. CFRP contains extremely thin carbon fibres (CFs) of about $0.005-0.010 \mathrm{~mm}$ in diameter in polymeric matrices leading to light weight composite structures. At a microscopic scaled level, carbon 
atoms of fibres are bonded together parallel to the fibre axis, and thus give rise to the unidirectional alignment, which in turn contributes to superior tensile strength along with lightweight structures and low thermal expansion. In most real-life applications, CFRP requires joining with metal frames to form complete structures, which play an important role in hybrid design. Hybrid design is an emerging process of joining composites and metals with desirable and unique material characteristics such as higher strength and stiffness, resistance to physical damage due to cracks, resistance to radiation damage, design versatility etc. [1]. The popularity of such specific functional properties can meet enormous demands towards superior structures to exploit the best performance of both metals and composites [2]. Thus it is very critical to understand the issues associated with fabricating, machining and joining of composite materials [3].

Stack-up formation is an effective means to build composite/metal structures with high bending rigidity and insignificant increase in structural weight [4]. Furthermore, the sandwich stacking formation is also well utilized particularly for manufacutre of composite panels in commercial aircrafts like Airbus A380 or Boeing 787. CFRP/titanium, CFRP/aluminum and CFRP/CFRP are some typical material formations that are commonly used in engine cowlings, fairings, and fixed trailing edges, wing panels, helicopter blades, space optical benches , ship hulls, etc. [4]. It is also forseen thatthese types of composite structure formations will dominate the future applications in Lockheed-Martin's X-33, Raytheon's Premier I, and tilt rotorcrafts from Textron-Bell Helicopter or Boeing [5].

From a manufacturing point of view, joining of composite and metal stack-ups contributes to substantial amounts of total manufacturing cost due to the number of steps from the beginning to the final structural completion with high labor intensiveness. As reported in previous literature [7] , such cost may be as high as the half of the total cost of the products. Conventional mechanical fastening and adhesive bonding are generally used to fasten composites and metals together in relatively simple structures. Mechanical fastenings using bolts or rivets usually provide adequate joining strength, and thus can be widely used in engineering structures. However, mechanical fastenings suffer from weight increase and low sealing capacity. In addition, the cross-sectional area of structures decreases due to the presence of bolt holes with the stress increase. In addition, drilling process towards the formation of bolt holes causes cracks in composite structures. In view of that, adhesive joints are more favourable in that the process offers sealing effect with less significant stress concentration as well as flaw-free effect 
in composite structures. The selection of proper adhesives is critical for joining dissimilar materials because the adhesive degradation with time can significantly reduce the bonding strength. To tackle this issue, co-curing during the joining is an effective means by using excessive resins as adhesives, which ensures that curing and joining take place at the same time. Since this process is free from additional curing process, labour consumption is reduced accordingly. However, a significant increase in joining strength with respect to conventional adhesive bonded joints has not been expected [8]. . Consequently, welding and hybrid bonding are recommended in order to address the weakness of above- mentioned methods. In hybrid bonding, mechanical fastening on the top of adhesive bonding is added to improve the overall joining strength. In general, manufacturing time, performance and cost are vital factors in the selection process of a specific mechanical joint. With challenging technology ahead, blends of mechanical joints with adhesive bonding are anticipated [6-8].

Much research work in the field of CFRP and metal joining is available in literatures with numerous results. . Nonetheless, it is difficult in having a good understanding of this field due to disorganised and less linked scientific results obtained. Our current investigation studied different types of joining methods for CFRPs and aluminium alloys available in literatures. The main objective of this paper is to find the knowledge available in the joining CFRPs and aluminium alloys and link such knowledge for comprehensive understanding of joining effect. In this study, all the possible joining methods of these two materials were critically analysed, and the information such as, bonding process and mechanism as well as mechanical properties are presented holistically. In this way, industrial partners and researchers can benefit from this comprehensive review and overcome associated limitations and drawbacks in order to meet the future challenging in joining such materials.

\section{Adhesive bonding}

Adhesive bonding is the process of binding two components using a suitable binder (i.e. an adhesive). Applications of adhesives for joining elements made of dissimilar materials are commonly employed in aviation, automotive and building industries [9-12]. Joining of CFRPs with aluminium alloys via adhesive bonding is by far the most conventional method with both advantages and limitations. Since adhesive bonding is an irreversible process, attempts to dissemble the joints can be expensive, which results in the complete material damage involved in the joints. Adhesive bonding not only seals the joints but also prevents crevice and galvanic corrosion between two dissimilar materials. Almost any pair of dissimilar materials such as 
metals, polymers or ceramics can be joined with this method. Adhesive bonding is the only viable method to achieve structures involving the joining of thin-walled elements, among which an element has substantial dissimilar thickness. Adhesive bonding offers light-weighted structures with respect to other assembly technologies and developments, particularly in aviation industries. In addition, stress concentration becomes less significant without the requirement of bolt holes, thus avoiding structure weakening [13].

The adhesives as the main elements in adhesive bonding should have good wettability with respect to joining components, such as CFRPs and aluminium alloys, which are generally in a semi-solid state to facilitate associated applications. However, to fabricate load bearing joints, liquid adhesives have to be used, which have inbuilt ability to harden without curing in elevated temperatures. Exceptionally, pressure sensitive adhesives are permanently sticky and basically perform their function in a sticky state [14]. The selected adhesive must have lower surface tension than that of CFRP/Al 6061 alloy to ensure uniform wetting of entire surfaces so that the occurrence of droplets is avoidable. Uniformly spread adhesives improve molecular contacts between adherents, thereby increasing the joint strength. To achieve the ultimate strength from the joint, adhesives should be allowed to have enough time to set and to follow surface profile (i.e. roughness profile) of adherents. However, this is not possible by using fast setting and highly viscous adhesives. As such hot-melt thermoplastic adhesives are not suitable for such applications [15]. In this case, two components of elastomers can be used to form rubber-like joints retaining their elasticity at low temperatures and elastic epoxy adhesives depending on different applications. Epoxy adhesives result in product high strength and durability after being cured at high temperatures [16].

\subsection{Joining Methods by adhesive bonding}

Prior to a bonding process, adherents (i.e. CFRPs and aluminium alloys in this case) are required to be thoroughly cleaned, which means that any contamination removal should be made by degreasing either via mechanical polishing or by using wipe cloths in order for the surfaces to be bonded. Hence the preparation depends primarily on adherents and adhesives to be used in the joining process. Emery papers of different grades and solvents like acetone can be used for this purpose. Usually etching or light abrasion is followed by the solvent wipe to get rid of grease and other loose dirt. Etching can be carried out in a chemical manner by using hydrochloric acid and water (e.g. 20 to 80\%). Despite such a quick process, it discolours metal surfaces owing to the oxidation effect. A universal etchant, used for aluminium alloys, involves 
chemical etching before microstructural contrasting in polarised light. Detergents must be avoided for both components in that they can further aggravate contamination [19]. More details of surface preparation coupled with their effectiveness are discussed in subsequent sections.

In case of aluminium alloys, surface films in the formation of aluminium oxide $\left(\mathrm{Al}_{2} \mathrm{O}_{3}\right)$ are unavoidable upon exposure to air or water, resulting from very low wetting capability. such tenacious films are hard to remove with the requirement of extensive chemical treatment [17]. Therefore, the surface should be chemically modified in order to prevent such film formation in first place. This can be done either by adding coupling reagents or by anodizing [18]. Coupling reagents form such strong and irreversible covalent bonds between surface oxides and hydroxides, which are in turn linked with adhesive during the curing process. On the other hand, anodizing results in the formation of rough and water-resistant oxide films at micro scale level by using sulphuric, phosphoric or chromic acid. Sulphuric acid treatment is used in lightly stressed joints to obtain the best results for the application of elastic adhesives. Anodizing with chromic and phosphoric acid is performed for highly stressed joints, which are meant to be used in the corrosive environment. This process actually forms regular micro pores in oxide layers towards underneath metal surfaces. During the curing process, adhesives fill up those micro pores and eventually reach the metal surfaces. The treatment with phosphoric acid gives best results when used with low viscosity primer [19]. If proper steps are followed to clean the surfaces using such strong oxidising agents, the results of this can lead to excellent surface finish without deteriorating their properties. Afterwards the application of primer prepares the surface for adhesion with stronger and more uniform bonding [20].

In addition to chemical treatment, acetylene and nitrogen plasma can also be used to modify aluminium panel towards adhesive bonding [21]. Figures 1 and 2 show the volume effect of different gases during plasma treatment as well as treatment time on contact angle of aluminium with water. This plasma treatment modifies the surface characteristics of structures, as evidenced by the change in contact angle between aluminium and water from $82^{\circ}$ to $135^{\circ}$. The contact angle was minimum in a gas mixture of acetylene/ nitrogen with a volume ratio of 3:7 for the exposure time of $90 \mathrm{~s}$ as opposed to $5: 5$ for $30 \mathrm{~s}$. 


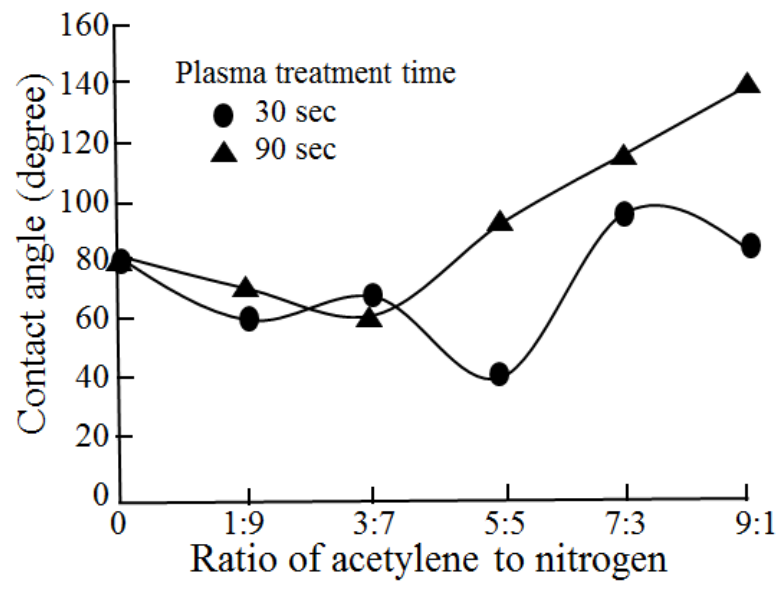

Fig. 1: Effect of volume ratio of acetylene /nitrogen on contact angle of aluminium with water [21].

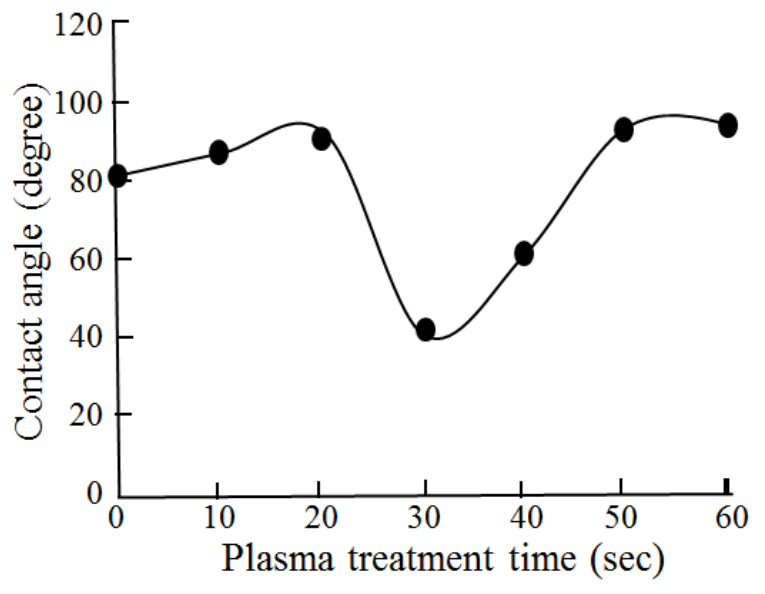

Fig. 2: Effect of exposure time on contact angle between aluminium and water for acetylene /nitrogen at the volume ratio of 5:5 [21].

Contact angle decreases because of surface cleaning and the formation of hydrophilic polar groups, as claimed by Rhee et al. [21]. Primer is recommended to be used for the components in the corrosive environment or where pre-treatments do not offer any obvious benefits. Most recommended treatments for aluminium alloys consist of a pre-treatment procedure that includes degreasing of materials, rinsing, acid/base etching, which are followed by a final rinse. The most commonly used etching solutions are sulphuric/chromic acid or sodium dichromate. Adhesives should be applied immediately to avoid any further contamination of freshly prepared metal surfaces [22].

In addition to aluminium panel, CFRPs also require the pre-treatment in the form of mild abrasion, which can be achieved by hand sanding using abrasive wash clothes or by grit blasting. However, the latter method is more preferable as hand sanding could trap the contaminants or moisture onto the surface, as well as interrupt uniform applications over the surface. Aluminium oxide $\left(\mathrm{Al}_{2} \mathrm{O}_{3}\right)$ grit blasting in dry nitrogen offers desirable surface finish and adhesion [23]. Grit blasting followed by treatment of saline makes a significant increase in bonding strength compared to an untreated material. Plasma surface treatment can also be used on CFRPs, as mentioned by Meyer et al. [24] to enhance the adhesion strength of CFRPs with $\mathrm{Cu}$-electroplated films in a dual frequency mode of $40 \mathrm{kHz}$ and $2.45 \mathrm{GHz}$ with a plasma surface etching process in $\mathrm{O}_{2}$ and $\mathrm{C}_{2} \mathrm{~F}_{6}$ atmosphere. Three-directional orthogonal oxygen plasma significantly improves the interfacial adhesion due to the activation of fibre surfaces and the formation of oxygenic functional groups [25]. Chemical etching with $\mathrm{KMnO}_{4}$ solution 
increases the surface roughness and offers interlocking surface sites to improve the performance of adhesive bonding [26]. Physical and chemical plasma treatments of CFRP with $\mathrm{Ar}$ and $\mathrm{O}_{2}$ gases, respectively, with the aid of linear ion beam enhance the adhesion and contact angle with water and gas permeation [27]. It is important to note that treatment parameters like voltage and etching period greatly impact surface wettability in such treatments [28].

Surface treatment of polymers by radio frequency plasma in air, oxygen, nitrogen, argon and helium for biomedical applications has also been reported [29], which can positively affect adhesion promotion, wettability/spreading while reduce friction. However, optimizations of plasma treatment parameters are essential as overdoing the treatment may deteriorate bonding properties [25]. Figures 3 and 4 show the effects of plasma treatment parameters, namely, voltage and duration on contact angle of CFRPs with water in $\mathrm{Ar}$ and $\mathrm{O}_{2}$ plasma etching atmosphere, respectively. Contact angle at 0 min was a reference for all specimens just before the start of the treatment. Maximum contact angle was recorded at this stage when a water droplet was placed on surfaces. A gradual decrease in contact angle was observed due to the materials' response to wettability and the droplets start to spread resulting in a decrease in contact angle.

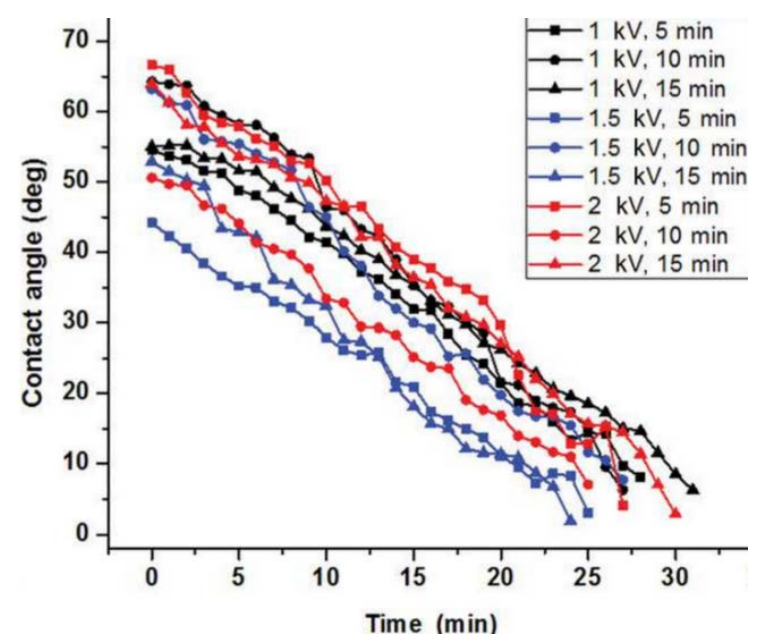

Fig. 3: Contact angle of CFRPs with water droplets treated in Ar plasma [27].

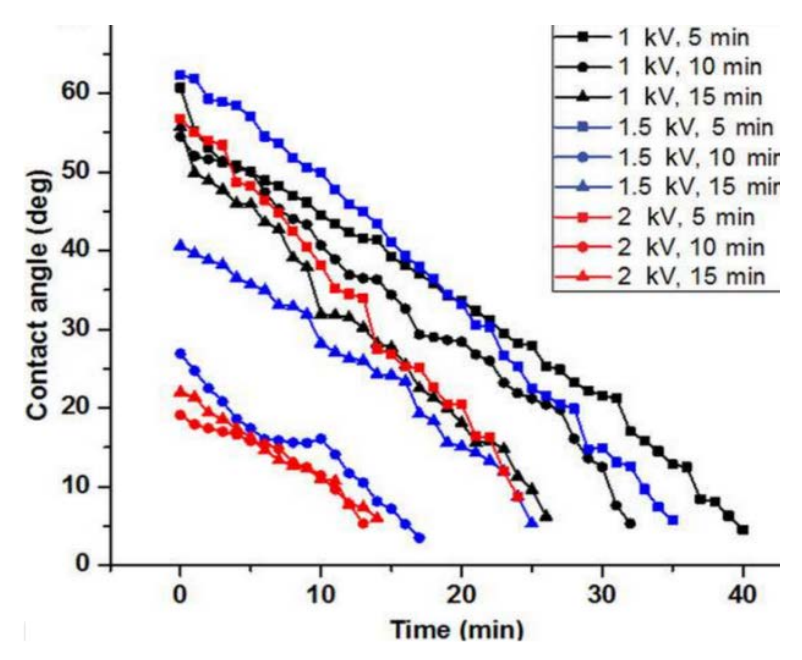

Fig. 4: Contact angle of CFRPs with water droplets treated in $\mathrm{O}_{2}$ plasma [27].

Ar plasma etching at $2 \mathrm{kV}$ for 5 min provides a higher contact angle as compared to others. With the further continuation of the process ( $2 \mathrm{kV}$ and 5 min to $2 \mathrm{kV}$ and 10min), the point angle decreased from $68^{\circ}$ to $52^{\circ}$ and then it increased to $65^{\circ}$ when the etching continued for 15 min. However, etching with high energy ions for a longer time causes fibre damage, thus 
resulting in decreases in tensile, bending and fatigue strengths. Therefore, 10 min etching at 1 $\mathrm{kV}$ energy was considered to be the optimum. Due to the use of low energy, the consequence of $1 \mathrm{kV}$ is not significant on preliminary contact angle, and the extension of etching time to 15 min decreases the surface tension causing an increase in spreading rate. This decreases spread out time of droplets by 14 min (Fig. 6). The same trend was observed for the $2 \mathrm{kV}$ process where contact angle increased to $58^{\circ}$ in the initial 5 min of etching and then reduced to $19^{\circ}$ and $22^{\circ}$ after 10 and 15 mins of etching, respectively. Hence etching time shorter or longer than 10 min decreases contact angles as the initial plasma etching lowers surface roughness and makes it smallest after $10 \mathrm{~min}$. Surface quality starts to degrade after that, as result of typical fibre breakage and cavity/pore formations. In addition, small air pockets were also formed in subsurface areas and water droplets enhanced contact angles. It has also been noted that oxygen plasma treatment is more effective to reduce contact angle compare to Ar plasma treatment (Figures 3 and 4) according to Chung et al. [30] and Rhee et al. [31]. Another variation of ion related plasma treatment is ion beam enhanced deposition (IBED), which involves the application of adhesives using a targeted ion beam onto the surface [18]. $\mathrm{Ar}^{+}$irradiation under the oxygen environment affects the contact angle and surface energy of CFRPs [21], as illustrated in Figures. 5 and 6.

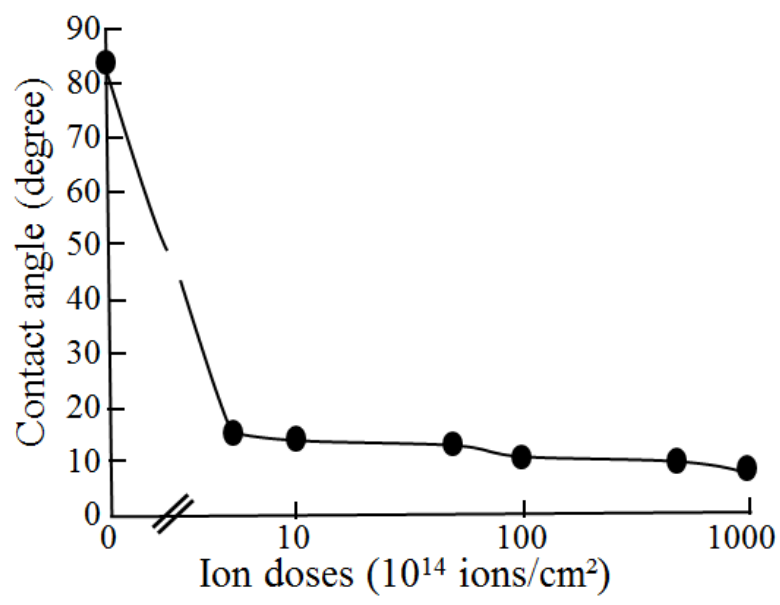

Fig. 5: Effect of $\mathrm{Ar}^{+}$dose on contact angle between water droplets and CFRPs [21].

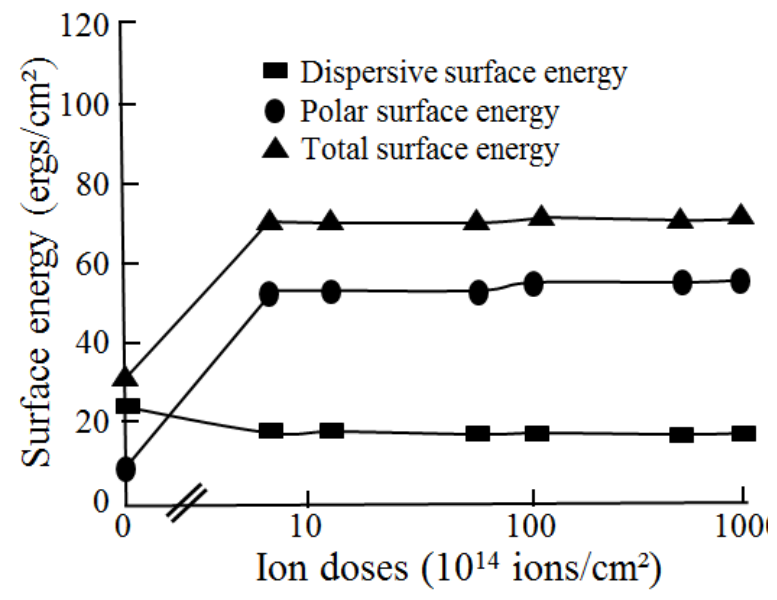

Fig. 6: Effect of $\mathrm{Ar}^{+}$dose on surface energy of CFRPs [21].

Figure. 5 shows that the contact angle decreasing for the dose of $\mathrm{Ar}^{+}$is up to $1 \times$ $10^{16}$ ions $/ \mathrm{cm}^{2}$ and then remains constant for the further increase dose. Contact angle for composite sheets before the treatment was around $80^{\circ}$ and then was reduced to $8^{\circ}$ after the surface treatment with $1 \times 10^{16}$ ions $/ \mathrm{cm}^{2}$ of $1 \mathrm{keV}$ energy in cold hollow cathode-type ion gun (5 cm diameter) with the vacuum pressure below $10^{-4}$ Torr. In this case, $\mathrm{Ar}^{+}$gas (99.99\%) was 
inserted into ion gun at $1 \mathrm{ml} / \mathrm{min}$ for $99.99 \%$ of oxygen gas to be gusted on CFRP surfaces at $4 \mathrm{ml} / \mathrm{min}$. Figure 6 shows an increase in polar surface energy with the increase of ion dose but the energy is stabilized at $10^{15}$ ions $/ \mathrm{cm}^{2}$. Dispersive surface energy is also reduced initially with the increase of ion dose until it reaches certain value as the threshold and then becomes almost constant with the intensification of ion dose thereafter. It is seen that aggregated surface energy increases in a similar trend to that of polar surface energy. This phenomenon indicates that polar surface energy backs the total surface energy. Total surface energy of composite sheets before the treatment was $31 \mathrm{ergs} / \mathrm{cm}^{2}$ and it became $72.4 \mathrm{ergs} / \mathrm{cm}^{2}$ afterwards with $1 \times$ $10^{16}$ ions $/ \mathrm{cm}^{2}$ dose [21].

Based on the above-mentioned discussion, surface preparation and treatments at optimal conditions are prerequisite towards superior adhesive bonding. There are a number of options available towards that and optimum parameters should be considered based on availability and materials in question.

\subsection{Mechanism of adhesive bonding}

A typical joint between CFRPs and aluminium alloys by adhesives, such as epoxy, is shown schematically in Fig. 7.

Adhesive in between the

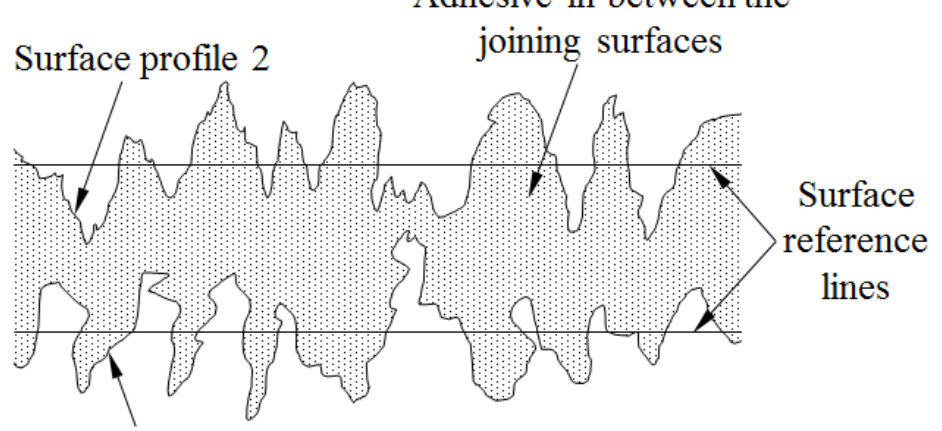

Surface profile 1

Fig. 7: Schamatic diagram of a typical adhesive joint between CFRPs and aluminium alloys.

A number of mechanisms take place in joints during the curing process to form active and strong bonds depending on location. Adhesive-CFRP interface (ACI), adhesive-aluminium alloy interfaces (AAI) and adhesives themselves are three distinct locations where different types of changes are anticipated in the course of curing process. Most significant changes occur in the surrounding areas of interfaces and generates 'interfacial zone' exhibiting the gradient 
effect in properties dissimilar to that of bulk properties [32]. The key factor that affects the level of adhesion is generally the cohesive strength of a weak boundary layer even when interface failure may occur [33]. Therefore, adhesion and cohesive energy of weaker interfacial layers are equally based on the possibility that fracture should not spread only through the interfaces of adhesive substrates, as the cohesive failure inside the weaker materials close to the interfaces is highly possible[32]. The distribution and concentration of stresses in materials dictate the failure propagation near the interfaces but not along the interfaces [32, 34, 35]. The concept of 'thick interface' or 'interphase', is commonly used in the adhesion discipline where interphases are generated regardless of substrates or adhesives. Interphase thickness ranges from several nanometres to a few micron or more. A number of physical, physio-chemical and chemical phenomena account for such interphase generation [36].

A numer of theories are avaible in literatures to describe adhesive bonding mechanism, namely adsorption and diffusion theories, and mechanical mechanism. These different theories and their contributions to the understanding of adhesive bonding mechanism are discussed briefly in subsequent sections:

(i) Adsorption: According to adsorption theory, adhesive provided an intimate contact between adherents due to the inter-atomic and inter-molecular forces at interface. Lewis acid-base and van der Waals interactions generate those interfacial forces. The amount of these forces depends on vital thermodynamic parameters like surface free energies of both adhesive and adherent. The first step towards bond formation is liquid-solid interaction and therefore good wetting of the surfaces dictate overall adhesion quality [37]. According to electronic theory of adhesion, mechanism of an electron transfer stimulate substrate and adhesive which have dissimilar electronic band configurations and can balance Fermi levels. This induces double electrical layer generation at interface and thus electrostatic forces are generated which back adhesive strength considerably [32, 38, 39].

- Diffusion theory: According to this theory, adhesion strength of polymers to polymers, or polymers to others is associated with the inter-diffusion of molecules through interface for the interphase generation. Thus the presence of macromolecular chains or parts of chains that are appropriately mobile and mutually soluble [40] in the interphases, enables the adhesion process for self-healing and welding. Joint strength for inter-diffusion phenomena depends on diverse aspects, namely contact time, 
temperature, nature and molecular weight of polymers and so on [40]. Chemical interactions in substrate-adhesive interfaces significantly contribute to adhesion between joining parts, which are usually assumed as main bonds as compared to physical interactions. For instance, van der Waals interactions are well-known as secondary force interactions. The molecules of adhesion additives, generally knows as coupling agent (based on silane molecules), promotes interfacial chemical bonds and increase the strength of joint between substrates and adhesives by forming a chemical linkage at borders [41]. Those are usually active in structures including glass or silica substrates and further specifically in CFRPs. In addition to the improved joint strength, coupling agents also resist the moisture on interfaces [32].

- Mechanical keying or interlocking: Mechanical keying allows adhesives to wet cavities, pores and asperities of adherent surfaces and thus contributes to adhesive strength significantly after curing [32]. Nonetheless, the chance to from decent adhesion among smooth surfaces indicates that theory of mechanical keying is not universal. The effects of mechanical interlocking and thermodynamic interfacial interactions are multiplying factors for assessing joint strength [42, 43] and the intensification of adhesion by mechanical keying is attributed to the increase in interfacial areas because of rougher surfaces. Moreover, wetting conditions enhance the adhesive penetration in pores and cavities. For example, high peel strength of polyethylene on metallic substrates can be achieved when rougher and fibrous oxide surfaces are formed [44], and the further improvement can be obtained by utilizing plasma surface treatment. In that case, the prolonged plasma treatment creates a rougher configuration on polyethylene surfaces, filled by epoxy resin later with dints of good surface wetting [45-47].

In reality, all above-mentioned mechanisms contribute to the strength of adhesive joints. Once adhesives and substrates are in contact, attraction forces start to act between them with adequate wetting, these forces are usually sufficient to afford high strength bonding. Main bonding is essential to achieve durable bonding in an aggressive atmosphere. Mechanical interlocking among rough surfaces and adhesives also require good wetting, otherwise surface roughening is likely to cause inferior bond strength. Superior adhesion is related to increased plastic energy release at the time of fracture in main adhesive parts. Electrostatic concept heads for electrical phenomena such as sparking, which may occur at the time of adhesive bonding break. The electrostatic charge transmission between substrates and adhesives is analogous to a parallel 
plate condenser. The energy related to this process is usually too small compared to that of adhesion fracture. A diffusion concept has attracted increasing interests in the provision of a model for polymer-to-polymer adhesion, which explains the dependence of adhesion on time and molecular weight for polymers with different compatibilities [48].

\subsection{Properties of adhesive bonding}

Bulk adhesive strength is much lower than that of metals. However, when it is used to bond surfaces with large bearing areas, adhesive strength is high enough for structural joints [15] and its credibility is proportional to joining surface areas. Bonding strengths of structures made of polymer composite and metals are considerably influenced by the preparation of composite surfaces as well as metallic structures [21, 49, 50]. It was reported that T-peel and shear strengths of plasma-treated aluminium/CFRP composites were six times higher than those of untreated aluminium/CFRP composites [51]. Fig. 8 shows a typical load-displacement curve for different adhesive bonded joints such as CFRPs and Al5052 H34. Initially, the load increases linearly with the displacement in a non-linear increasing manner up to the maximum load at different rates. The specimens show highest stiffness when both CFRP and Al5052 H34 surfaces are treated (curve 1) and lowest stiffness is noted when none of the surfaces is treated (curve 4). In case of curve 1, the joint failed at the highest load with the shortest displacement opposite to curve 4, where displacement continued at an almost constant load till it fractured.

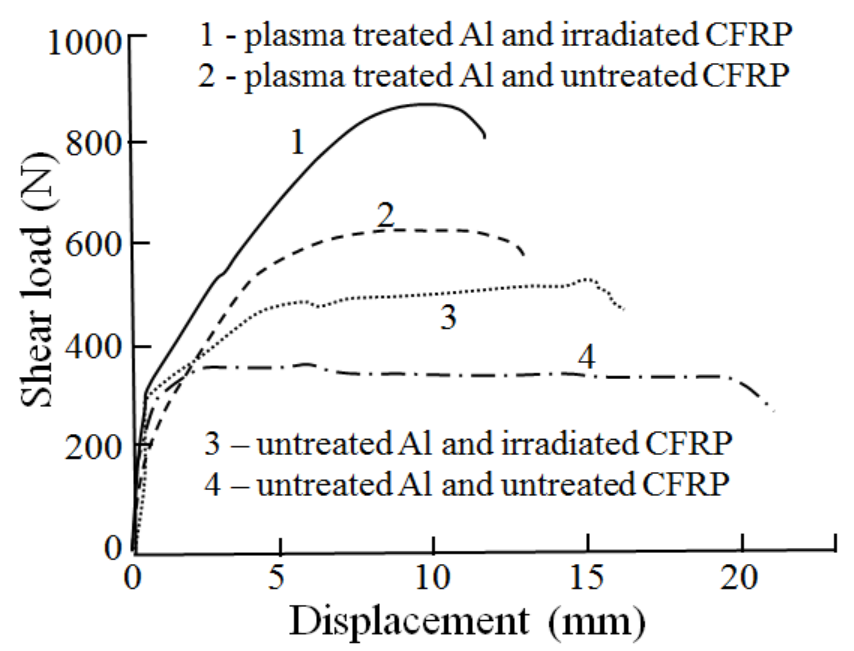

Fig. 8: Shear-load versus displacement curves for adhesive bonded CFRP and Al5052 H34 joints subjected to different surface preparations of adherents [21]. 
Second highest stiffness was noted when Al5052 H34 was treated, which was not the case for CFRPs. Fracture loads of the specimens were found as the highest load in the relevant loaddisplacement curve. Average shear strengths of plasma-treated aluminium/irradiated CFRPs, plasma-treated aluminium/untreated CFRPs, untreated aluminium/ irradiated CFRPs and untreated aluminium/untreated CFRPs were determined to be $0.75,0.56,0.48$ and $0.36 \mathrm{MPa}$, respectively [21]. Figure 9 presents load-displacement curves from T-peel tests of abovementioned specimens, whereas Fig. 10 shows a data comparison calculated from Fig. 9.

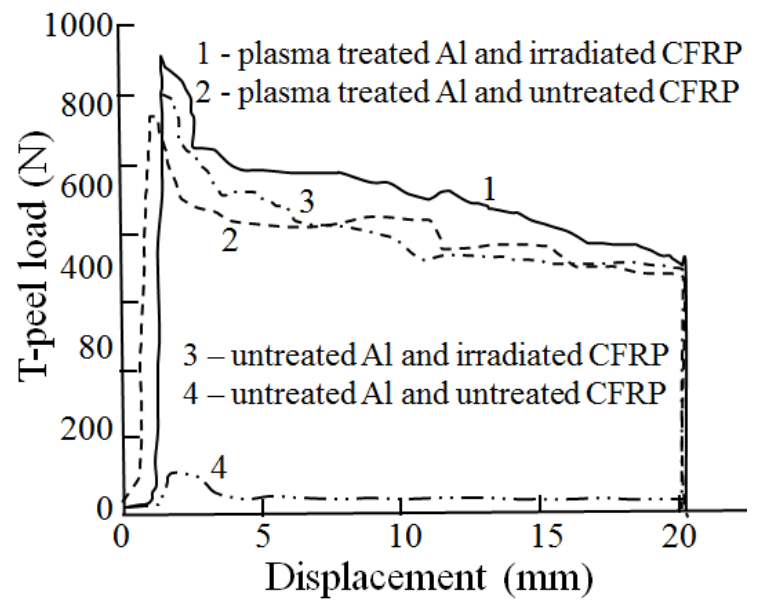

Fig. 9: T-peel load-displacement curves for different specimens [21].

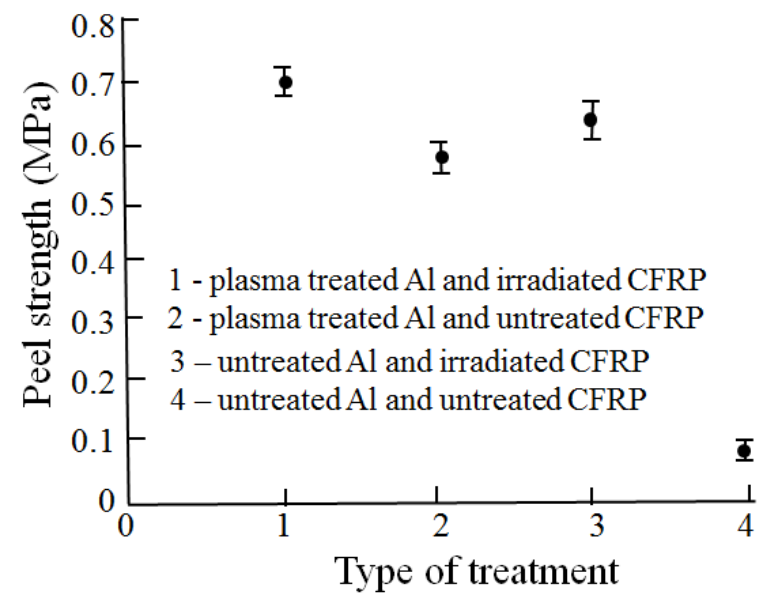

Fig. 10: T-peel strength for different specimens [21].

As shown in Fig. 9, loads increase significantly without causing noticeable displacements for almost all cases till they reach peak values. At the peak stage, fracture initiation occurs resulting in the decrease of loads with continuously increasing the displacement until the completion of fractures. It is interesting to note that complete fracture occurred at almost similar loads and displacements in all cases irrespective of surface treatment except for the joints between nontreated aluminium and CFRPs (curve 4). T-peel strengths of the specimens were calculated by considering the highest load in corresponding load-displacement curves. As shown in Fig. 10, T-peel strength was improved considerably by treating the surface by $\mathrm{Ar}^{+}$irradiation and plasma. Compared to the trend of shear strength, T-peel strength of plasma-treated aluminium/irradiated CFRPs is the highest and that of untreated aluminium/untreated CFRPs is the lowest. Average T-peel strengths of plasma-treated aluminium/irradiated CFRPs, plasma-treated aluminium/untreated CFRPs, untreated aluminium/irradiated CFRPs and untreated aluminium/untreated CFRPs were detected to be $705 \mathrm{~N}, 575 \mathrm{~N}, 630 \mathrm{~N}$ and $97 \mathrm{~N}$, respectively. $\mathrm{Ar}^{+}$ion irradiation of CFRPs in $\mathrm{O}_{2}$ atmosphere considerably affects fracture 
displacement, fracture load and fracture toughness of adhesive joints of CFRP/aluminium sheets. Load of fracture as well as fracture toughness were increased by 28 and $72 \%$, respectively, due to the treated CFRP surfaces. Adhesive failure is the main reason for the fracture of untreated aluminium/CFRPs. On the other hand, cohesive failure was the major failure approach for ion beam-treated aluminium/CFRPs [52].

A schematic diagram of typical brittle adhesive joints together with scanning electron microscopic (SEM) images is shown in Fig.11. non-uniform thick adhesive layer remains between two parts and interlocks peakes/ valleys of surface profiles, as shown in Fig. 7, which implies the complex nature of load bearing mechanism of adhesives.

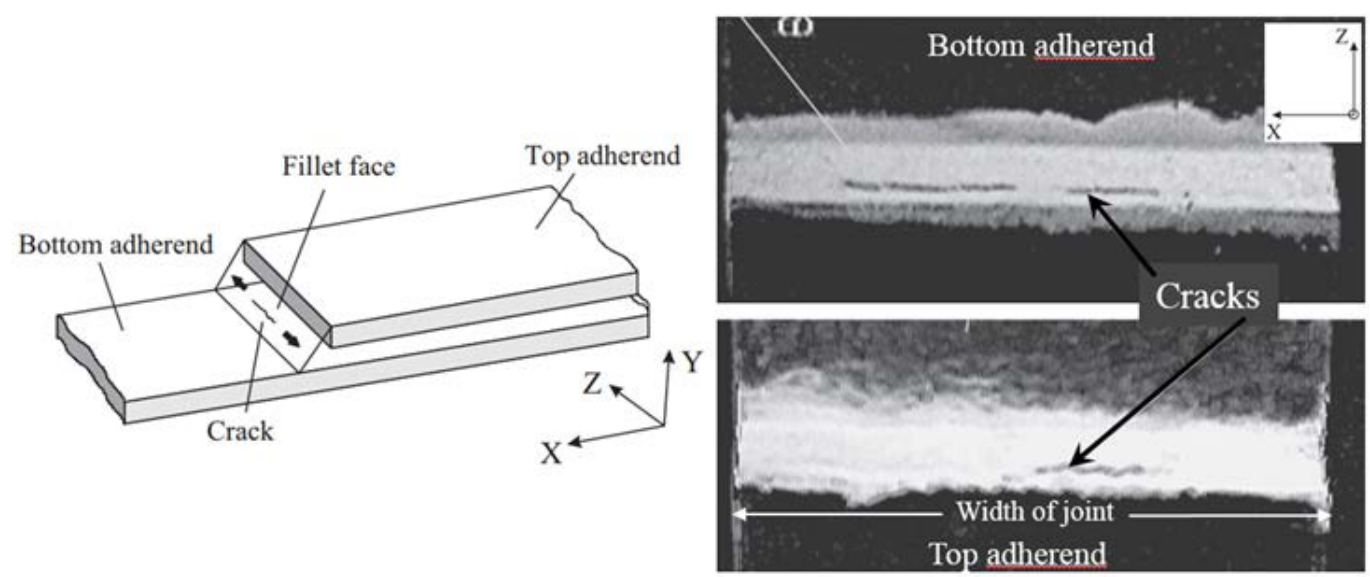

Fig. 11: Joint failure with brittle adhesives [53].

An adhesive fails when the strength of adhesive materials becomes much weaker as compared to that of the adherents for a perfectly bonded adhesive joint. Otherwise either of adherents fails and the adhesive behavior is assumed to be linear-elastic up to the point of damage initiation. Cracks start to occur around entrenched adherend corners under the overlap)in the middle of the joint along its width. With time elapsing, these cracks spread out to fillets and under overlap [54] and primarily depends on brittle or ductile nature of adhesives. Cracks initiate and spread out till disastrous failure occurs at the point when an adhesive has the brittle behaviour. On the other hand, plastic zones appear ahead of 'crack tip' by generating a damaged zone when an adhesive deforms plastically. In case of a typical brittle adhesive, cracks appear in the fillet face [54] at the middle of joint width. As for a ductile adhesive, cracks leave the whitened zone. Fig. 12 illustrates the process for ductile adhesives as well as corrosponding micrographs [53]. 

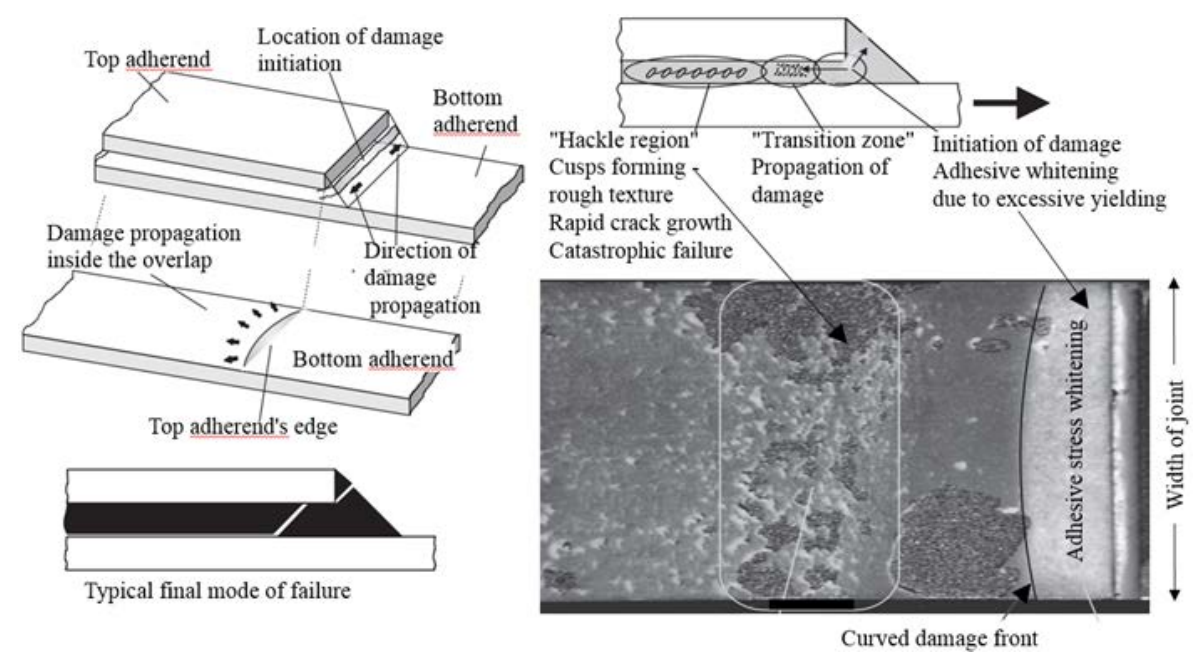

Fig. 12: Failure mechanisms for ductile adhesives in steels [53].

As seen in Fig. 12, three distinctive cohesive types in fracture regions were noticed with respect to surface roughness. These are: (i) the mirror region that is smooth and featureless and commonly known as 'stress whitening'. This is due to high adhesive deformation usually taking place around the failure origin and related to the gentle spread with the occurrence of the damage; (ii) a smooth, matt-finish area known as 'mist' in which the fracture speeds up and changes to hackle. It is rough-textured surface due to rapid damage progression. The speed of damage propagation depends on the morphology of fracture surfaces [55]. Smooth areas are related to certain zones where damages (or cracks)are accelerated and (iii) rough area in relation to disastrous failure corrosponding to fast damage growth and crack bifurcation.

Figures 13 and 14 present SEM micrpgraphs of fractured surfaces from T-peel tests for the combined treatments such as plasma-treated aluminum/irradiated CFRPs and untreated aluminum/untreated CFRPs Accordingly. Figure 13 indicates that epoxy adhesives were evenly disseminated on composite and aluminum panels for plasma-treated aluminum/irradiated CFRPs. The reason behind this is the improved surface energy due to the treatment of joining surfaces. Cohesive failure was the predominent fracture type as epoxy adhesives on CFRP and aluminum panel surfaces were fractured and damaged (Fig. 13). In contrast, Figure 14 exhibits non-uniform and localized distribution of epoxy on CFRP and aluminum sheets for untreated CFRP / untreated aluminum. This indicates that adhesive failure is a primary fracture mode as the failure happens at the border among CFRP/aluminum panels and adhesives. 


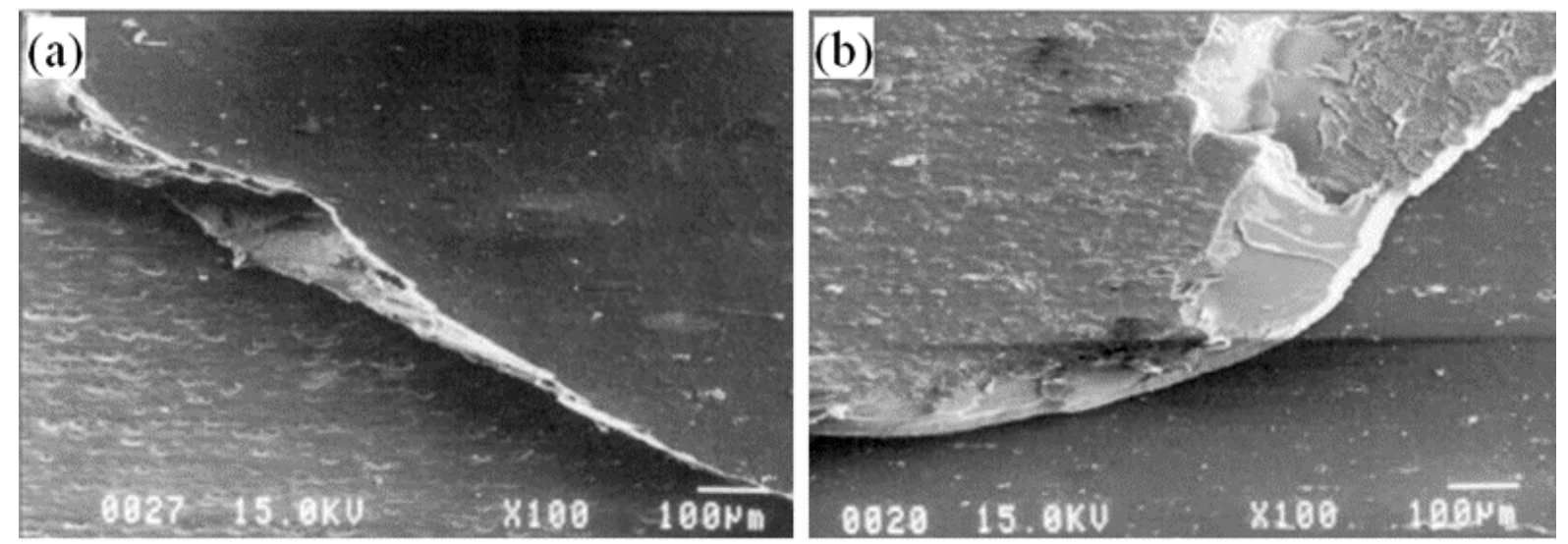

Fig. 13: Plasma-treated aluminum/irradiated CFRP joint after T-peel test: (a) aluminum panel and (b) CFRP panel [21].
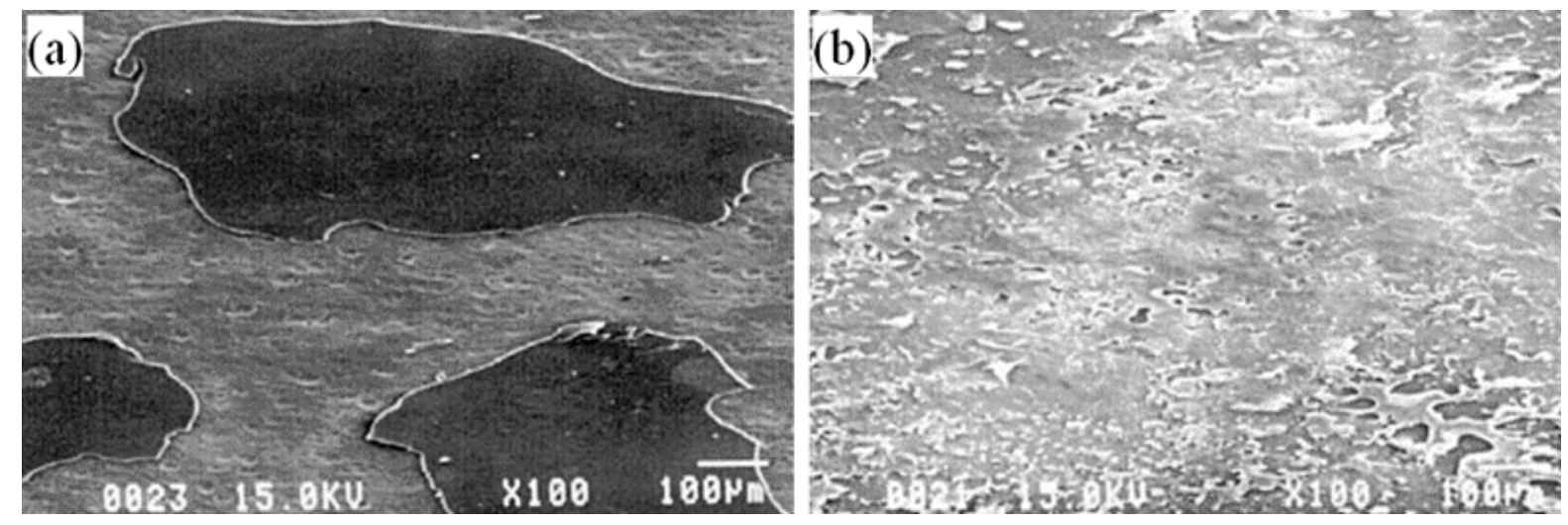

Fig. 14: Untreated aluminum/untreated CFRP joint after T-peel test: (a) aluminum panel and (b) CFRP panel [21].

If adhesive joints are exposed to temperature gradient, thermal stresses arise because of thermal and mechanical divergences. Thermal loads plays an important role in the course of bonding adherents with dissimilar thermal expansion/contraction coefficients. Moreover, in case of a restrained joint, stresses can reach considerable levels towards joint failure. Developed stresses due to mechanical shrinkage of adhesives have lower impact on lap joint strength when compared to those occurring due to thermal mismatch [56]. However, gradual variation of adhesive properties owing to temperature change is the major concern for applying adhesives in environments where the temperature fluctuates considerably. The situation becomes more complex in that most of structural metals have relatively stable properties in a temperature range of $-50^{\circ} \mathrm{C}$ to $+150^{\circ} \mathrm{C}$, whereas adhesives show a dramatic change $[57,58]$. As reported by Harris and Fay [59], joints are subjected to fatigue and static loading at diverse temperatures, and thinner adhesive coats give stronger and fatigue resistant joints. The temperature increase decreases the joint strengths for different bond line thicknesses [57]. 
Several limitations could arise as a result of binding two very dissimilar materials (i.e. CFRPs and aluminium alloys). For example, thickness of graphite or epoxy adhesives is limited for bonding purposes only. As a whole, stiffness difference remarkably decreases load bearing capacity of the structure. A further decrease in the overall strength is the result of thermal imbalance as discussed in previous sections. Therefore, in order to have a balanced joint, two materials should have similar thermal and elastic properties, as well as other physical properties. In particular, elastic constant and thermal expansion coefficient should also be as close as possible. Greater variations in these values could result in residual stress [19] with predominant effect on mechanical properties of single-lap joints, thus decreasing mechanical properties and service life [63]..

A number of extensive research was performed to calculate the overall joint strength, crack formation and propagation in single lap joints $[60,61]$ as well as residual stress in composite structures [62, 63]. There are numerous models available that are used for the modelling of joint properties such as Baker double-sided reinforcement patch model, Rose model, WangRose model and Van Bameveld-Fredell [64]. Based on original Rose model, Wang-Rose model is an improved model form to explore the circular composite patch repairing circular flat-sided patch and able to estimate residual thermal stress of patch templates in the centre as well as in downsides. Effects of heating and cooling processes associated with curing arrangement were taken into consideration for the estimation of residual stress in this model. Van Bameveld-Fredell model calculates residual stresses of various structures and includes effective thermal expansion coefficient. However, heating and cooling in the curing process were overlooked. Daverschot et al. [65] reported a larger deviation in the results obtained from Wang-Rose and Van Bameveld-Fredell with respect to finite element analysis (FEA), though the former models were able to calculate residual thermal stress precisely in an unrestrained state of components. Modelling the distribution of thermal residual stress in adhesive joints was conducted by FEA and continuum mechanics and a comparison was performed by Jumbo et al. [66] to define the most precise and effective way to predict thermal residual stresses. Zhang et al. [64] noted that coefficients of thermal expansion of adhesives and $\mathrm{Al}$ are higher than that of CFRPs. Thus CFRP plate restrained the contraction of Al plate and glued layer developed residual compressive stress. In contrast, $\mathrm{Al}$ panel and glue coat were subjected to tensile residual stress. In case of Al/CFRP single-lap adhesive joints, residual stress concentrates on adherents, and residual stress of glue coat is smaller than that in adherents, leading to the occurrence of joint failure in the glued layer. Joint residual stresses go up 
considerably with increasing curing temperature. Thus whenever possible, materials with a lower curing temperature and similar thermal expansion coefficients should be selected for desired applications [64].

\section{Diffusion bonding}

Diffusion is the process where the migration of major constituent atoms and molecules takes place according to their concentration gradient and usually from low side of concentration to the higher end. As also known as diffusion welding or solid state bonding, diffusion bonding is the process to bond two similar or dissimilar materials based on atomic diffusion of associated elements at joint's interface. In case of metallic materials, it involves the movement of atoms from one material to other lattice structures. Unlike adhesive bonding, this takes diffusion as a 'welding' process and does not require any additional materials.

There is no study on direct diffusion bonding between aluminium alloys and CFRPs, though researchers have used wires (titanium), foils (titanium) and fibres (glass fibre) between aluminium and CFRPs as transition elements in the course of diffusion bonding [67-70]. In these cases, one side of titanium wire or foil was diffused to aluminium while the other was holding CFRPs. Detailed cross-sectional metallographic investigation on such joints reveals the growth of a sealed intermetallic seam for the joints carried out at $540{ }^{\circ} \mathrm{C}$ for2 $\mathrm{h}$. However, if the procedure temperature was lowered or surface roughness increased, the seam became discontinuous due to the decrease in diffusion.

A common problem of such bonding is the absence of an integral CFRP-metal structural bond between two materials as the formation of an adhesive bond as a result of partial melting of metal matrices. An overlap between joining panels is necessary for thermal as well as nonthermal joining to achieve sustainable joints, and consequently an increase in the structural weight due to such overlapping. Möller et al. [71] has shown an innovative technique to establish a strong bond between two materials where the metal layer is melted to form a brazed bond with titanium wire, as shown schematically in Fig. 15. Subsequently, fibres immerse with metal matrices and form an integral CFRP-aluminium structure [72], thereby eliminating the drawbacks of limited load bearing capacity. 


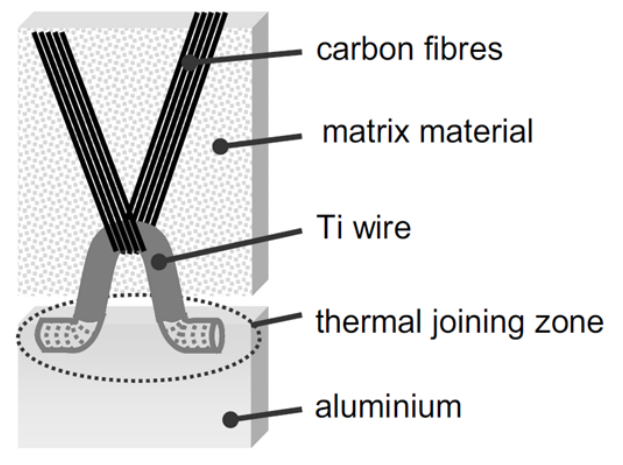

Fig. 15: Schematic of laser beam welding in CFRP-aluminium structures [71].

\section{Self-piercing rivet (SPR) technique}

Self-piercing rivet (SPR) is a common joining technique especially used in automobile or aeronautics industries with typical applications such as joining structures of aluminium with steel body panels. This method is adopted to join CFRP- aluminium panels together with a number of limitations. Mechanical properties of SPRs are influenced by both geometrical features and important factors such as die pressure and shape, subjected to required clamping forces. These have a significant impact on fatigue life and static strength on CFRP- aluminium joints, and hence can be further explored as described hereafter [73-76].

\subsection{Method of joining by self-piercing riveting}

Two major SPR techniques are standardized namely, cord-shank and semi tubular rivet. This rivet perforates top joint elements with the aid of a punch to join the opposite side of lap panels when a die is used. Rivet shank is subjected to plastic deformation inside the bottom element as the punch progresses and thus creates a high strength in the joint. The whole process is carried out in a single operation (involving forming and piercing) where pre-drilled holes are not required [74, 77]. Thus there is no need of exact alignment among components and rivet setting apparatus. As SPR joints are highly dependent on their interlock with base materials, rivets should be inserted for optimal results from thin to thick sections and from hard to soft panels, as schematically illustrated in Figure 16. 

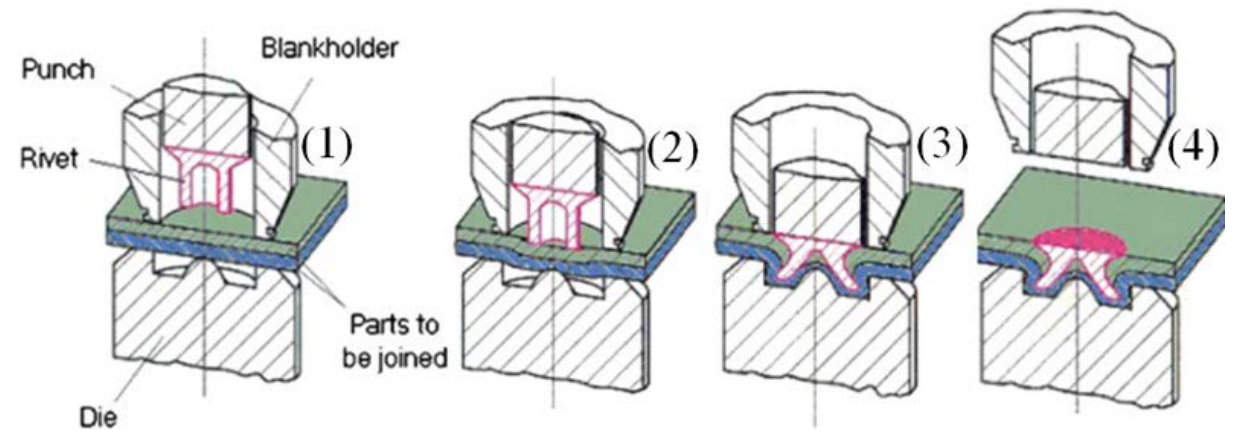

Fig. 16: Schematic of SPR technique [77].

The whole process involves four steps [78, 79]: (1) Clamp- a flat punch is used at top sheet surface to force the rivet in a perpendicular direction against the die, (2) Pierce-as a result of an excessive force, perpetuation takes place and the rivet is pushed through top sheet towards the bottom, (3) Flare- lower panel material flowing into die and rivet shank is widened and forms a mechanical interlock between two sheets and (4) Release-the punch stops and pulls back as it reaches a pre-set force or stroke [80]. The panel thickness in a joint vary from material to material. For example, in case of steel, the thickness can be in the range of 0.5 to $3 \mathrm{~mm}$ where the thickness of joint can be around $6 \mathrm{~mm}$. Total thickness of joints increases to be as high as $10 \mathrm{~mm}$ in the case of lightweight alloys or metal-polymer joints. High strength steel is used to manufacture rivets in correct shapes and sizes with respect to specified joints. Die steel is used to make dies that are also of desired shape and size to accommodate the preferred joint geometry [80].

There is a record of using localised heat during thermo-clinching process where the composites are pre-cut in the joining zone and locally heated to increase their plastic deformation capability and then pushed through the pre-punched metal sheet and compressed from the backside to generate a form-locked joint [81]. The positioning of aligned joining partners takes place before heating. The mold is closed after heating and a tapered pin pushes the soft composites and parts of reinforced structures through the pre-punched pilot hole of metallic components. The passed-through material is compressed by a ring shaped die and lock head of the joint is formed. When cooled a defined fibre orientation is formed in the neck and head areas of composites, without the necessity to apply any additional or ancillary joining elements.

\subsection{Mechanism of self-piercing riveting (SPR)}


In SPR, there is no requirement for any kind of surface preparation such as chemical treatment, plasma irradiation etc. This is because the joint is formed by plastic deformation of joint components. Essentially, it is a form of cold forming process to tie up two or more material panels with the aid of semi-tubular rivet (Fig. 16) and the bonding takes place between two sheets due to the compression by rivet head and flare of shank, which partially penetrates bottom sheet and then flares inside to have a mechanical interlock. Thus the crack formation is less likely due to the presence of a bottom sheet, though it suffers from severe plastic deformation. CFRP is brittle in nature and thus prone to cracks due to such sever plastic deformation. To avoid such situations, CIRP sheet is usually placed on the top of aluminium alloy sheet during the SPR formation. A characteristic force-displacement curve exhibiting a typical four-step deformation of a SPR joint is shown in Fig. 17.

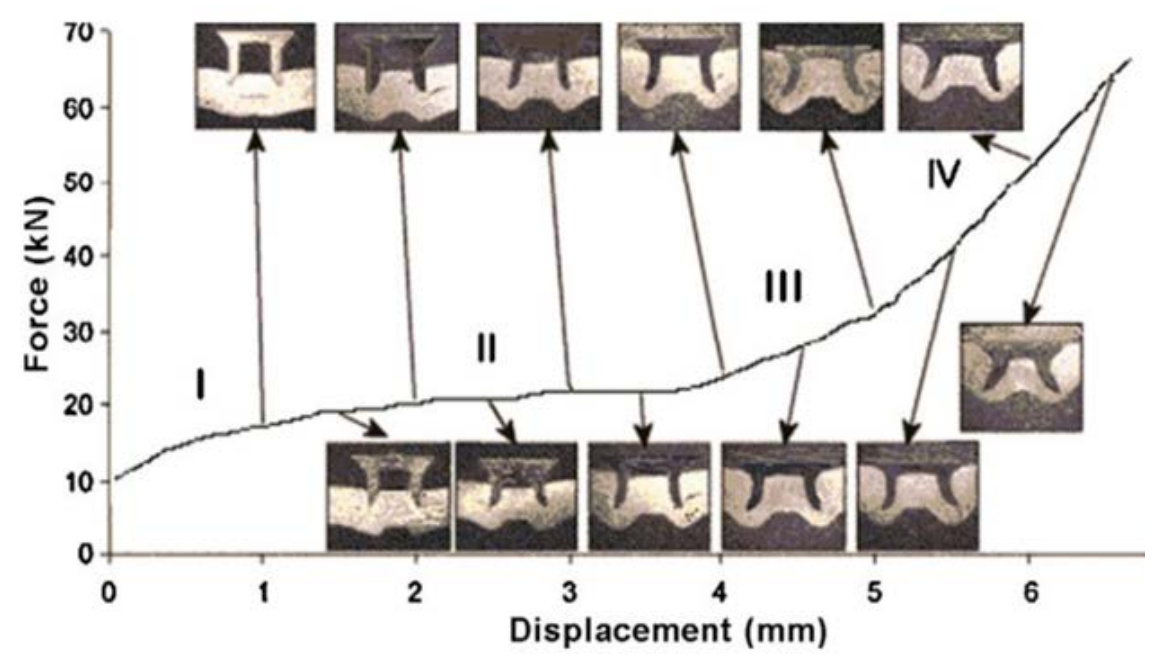

Fig. 17: A typical force-displacement curve to represent a four-step deformation behaviour in the SPR process [82].

The above-mentioned force-displacement curve is a general guideline for the fasteners fabricated in constant process settings. It corresponds to the variations of processing parameters as well as sheet materials involved in the process. A curve from a sufficiently well- formed joint can be used as a benchmark to evaluate other joints formed under the same processing conditions. Such a comparison act as $100 \%$ inspection and partial control of fastening quality $[80,83]$.

4.3 Properties of self-piercing riveting 
Figure 18 shows the load-displacement curves of a SPR joint between 2.7 mm AA2024-T6 and $1.5 \mathrm{~mm}$ CFRP sheet of two different lay-ups. Initially, load increased linearly with the displacement till 2000-2500 N. After that, a significant deviation from linearity took place, showing a characteristic of elasto-plastic behavior where the load remained constant. Finally, the load decreased until complete failure [54]. In case of a cross-ply arrangement, failure suddenly occurs, whereas it is a progressive damage in case of angle-ply laminate. It also indicates that the highest load for SPR joints of cross-ply laminates before failure is higher than that of angle-ply laminates (not larger than $12 \%$ in their difference). In addition, the amount of displacement occurring before failure is approximately doubled, which indicates greater absorbed energy takes place in the first case compared to later one [77].

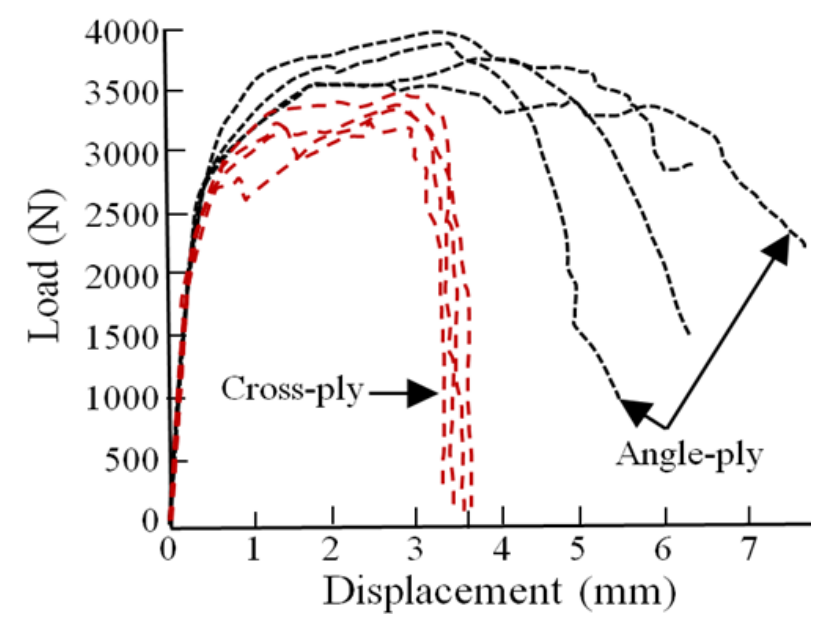

Fig. 18: Representative load-displacement curves of SPR joints for Al/CFRP laminates [54, 77].

Fig. 19(a) shows the load-displacement curves of aluminium and steel rivets. Analogous to the previous example, initial linear form of curve is trailed by consecutive elasto-plastic stage with the final phase corresponding to a decreasing load until complete joint failure. Both steel and aluminium rivets display similar stiffness in elastic and elasto-plastic phases. Nonetheless, corresponding loads at the point of linearity deviation (around 6 and $3 \mathrm{kN}$ for steel and aluminium rivets, respectively) and tensile strength (about 5 and $8.5 \mathrm{kN}$ for aluminium and steel rivets, respectively) are different [54]. Linearity deviation in load-displacement curve corresponds to the transition of load bearing mechanism. Initially, due to the rivet preloading, the load is transferred solely by friction, followed by shear stresses near the hole edge. Steel rivets display $70 \%$ higher failure load than that of aluminium rivets [54]. Experimentally obtained data from simple riveted samples (by steel rivets) demonstrates that the failure stems 
from flexural deformation (Fig. 21b), followed by significant localized damage of CFRPs around the hole and complete withdrawal of the rivet. Ultimately the joint fails due to shear of the $\mathrm{Al}$ rivet without substantial bending or pull-out phenomena. In addition, no significant damage of CFRP and aluminium panels was detected when Al rivet was used [54].

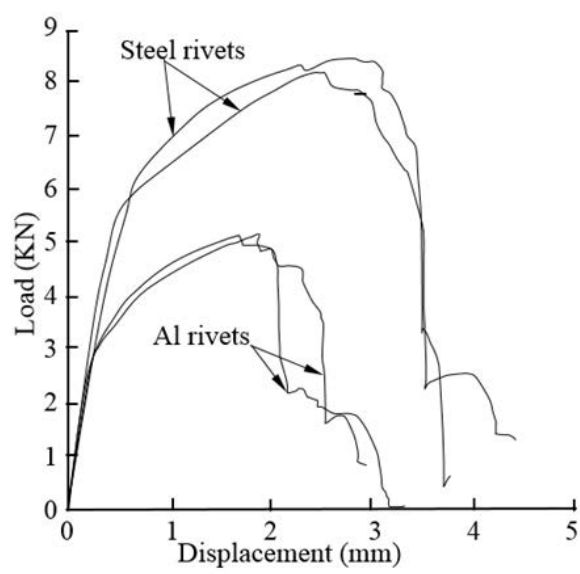

(a) Tensile test results

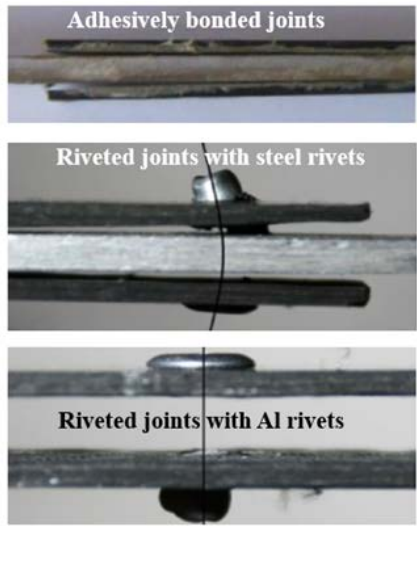

(b) Failure modes

Fig. 19: Properties of different types of riveted joints [54].

Fig. 20 shows representative load-displacement curves for hybrid joints of metals with cross and angle ply CFRP laminates under heat treated and untreated conditions. As mentioned in previous sections, hybrid joints use adhesives in addition to SPRs. In all cases, as shown in Fig. 20, load-displacement curves display initial load increases and are trailed by sub-horizontal non-linear style (elasto-plastic behaviour) with a final abrupt failure. In general, the progressive failure of adhesive layers is attributed to ongoing load transfer to rivets (area with non-linear behaviour due to the variation of stiffness), followed by succeeding abrupt failure. The sudden failure is identified as shear failure as the rivet is unable to absorb applied load after the giving-up of adhesive layers. 


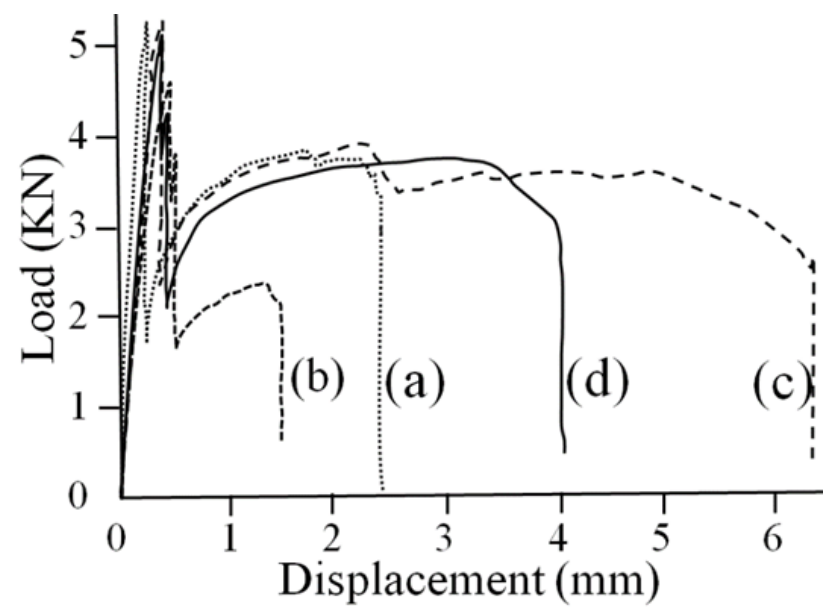

Fig. 20: Representative load-displacement curves for hybrid joints: (a) treated CFRP cross-ply laminates, (b) untreated CFRP cross-ply laminates, (c) treated CFRP angle-ply laminates and (d) untreated CFRP angle-ply laminates [77].

Heat treatment improves the performances, as evidenced by increasing tensile strength by about 14\% than untreated ones according to the load-displacement curves shown in Fig. 20 (curve (a) and (b)). In case of angle-ply laminated specimens (curve (a) and (b)), the curve is identical to that of cross-ply despite being $16 \%$ greater in failure load. A larger displacement before complete failure was observed for heat treated hybrid joints, as compared to untreated ones (almost double) [77], indicating the capacity of more energy absorption before failure.

A comparison among simple riveted, simple bonded and hybrid joints with cross-ply and angleply laminates in terms of the number of mechanical data is shown in Fig. 21. Generally, hybrid joints with heat-treated and untreated cross-ply laminates demonstrate improved performances compared to other joints where the maximum load transfer is enhanced around 13 and 23\% for heat-treated and untreated joints, respectively. Regarding absorbed energy before failure, heattreated hybrid joints possesses similar behaviour to that of SPRs, whereas energy absorption of SPRs is four times superior to untreated SPR-bonded joints. SPR-bonded joints with and without heat treatment demonstrate 16 and 25\% higher stiffness relative to that of bonded joints alone [77]. The tensile strength of heat-treated and untreated hybrid joints with angle-ply laminates have 17 and 32\% higher respectively than that of bonded joints. In terms of energy absorption, heat treated hybrid joints are similar to that of SPRs, which have superior performance to SPR-bonded joints. 

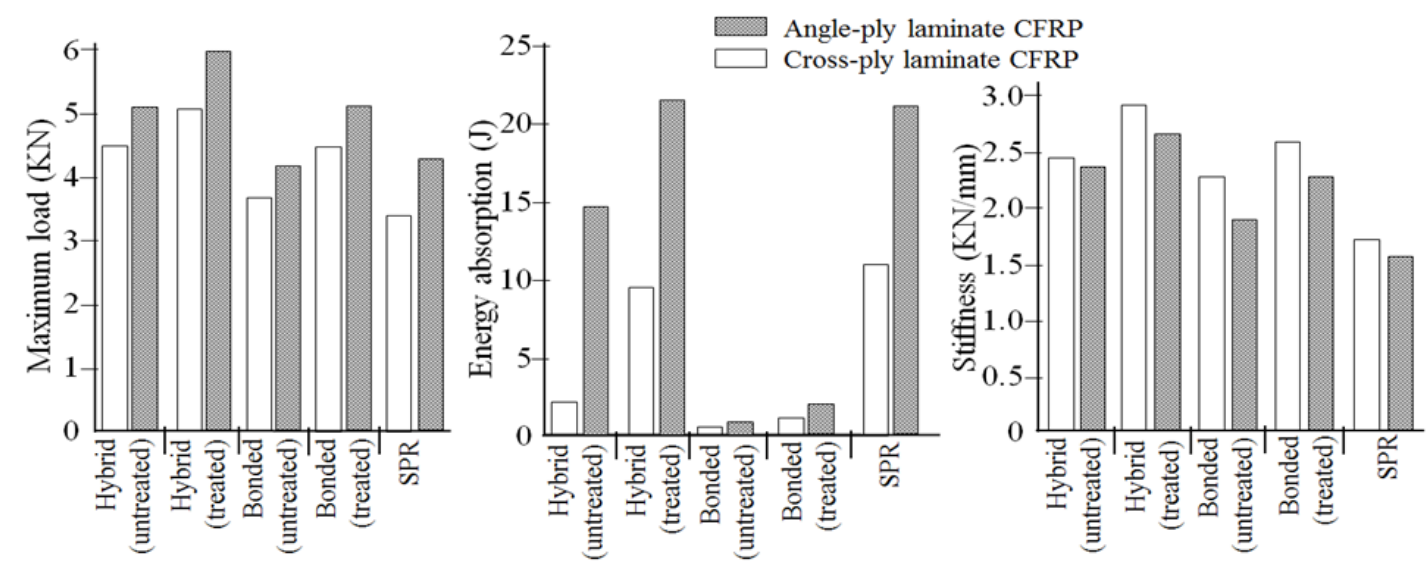

Fig. 21: A comparison among (a) maximum load, (b) energy absorption and (c) stiffness for different joints with CFRP cross-ply and angle-ply laminates [77].

The failure of SPR joints occurs only in the top element for cross-ply as well as angle-ply laminates as observed in Fig. 22. In case of cross-ply laminates, normal stresses near the rivet section (i.e. with high stress concentration around the hole) is behind the joint failure $s$ with the absence of bearing failure mechanism. In contrast, angle-ply laminate fails with noticeable pull-out of SPRs. In addition, rivet heads cause fibre damage near the hole and also contribute to the partial laminate failure. For hybrid joints, minute fibre damage with rivet pull-out occurs for joints with cross-ply laminate CFRPs after adhesive failure due to the breakage of CFRP laminates close to rivets. Angle-ply CFRP are categorized by the high pull-out of rivet s with compression and successive folding of composite materials at the back of rivets. The failure occurs as a result of debonding of composite materials (Fig. 23) as rivet holes add discontinuity in joints.
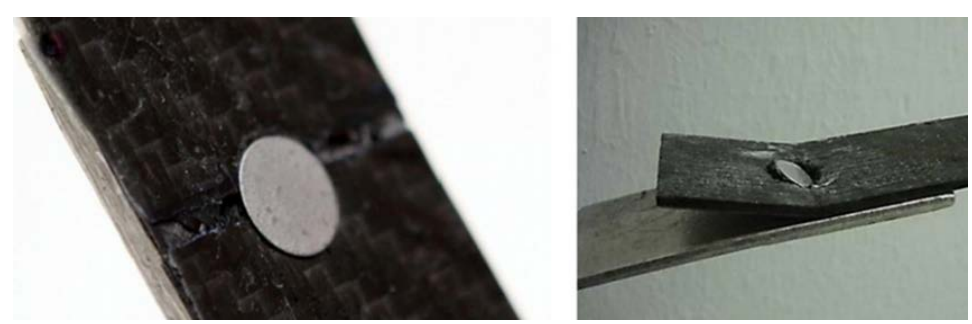

Fig. 22: Failure types of SPR joints with (a) CFRP cross-ply and (b) CFRP angle-ply [77].
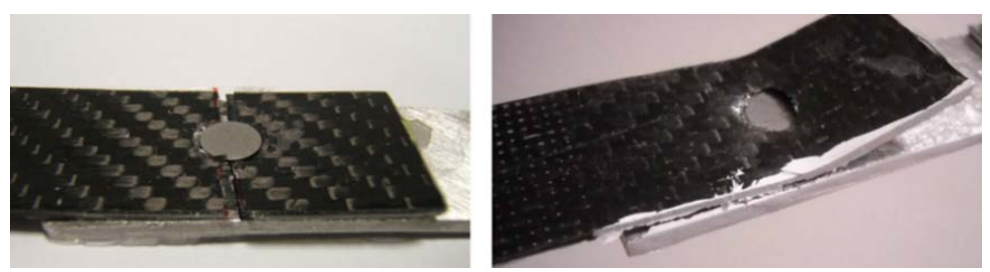
Fig. 23: Failure types of SPR-bonded joints with (a) CFRP cross-ply and (b) CFRP angle-ply [77].

As evidenced from Figs 22 and 23, parts of CFRP laminates (lined up with the joint axis) on the top remains are bonded to aluminium plates even after failure in the case of hybrid joints with aluminium rivet. In addition, tensile failure mode was detected in transversal segments corresponding to one of the two rivets [54]. In general, no substantial deformation in CFRP laminates happen due to rivet heads. The failure occurs mostly due to rivet bending and subsequent withdrawal from composite panels after the brittle rupture of adhesives. Because of stronger steel rivets used in hybrid joints, CFRP panel deforms locally and can be broken afterwards. It was also observed that the load of hybrid joint failure with aluminium rivets is equivalent to the summation of failure loads of corresponding simply bonded and riveted joints [54].

Under fatigue test conditions up to 250,000 cycles, riveted joints exhibit a failure type similar to static tests. For example, failure of carbon laminate in transverse direction near to rivet holes. On the other hand, composite panels remained undamaged and cracks grew in it after more than 250,000 cycles [84]. The distance among rivets is another factor also affecting tensile and fatigue strengths and the nature of fracture [84]. Joints with higher distance at $60 \mathrm{~mm}$ between two rivets showed best tensile and fatigue strength compared to that of lower distance at 30 $\mathrm{mm}[54]$.

Fatigue behaviour of different joints can be defined by a linear function [54] between the maximum load and the number of cycles during fatigue tests. As clearly shown in Fig. 24, the introduction of rivets in adhesive joints contributes to a substantial improvement of fatigue life. In addition, regardless of the number of fatigue cycles, fatigue curve of hybrid joints with steel rivets is nearly parallel to that of simple adhesive joints. That makes fatigue strength remain constant at around $3 \mathrm{kN}$. In comparative terms, paybacks rise from around $20 \%$ at $10^{3}$ cycles for the low-cycle fatigue to around $45 \%$ at $10^{6}$ cycles for high- cycle fatigue. This implies that fatigue behaviour of hybrid joints with steel rivets arises additionally by moving from static loading (+20\%) to high-cycle fatigue loading (+45\%). On the other hand, the fatigue curve of hybrid joints with aluminium rivets has a higher slope compared to that of simple adhesive joints. Therefore, the improvement of fatigue performance decreases due to moving from static loading to high-cycle fatigue. For example, the enhancement of fatigue strength is around $2 \mathrm{kN}$ for low-cycle fatigue (around $+10 \%$ at $10^{3}$ cycles) along with a tendency to zero for high-cycle 
fatigue ( $10^{6}$ cycles). This is evidently demonstrated in Fig. 24(b), which exhibits the abrupt failure of simple adhesive joints due to the damage in adhesive and crack propagation at aluminium-adhesive interfaces. Comparable fracture type has been noted for hybrid joints with aluminium rivets where adhesive failure at aluminium-adhesive interfaces tails an abrupt load transfer to rivets with a consequence of shear facture. However, in the case of steel rivets, two distinct phases of failure have been observed, namely successive failure of bonding interfaces trailed by bearing failure of composite adherents and succeeding rivet pull-out from CFRP laminates [54].

Fatigue tests at low loads are characterized by slow crack growth at adhesive-aluminium interfaces with a gradual load transfer on rivets before final failure, representing a significant impairment of CFRP layers due to the fatigue taking place close to the hole-edges. Fatigue failure of holes on CFRP adherents is low and comparable to that noted in static failure when the fatigue loads are around the half of the static failure load. According to Fig. 24, when the maximum applied load $\left(\mathrm{P}_{\max }\right)$ is 40 to $70 \%$ of the static failure load, fatigue life increases by 5 to 6 times. When $\mathrm{P}_{\max }=70 \%$ of static failure load, the cycle number to failure increases from 1000 to 6000 , whereas as for $P_{\max }=40 \%$ of static failure load, the cycle number to failure is enhanced from $2 \times 10^{5}$ to $10^{6}$. For hybrid joints with aluminium rivets, much less performance was observed and the number of failure cycles does not increase for $\mathrm{P}_{\max }=40 \%$ of static failure load, whereas joint life increases from 1000 to 3000 cycles for $\mathrm{P}_{\max }=70 \%$ of static failure load [54].

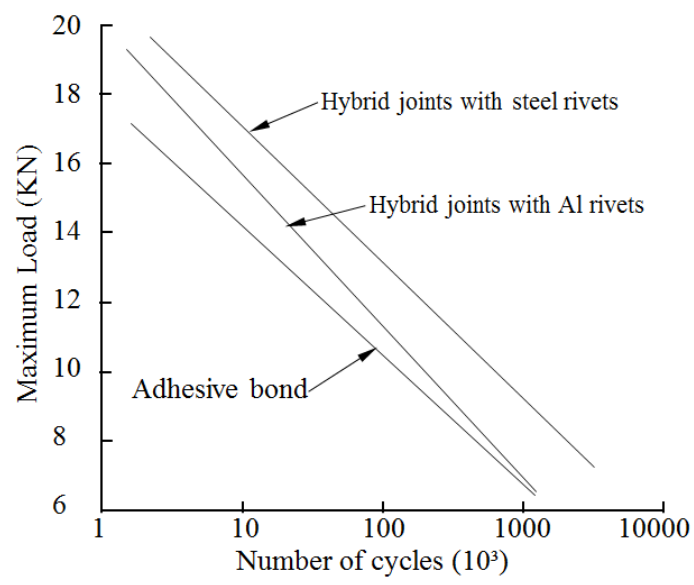

(a) Wöhler curves

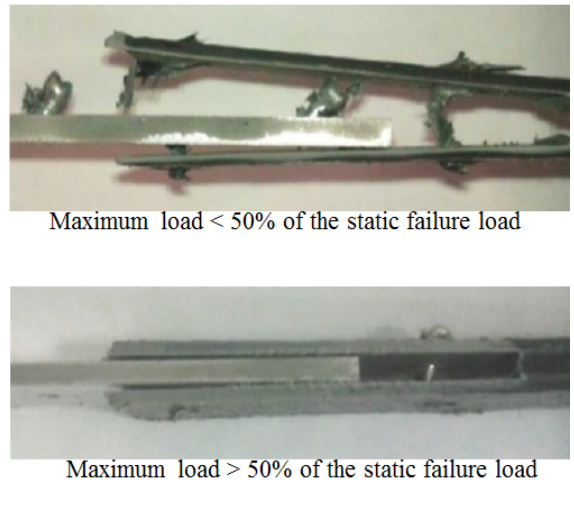

(b) Fatigue damage

Fig. 24: Fatigue for various joints [54]. 
From the economic point of view, SPR techniques are of relatively low costs without any material wastage or hazardous conditions with the ability to be highly automated and relatively simple to operate. For better joint mechanical performances, it has to be warranted that corresponding oil pressure parameter has been correctly selected for specific applications [8587].

SPR limitations specially focuses on $\mathrm{Al} 6061$ where their strength is quite weak compared to that of steel alloys, and can be deformed easily during the process without forming any interlocking with CFRPs. The SPR process requires a considerably large force to form, which is not appropriate for brittle materials since the access to both joint sides is essential in certain applications [83, 88, 89]. For aircraft applications, clamping modifications must be done accordingly as aluminium alloys would deform easily when exposed to extreme temperatures. This could affect the overall stability of clamping forces. Coating the Al 6061 fasteners to avoid galvanic corrosion with carbon fibres is an expensive process. Hence fibres are configured with the metal composition in order to perform the assembly [90-92]. The occurrence of 'fretting' is common in mechanical fastening applications which comprises fatigue and corrosion. Fretting can be eliminated to some extent by bonding fasteners with adhesives. However, it affects CFRP/Al 6061 joints significantly by friction wear over a period of time [93-96].

Similar to metallic clinching joints, the joining zone dimensions of thermo-clinching joint significantly affect the load bearing behaviour during shear tests. There are two different failure modes worth noting. The joints with a low neck thickness and high head height undergo shear failure, which means that the fibres in the neck areas are cut by the steel sheet to separate the head from the rest of joints. In contrast, joints with an increasing neck thickness and a reduced head height are subjected to pull-out failure in which the whole joint head is pulled through the pilot hole of the steel sheet [81].

\section{Bolted joints}

5.1 Method and mechanism of bolted joints

Bolted joints are one of the most common joining methods in many applications similar to that of SPRs in principle, which have a uniaxial common hole through the components to be joined. These holes are generally created by drilling and bolts are then inserted into holes from one side of the joint and screwed into the nuts on other side. Bolts and nuts have threads to help to 
hold the joint components at required compression by tightening the bolt at a proper torque. Bolt diameter is smaller than that of drilled holes though the diameters of bolt heads and nuts are relatively big to that of hole. The bolt heads and nuts act as flanges to hold the joint components tightly. Bolts don’t deform plastically and bolt diameter and material determine the strength of bolted joints when other components of the joint are stronger.

\subsection{Properties of bolted joints}

Fig. 25 shows representative patterns of load-displacement curves for bolted joints. In bolted joints, applied stress increases progressively up to a maximum stress at a certain displacement, which is followed by the gradual degradation of joints [97]. Joint failure mechanism is generally, bearing-mode failure occurring by using a method of damage built-up. On a macroscopic level, the whole method is allocated into four phases including damage onset, damage growth, local fracture and final structural fracture. Damages on contact surfaces between bolts and holes is a nature of severe damage. Though this damage is noteworthy, this is not a principal incident in a general evolvement of bearing failure. The destruction in insidewasher section might be categorized by damage built-up routes. For example, fibre kink bands of 0 -plies promotes shear cracks and delamination in the surrounding \pm 45 -plies. As the out-ofplane deformation of CFRP layers are repressed by the clamping pressure of washers, compressive damage grows principally along the in-plane direction in a stage-by-stage fashion. At the point where the damage of inside-washers progressively saturates, extensive delamination takes place under washer areas with the rapid reduction of the joint response [98]. Fig. 26 shows a typical deformed surfaces around fastener hole after the bearing failure of a bolted joint due to delamination, fibre breakage and surface splitting. The spread of delamination corresponds to fibre orientation or splitting direction of ply-contacting aluminium adherents. As not all the bolts break at a time, stresses declines step-by-step [8, 97] with a signature mark in the load-displacement curve. 


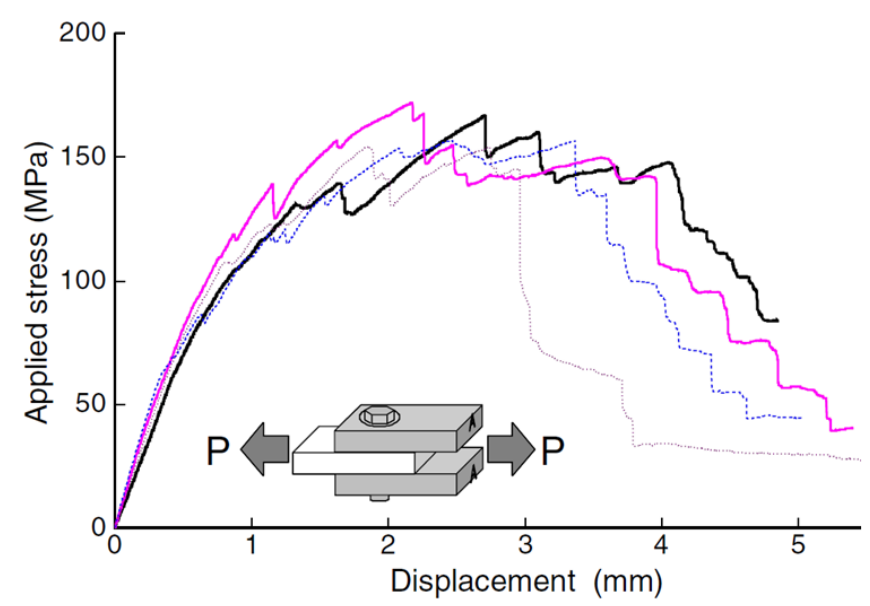

Fig. 25: Load-displacement curves for different bolted joints [97].

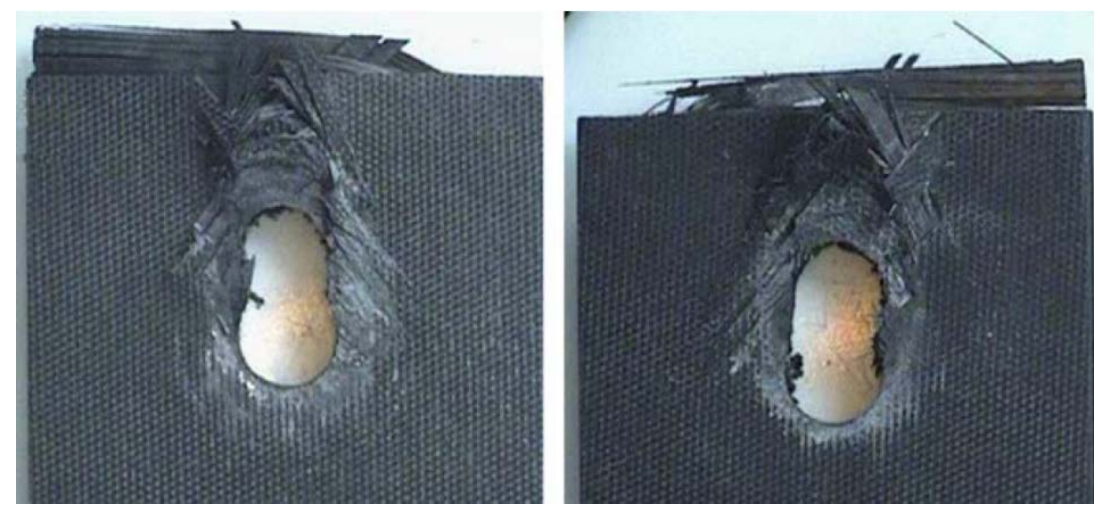

Fig. 26: Laminates after bearing failure of bolted joints [97].

The effect of tightening torques on load-displacement curves of simple bolted joints is given in Fig. 27. Tightening torques of $8 \mathrm{Nm}$ (recommended value by manufacturer) and $14 \mathrm{Nm}$ (to obtain the maximum tensile strength) were evaluated. Load-displacement curve is represented by 'elastic' phase where load transfer occurs due to the static friction between adherents as a result of axial pre-loading and then is followed by 'sliding' phase described by the dynamic friction under a quasi-constant load. Finally an 'almost linear' phase happens, where load is partially transmitted due to the friction between adherents and shear stresses. This phase occurs at a maximum load and followed by the advanced shear failure of composite laminate lips, thus corresponding to complete failure. The processes result in the hole ovalization as depicted in Fig. 26 [99]. 


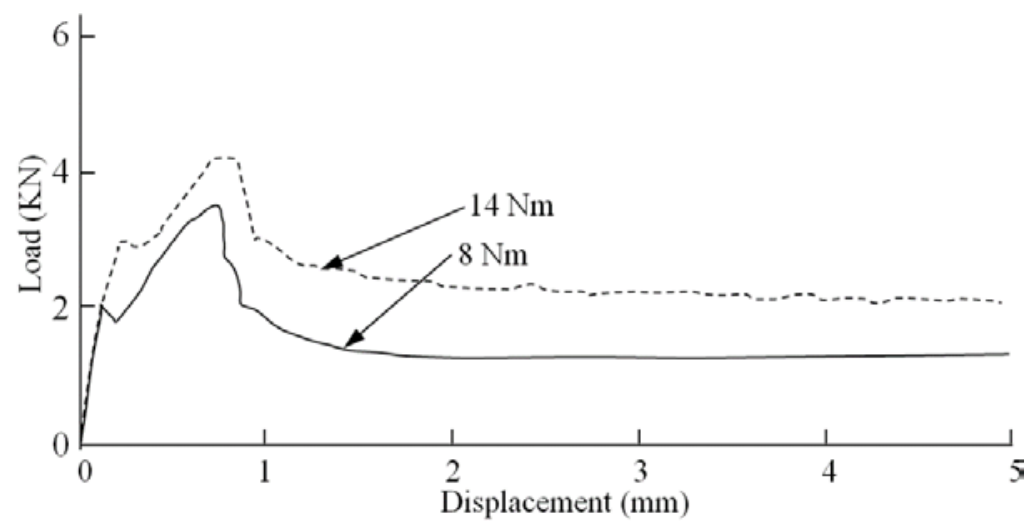

Fig. 27: Load-displacement curves for bolted joints with two different tightening torques [99].

Fig. 28 (a) shows characteristic tensile curves corresponding to hybrid bolted joints with 25 mm overlap length, which is subjected to bolt tightening torques of 8 and $14 \mathrm{Nm}$, respectively. In order to compare their behaviour with that of simple bolted and simple bonded joints, loaddisplacement curves have been employed accordingly. It is evident that hybrid bolted joints exhibit an elastic phase that is wider than that of simple bonded joints. Moreover, it stops at a strain level actually matching the failure strain of simple adhesive joints, which confirms the benefit of compression. This also decreases peeling and shear stresses at free edges and simultaneously increases shear stresses close to the bolt because of partial load transmission through the bolt. The bolt yields even stress distributions along the overlap with a consequence of a substantial increase in the maximum load relating to the commencement of adhesive brittle failure. The load at the end of elastic phase of hybrid bolted joints is around 30\% higher than that of a simple adhesive joint with 35\% higher stiffness. This proves that a significant portion of load is being transmitted by the bolt at relatively low strain levels. Diverse tightening torques cannot induce substantial variation to the elastic phase, which is in good agreement with relative curves [99].
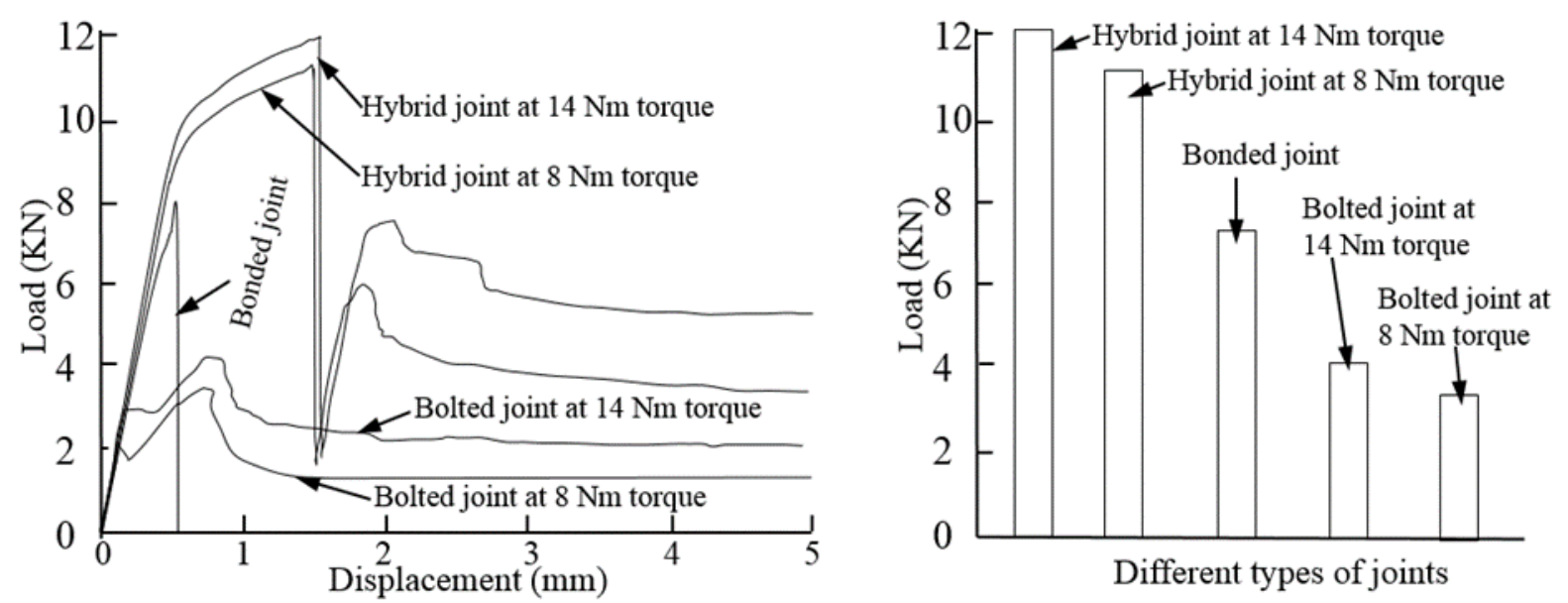

(a) Load-displacement curves
(b) Maximum load

Fig. 28: Comparison among different types of joining combination [99].

Linear phase is followed by successive elasto-plastic phase until a maximum load is reached. This phase is regarded as the plasticity of aluminium adherents in which tensile stress is greater than corresponding yield stress. In addition, substantial shear strain of adhesives is beneficial regarding compression effects of bolt tightening. This increase in bolt tightening torque leads to a maximum load to be about $10 \%$ higher due to the increase in the tightening torque of 2 Nm [99]. Maximum load is also increased more by $60-70 \%$ than that of a simple adhesive joint. At a peak load, a substantial load plummeting for about $85 \%$ arises due to the brittle failure of adhesives. Load plummeting is followed by a new load increase until a local maximum load of about 75\% higher than the failure load of corresponding simple bolted joints is reached for both tightening torques. This important fact can be explained by considering compression effects that prevent adhesive fracture in annular region close to the bolt. In other words, adhesives continue to contribute substantially to the load transmission. After that, a second local maximum load is trailed by a slightly smaller load as the ultimate load of a relevant simple bolted joint. These signatures in load-displacement curves are related to the complete fracture of adhesives and shear failure of composite laminate lips leading to a complete joint failure. It can be stated that hybrid bolted joints with the minimum overlap undergo a complex damaging method that is the arrangement of failure mechanisms of adhesive bonded and bolted joints. This means that adhesive failure at interfaces between adhesives and aluminium is trailed by the shear failure of lips at composite adherents [99].

Tensile strength of a hybrid bolted joint is the summation of those of simple bonded joints and simply bolted joints with a minimum overlap. On the contrary, different results are observed experimentally with a greater overlaps, which are more common in practical applications where bolt is positioned in the central section of joints. Thus being away from free adhesive edges.

This type of configuration weakens the joint due to the presence of holes to decrease the maximum load-bearing capacity. A load-displacement curve for hybrid bolted joints with a larger overlap exhibits an initial linear stage that halts due to the early fractional failure of adhesives at a load less than that of simple adhesive bonded joints. This trails a comparative load plummeting of around $50 \%$ of the final load similar to that supported only by the bolt itself. At this stage, most of adhesives are fully damaged except the central zone offering a minor contribution to load bearing while subjected to comparatively low stresses. This 
intermittent load plummeting is followed by the load increase up to about $80 \%$ of the maximum load where the applied load is divided between non-damaged adhesives and bolts [99].

Various adhesives are applied in addition to bolts to make the joints stronger in hybrid joints. Load-displacement curves of hybrid joints with film-type adhesives are shown in Fig. 29. Similar trends of curves appears for that of simple bonded joints. Local failures are evident even before the displacement reaches $1.0 \mathrm{~mm}$. If this is assumed to be the same in hybrid joints, bearing failure of laminate would start the displacement of around $1.0 \mathrm{~mm}$, and the final failure would occur at the displacement of approximately $2.0 \mathrm{~mm}$. However, Fig. 30 presents that a bonded joint withstands its structural integrity even at the displacement of $2.0 \mathrm{~mm}$. Therefore, composite laminate layers fail in the bearing mode before adhesive failure. If the adhesive fails first, hybrid joints behave like bolted joints until the maximum stress is reached at joint failure [8]. At the point of bearing failure, joint load is sustained by adhesives alone. This is because adhesives have large areas and comparatively small thickness, thereby yielding significantly high adhesive shear stiffness. It also does not permit sufficient relative displacements between laminates to employ forces on bolts in the opposite direction. Consequently, the force applied by bolt (when the contact happens) would be negligible and bolt-load transfer does not occur till certain deboned length is reached. Bolt starts to carry a part of the load when the deboned length becomes longer than a critical value at which a rapid increase in bolt-load transfer occurs and ultimately the entire load is carried with full debonding [100]. Usual failure modes are presented in Fig. 30 and exhibit the partial failure of composite laminates due to delamination and delaminated parts remain bonded to aluminium surfaces after the final failure. Over $50 \%$ bonded areas fail in a mixed mode, where remaining adhesives appear in both aluminium and composite sides. Bearing failures of laminates are easily seen in Fig. 30(c) and (d) and the presence of white rings are associated with existing washers. Bolting does not affect the bonded joint strengths when film-type adhesives are used. Conversely, bolt joints significantly increase the hybrid joint strengths when low shear strength is applied by paste type adhesives cured at room temperature. It should also be noted that the strength of hybrid joints is even greater than that of simple bolted joints, which implies that adhesives contribute to strengthening bolted joint and delay complete failure of joints [8, 97, 101]. 


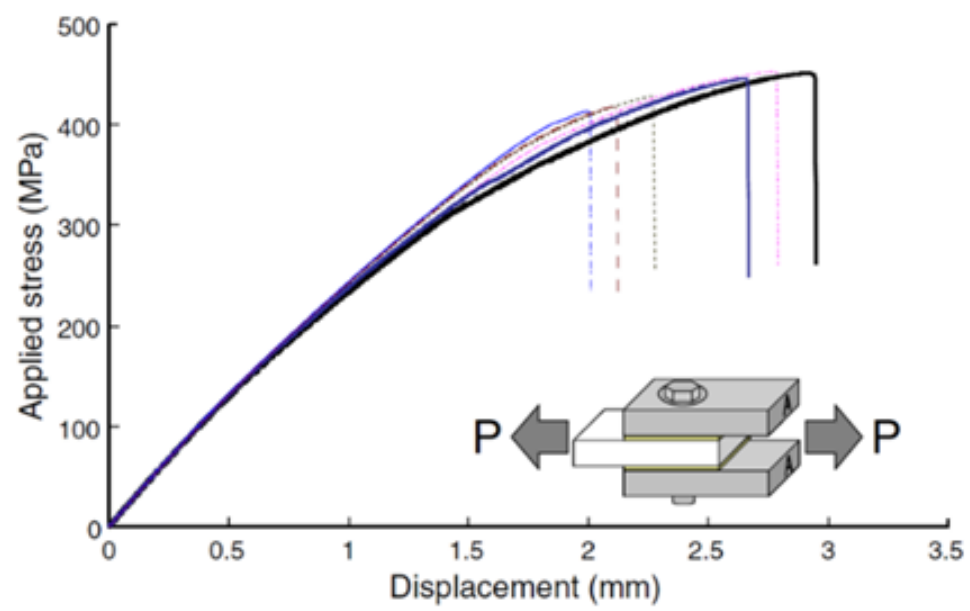

Fig. 29: Load-displacement curves for hybrid joints with film-type adhesives [97].

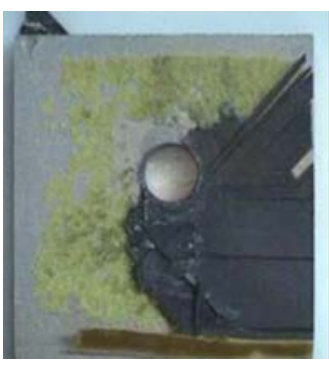

(a)

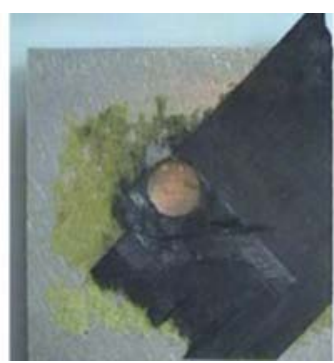

(b)

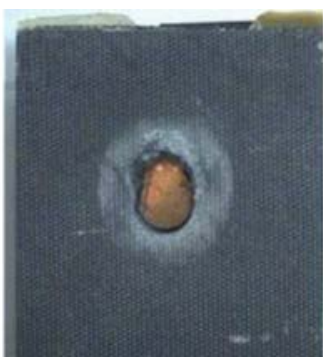

(c)

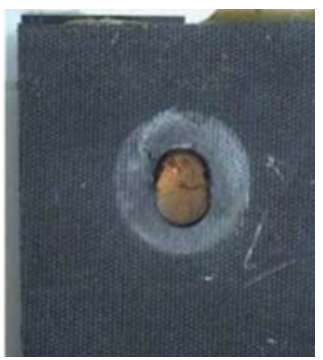

(d)

Fig. 30: Typical failure modes of hybrid joints with film-type adhesives: (a) Al (top), (b) $\mathrm{Al}$ (bottom), (c) laminates (top) and (d) laminates (bottom) [97].

\section{Clinching}

Clinching is a mechanical fastening method widely used in automobile industry for manufacturing automobile body panels and electrical appliances such as washers and dryers. This is a cold joining process similar to mechanical press joining. Mechanical joint strength of clinching significantly depends on variable undercuts and neck thickness with respect to applications. Clinching has a wide range of different parameters, hence analysis such as Taguchi method, optimization method and finite element analysis are often employed [102]. Clinching has been a popular alternative for joining dissimilar materials that are challenging to weld. Clinching is classified into two major categories, namely single stroke and double stroke. Single stroke clinching needs specific parameters and tools primarily focussing on sheet thickness. Double stroke clinching can adapt to a variety of thicknesses, but is challenging to 
amalgamate into stamping press line due to the requirement of large capital investments [103$105]$.

\subsection{Method and mechanism}

Clinching techniques use a punch and a die while joining Al 6061 and CFRPs by local hemming without rivets, thermal effects, waste and noise. No prior arrangement is required to post prepare samples as clinched joints can be used immediately only involving simpler equipment. There is no plastic deformation outside structures, which allows for the easy process automation [106-114].

Sheet thicknesses of $\mathrm{Al} 6061$ and CFRPs are taken care of by punch and die properties and processing parameters. Punch moves downward forcing the sheets to flow into the die cavity. Since there is no rivet involved during this process, $\mathrm{Al} 6061$ sheets are bulged initially and compressed with a punch and a die and interlocked with CFRPs with various amounts of deformation between the sheets.

The die cavity consists of a ring groove that supports the interlock formation and sheets are forced into the die cavity form the required undercut. The final joint does not need any additional finishing after this process [103, 115, 116]. A schematic of hole-clinching process is shown in Fig. 31, in which high-strength materials (DP780 steel), hot-pressed 22MnB5 steel and CFRPs are used as the lower sheets. Within them, a hole is formed and Al6061-T4 alloy is used as the upper sheet. The process geometry is based on geometric relationship between holeclinching tools and interlocking of clinched joints.
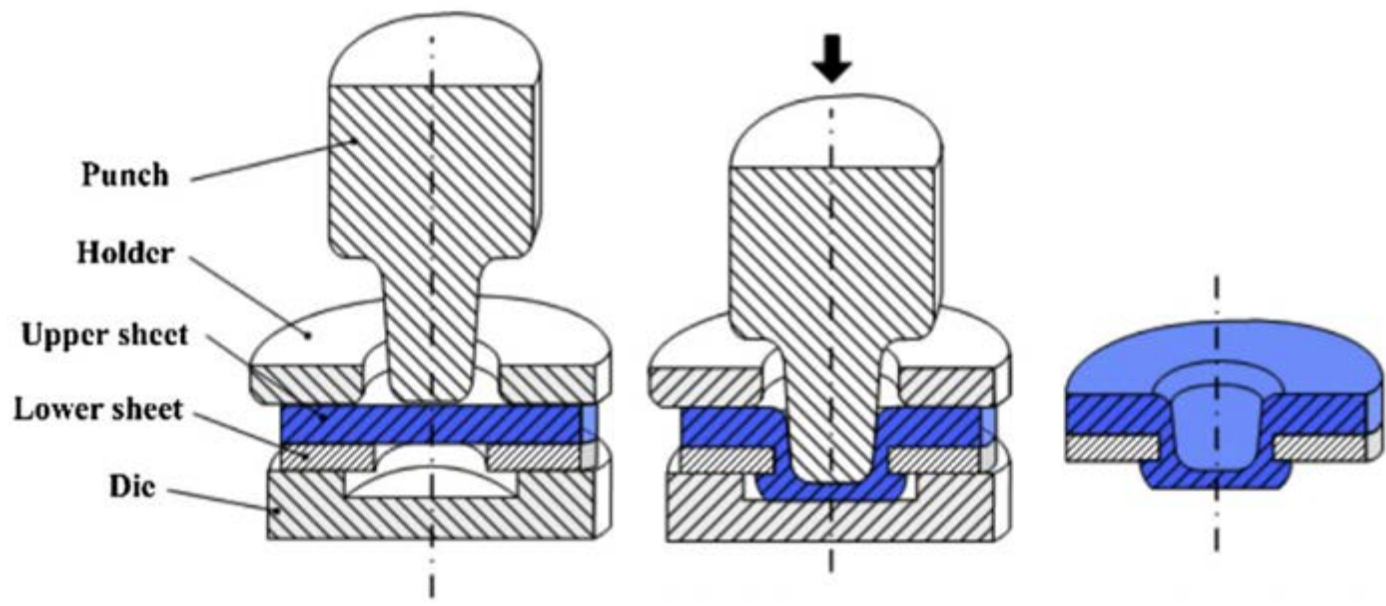

Fig. 31: Hole clinching process [116]. 
At the first processing step, the upper sheet is squeezed into the gap between punch and the lower sheet while the upper sheet is deformed by shearing. Movement of the upper sheet under the holder should be constrained for successful hole-clinching. However, damage is intensified at the neck of hole-clinched joint with the possible occurrence of the necking of upper sheet. As such the punch shape should be adjusted to avoid necking or deep-drawing deformation of the upper sheet. When the upper sheet contacts the die bottom, forming load increases dramatically, as shown in Fig. 32. The upper sheet's material spreads in the die cavity between the die and lower sheet. At this step, the upper sheet is indented into the die cavity and simultaneously drags the lower sheet into the die cavity due to the friction between AA6061 alloys and CFRPs [117].

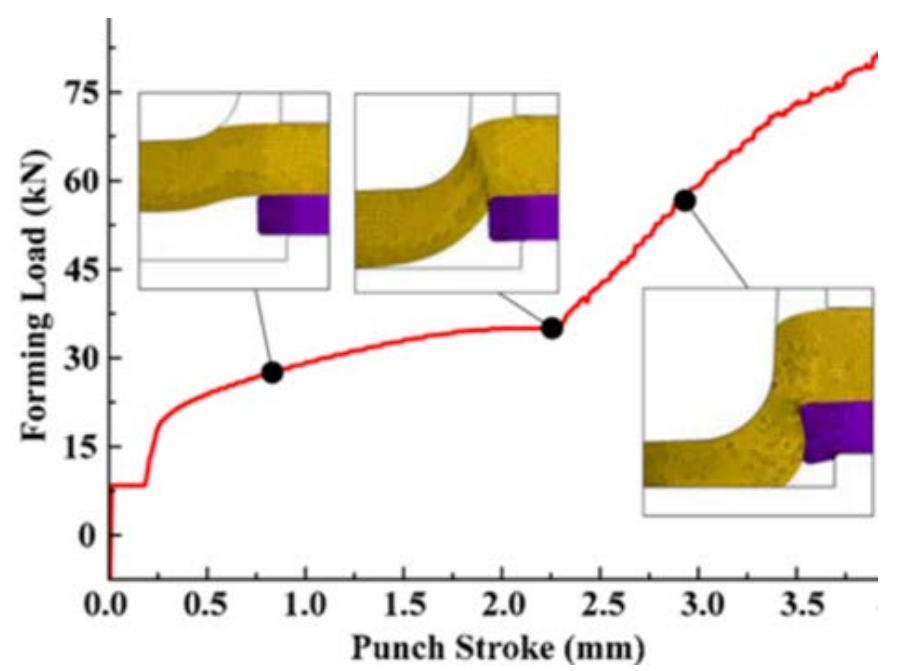

Fig. 32: Forming load and deformation behaviour of CFRP and AA6061 alloy sheet during the hole-clinching process [117].

Fig. 33 shows the effect of CFRP thickness on geometric interlocking and dragging length of CFRPs during the hole-clinching. Geometric interlocking has been observed in the CFRP dragging region and dragging length decreases with increasing the CFRP thickness, which is because thicker CFRPs have higher bending stiffness. The gap between the punch and hole is widened as upper sheet is being dragged due to the CFRP bending. CFRP dragging length had a direct influence on neck thickness. As CFRP thickness increased, neck thickness decreased from 0.904 to $0.584 \mathrm{~mm}$. However, neck thickness of upper sheet was larger than the designed value. Undercut was also increased when CFRP thickness became larger. Even though CFRP thickness of $1.0 \mathrm{~mm}$ yielded the longest dragging length, undercut of 1.6-mm-thick CFRP was larger than that of 1.0 mm-thick CFRP. Tapered CFRP shape was detected around the hole, as shown in Fig. 34. For thicker CFRPs, the undercut was formed because of the tapered shape of 
CFRPs, which was influenced to a greater extent by this size effect compared to the dragging length. In addition, punch stroke increased with an increase in CFRP thickness; therefore, bottom materials of upper sheet had more indentations and spread to a greater extent during the hole clinching. As opposed to conventional mechanical clinching, a low hydrostatic stress was applied to the upper sheet during the hole-clinching. This is because that the lower sheet could not support the upper sheet when the upper sheet was drawn into the die cavity leading to the necking of the upper sheet.

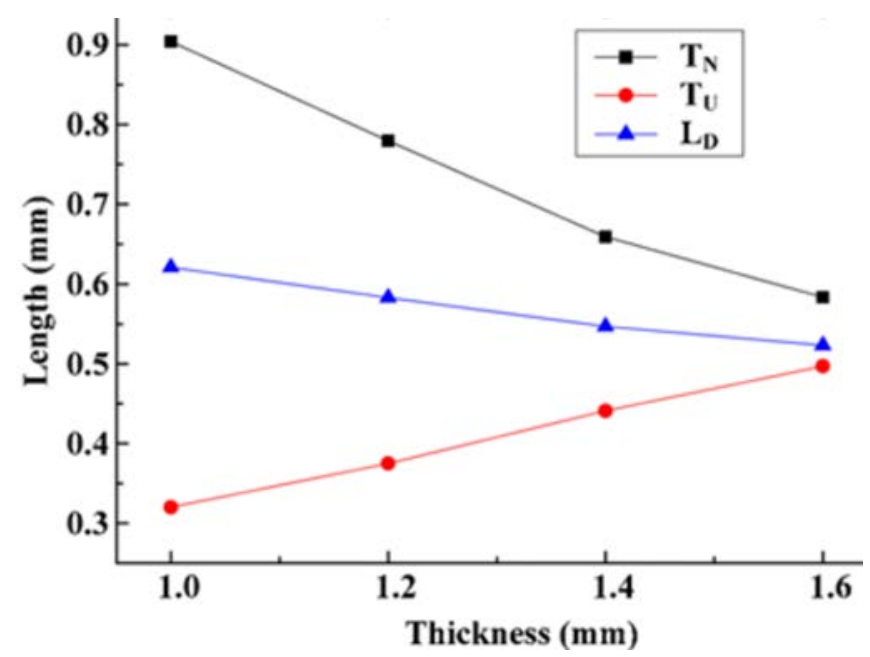

Fig. 33: Effect of CFRP thickness on geometric interlocking and dragging length [117].

The hole in this process is created in high-strength materials to avoid plastic deformation. Clinching between Al 6061 and CFRPs combined with a sealant acts as a sound dampener and works well with pre-coated or galvanised materials in order to ensure that there is no thermal stress induced within the work pieces. Initial shapes of tools for clinching holes were based on factors of strength of mechanical joints and geometric interlocking [111]. A cross-section view of the hole-clinched joint between Al6061-T4 and CFRPs is shown in Fig. 34. It is clear that there is unanticipated CFRP deformation o in both FEA simulation as well as physical experiments. CFRP dragging appears because of the flow of upper sheet metal around the hole. The friction between AA6061 alloys and CFRPs causes dragging in the lower panel (i.e. CFRPs) when the upper panel is indented into the die cavity. Notwithstanding that CFRPs are dragged, the upper panel forms the physical interlocking of $0.601 \mathrm{~mm}$ for neck thickness and $0.512 \mathrm{~mm}$ for the undercut. During this process, the opening between the punch and hole in CFRPs was broadened owing to the laminate bending, causing larger neck thickness of upper sheet than the designed value of $0.5 \mathrm{~mm}$ [116]. CFRP dragging also significantly influenced the undercut and neck thickness, and the undercut increase was directly proportional to CFRP 
thickness. Due to dragging and compression load resulting from spreading Al 6061 alloys, significant delamination occur around the hole region [118]. Due to the inability of delaminated CFRPs to sustain the shear load, the strength of CFRP interfaces is lower when compared to the required joint strength $[116,117,119]$. Delamination at interfaces due to dragging effect is shown in Fig. 35, which is a serious issue because it can make CFRPs underperformed for enduring the external loading.

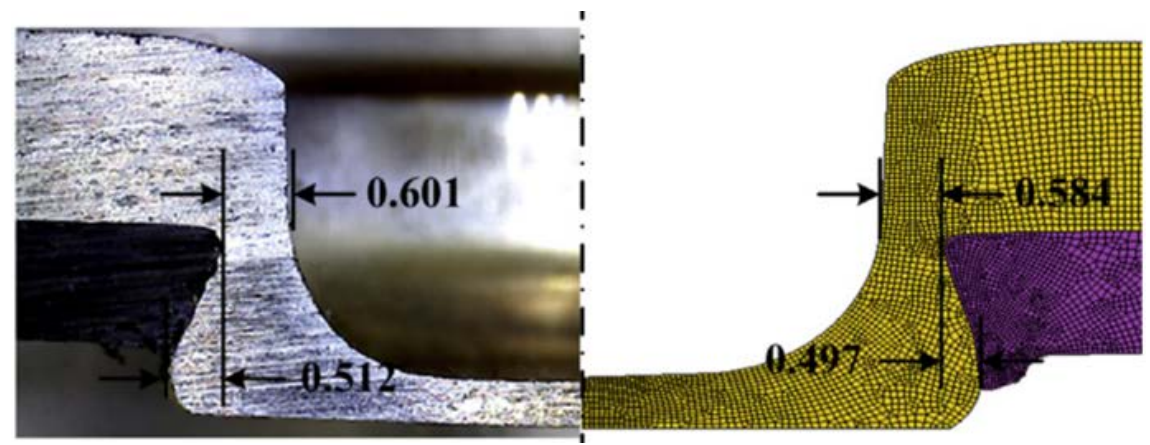

Fig. 34: Cross-section of hole-clinched joints between Al6061-T4 alloys and CFRPs [116].

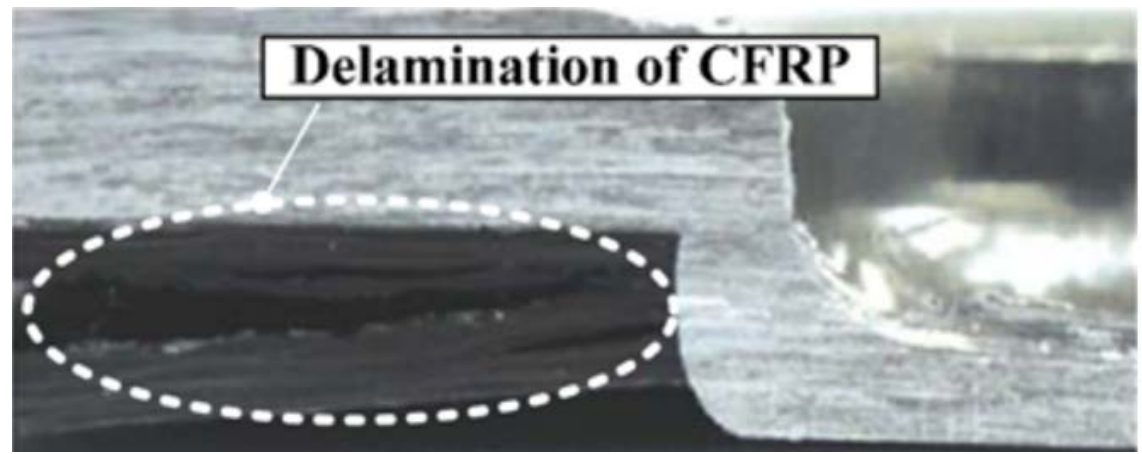

Fig. 35: Delamination of CFRP laminates in hole-clinched joints [117].

To ensure a strong mechanical joint, it is important to increase neck thickness and undercut of the sheets used, respectively. Smaller neck thickness separates Al 6061 and CFRP sheet due to the weak interlocking, resulting in a fracture. Impact tests performed to estimate crash resistance of mechanical joint strength demonstrate that clinching is highly invaluable in automobile industry [102]. The essential criteria to join sheets in clinching are, firstly to carefully control the deformation while interlocking sheets. Secondly to avoid unnecessary neck thinning , and finally to avoid any fracture of Al 6061 or CFRP sheet, with anti-corrosion [115]. To achieve a successful hole-clinch joint, a proper alignment between centres of clinching tools and holes in the bottom panel is definitely necessary. In fact, this alignment controls the deviancy in neck thickness, development of undercut and joint strength. In this case, the neck thickness of upper panel is less than the necessary value due to the partial 
deviancy of the tool centre when compared to the hole in the lower panel, resulting in significant reduction of the joint strength [116].

\subsection{Properties of clinched joints}

The strength of a clinching joint depends on neck thickness, undercuts, diameter of die cavity, punch diameter and displacement of the upper die. In view of practical manufacturing, a compromise is generally required between tool-life and clinch joint properties to avoid overloading the tools and high interlocking forces are required based on respective applications [113, 120, 121]. The stress distributions in Al 6061 and CFRPs are likely to be identical. Hence there is a low stress concentration in joint structures, which is highly favourable for dynamic loading. The usual mechanical failure mode of clinched joints is either neck fracture or button separation. Joint strength achieved by mechanical clinching is lesser than that of self-pierce riveting. Low-energy running costs of mechanical clinching is due to the absence of rivets since the metal sheet is fastened by the punch and die inducing geometric interlocking. Mechanical clinching and self-pierce riveting have been found to achieve the improved fatigue performance [106, 107, 109, 114].

Load-displacement curves achieved from the shear testing of single-lap clinched joint of Al6061 and CFRPs is shown in Fig. 36 with average shear fracture load of about $3.16 \mathrm{kN}$. As a result of dragging effect, as mentioned earlier in this section, neck thickness of hole-clinched joint was higher than that required. Therefore, shear fracture load was considerably greater than the anticipated load of $2.5 \mathrm{kN}$. Clinched joints with more shear fracture load of $3.0 \mathrm{kN}$ fail due to the fracture at the upper panel neck. For a shear fracture load smaller than $2.5 \mathrm{kN}$, button separation is dominant, as evidenced in Fig. 36. Furthermore, the dragging effect causes the CFRP delamination leading to the final separation due to shear load.

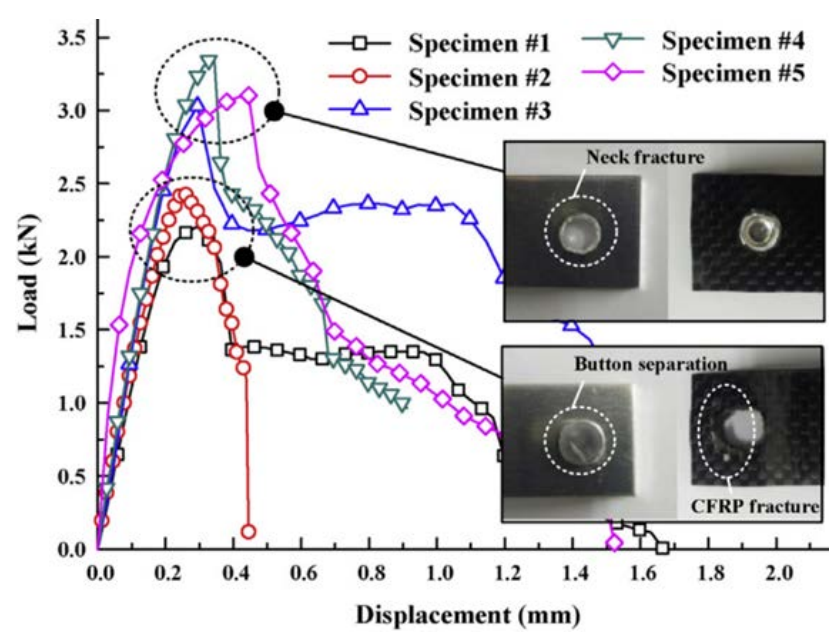


Fig. 36: Load-displacement curves from shear testing of single-lap clinched joints of Al6061T4 alloys and CFRPs [116].

Failure modes of hole-clinching joining between CFRPs and aluminium alloys are shown in Fig. 37, which was mainly due to the button separation as a result of insufficient undercut. In addition, CFRP fracture was observed around the hole-clinched area. During the single lapshear test, a bending moment acted at the end of the overlap and prompted a peel load. The presence of this peel load caused the fracture of CFRP laminates. Delamination due to dragging weakened the CFRP around clinched areas and further accelerated CFRP fracture. Thus, unexpected button separation failure occurred at clinched joints for the CFRP thickness of 1.0 and $1.2 \mathrm{~mm}$, respectively. In addition, the fracture load was estimated to be lower than the design value, indicating that sufficient interface strength is required to prevent CFRP delamination and secure joint strength. An increase in clinched joint diameter improves the joint strength. For specimens with the CFRP thickness of 1.4 and $1.6 \mathrm{~mm}$, necking fracture was observed in the upper sheet, as observed in Figs. 37(c) and (d), with resulting fracture loads of 2.75 and $3.34 \mathrm{kN}$, respectively. This implies that the undercut offers the sufficient strength to avoid button separation.

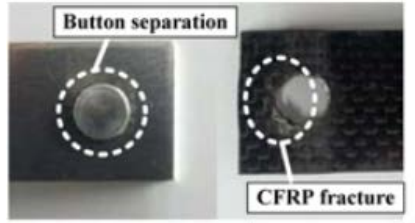

(a) $T_{\text {CFRP }}=1.0 \mathrm{~mm}$

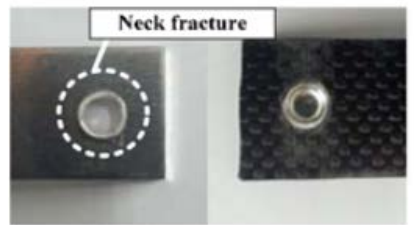

(c) $T_{\text {CFRP }}=1.4 \mathrm{~mm}$

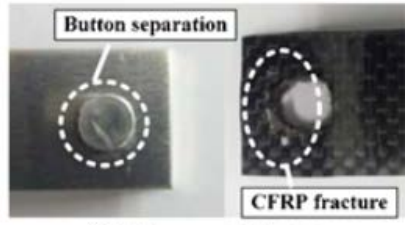

(b) $T_{\text {CFRP }}=1.2 \mathrm{~mm}$

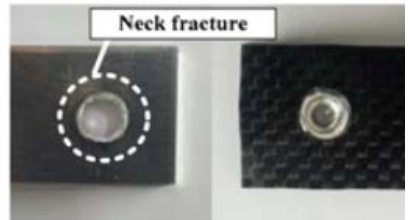

(d) $T_{\text {CFRP }}=1.6 \mathrm{~mm}$

Fig. 37: Failure modes of clinched joints [117].

\section{Welding}

Conventional joining methods for CFRPs to metals and to CFRPs such as bolting, riveting, adhesive bonding etc. fall under non-thermal process category, whereas welding process is in thermal process category [71, 122]. Therefore, this method is only valid for CFRPs based on thermoplastic matrices. The applications for microwaves, induction heating (i.e. wire fabric of stainless steel) and friction heating have been reported to attain localized melting of thermoplastic matrices [71, 123]. The trend of all these thermal processes is the partial melting 
of matrix material within CFRPs, causing the adhesive bonding and interlocking to metal surfaces [71].

\subsection{Laser assisted welding}

\subsubsection{Method and mechanism}

During welding of CFRPs to CFRPs and to metals, laser can be used as a heat source. It is a non-contact procedure which requires the entrance to the weld zone from one side of the parts being welded. Two types of processes consisting of laser deep penetration welding and laser beam conduction welding have been used for joining metals and CFRPs [124]. In penetration welding, also known as keyhole welding, a characteristic 'keyhole' is generated, which facilitates higher aspect ratios of weld-seam and enables the higher penetration depth and smaller heat-affected zone where laser power intensities are greater than $10^{6} \mathrm{~W} / \mathrm{cm}^{2}$. However, it has several disadvantages such as high porosity and welding defects, which make it unsuitable for welding highly reflective metals such as aluminium. The porous formation is ascribed to the gas entrapment during the welding and subsequent solidification processes thanks to the vaporization of low melting-point elements. High power is required for the keyhole formation. However, after starting, the rate of absorptivity is raised from only $8 \%$ to approximately 95\%, resulting in low-quality products with major welding defects. On the other hand, laser beam conduction welding (LBCW) employs the use of a laser beam from low laser power (i.e. intensity less than $10^{6} \mathrm{~W} / \mathrm{cm}^{2}$ ). This process is carried out at the low energy density and forms characteristic weld 'nugget', which is shallow and wide with low aspect ratios in range of 100 to $300 \mu \mathrm{m}$ with the depth of the same order. It has been shown to be more stable compared to laser beam penetration welding since the vaporisation is minimal. The laser beam conduction welding results in products with satisfactory properties in the case of high reflective metals such as aluminium [124].

Innovation in this area leads to the development of laser-assisted metal and plastic (LAMP) direct joining procedure, which has been developed to join metals with CFRPs, as schematically exhibited in Fig. 38. This method includes the use of yttrium aluminium garnet (YAG), diode and disk/fibre laser. As the laser beam hits the metal surface, metals can melt by absorbing laser beam energy, thus creating a melt pool. In general, the absorption ability of any material to laser beam is influenced by two parameters, which are known as material resistivity laser wavelength. Additionally, samples can be sandblasted prior to welding in order to increase laser beam absorptivity. The weld is formed due to the melting of mating parts and intense heat 
is generated with the rapid heat of materials by the laser (typically calculated in milliseconds). This unique heating mechanism facilitates an interfacial region reaction at very high temperatures. As a result, it is suggested that the joint was produced by bonding CFRPs with oxide films covering the total surface area of the metal. Both SEM and transmission electron microscopic images, particularly in bonding regions show the presence of small bubbles formed in CFRPs on metal surfaces [125].

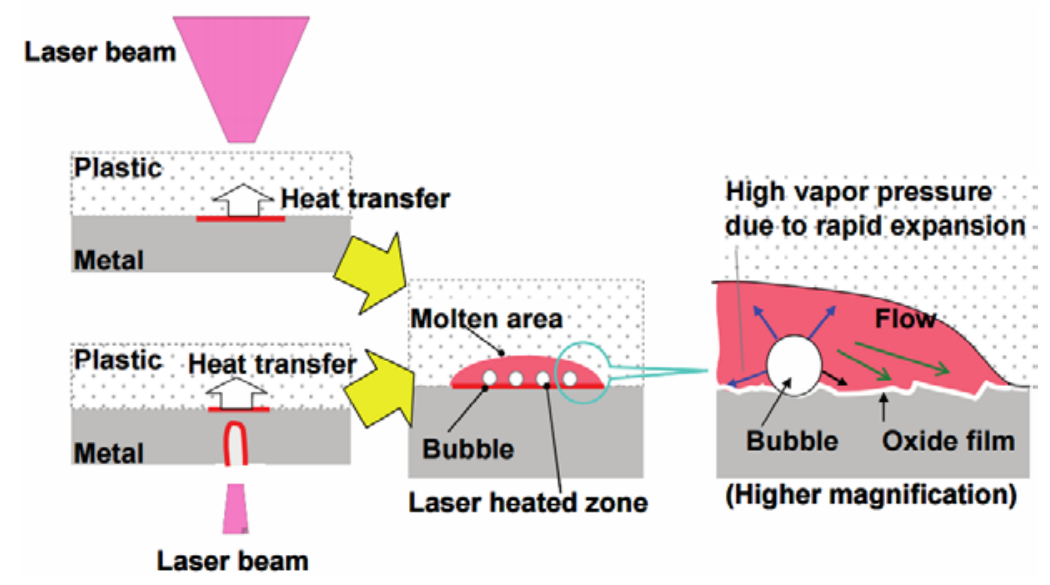

Fig. 38: Mechanism of laser-assisted metal and plastic (LAMP) direct joining process [125].

\subsubsection{Properties}

The presence of porosity in weld joint significantly deteriorate the joint performance. The joint failure takes place at the porous zone, but not at metal/CFRP bonding interfaces. Porosity is produced inside CFRPs for all joining parameters with uneven shapes and sizes ranging from ten to hundreds of microns [126]. Pores were distributed close to bonding interfaces with a high concentration at the central melted zone. Tan et al. [127] reported that when the temperature was higher than $350{ }^{\circ} \mathrm{C}$, the pyrolysis of polymer matrices of CFRPs occurs in formation of gassy products such as $\mathrm{CO}_{2}$ and $\mathrm{NH}_{3}$. Such experiments were carried out with the help of a Q-mass spectrometer during the laser welding of SUS304 stainless steel and polyethylene terephthalate (PET) [128], which could mainly contribute to the pyrolysis of CFRPs [125]. Based on material morphology, two kinds of porosities are reported in literature, namely porosity I and porosity II. Porosity I is deep with smooth inner walls where carbon fibres can be detected inside the pores. In case of porosity II, a relatively rough inner wall with minor pores, grooves and cracks, takes place without any noticeable bare carbon [126].

Depth and width of melted zone are increased with increasing the laser power, which also applies to the size and dispersal features of pores. At the laser power below $700 \mathrm{~W}$, pores are 
comparatively small at dozens of microns and are distributed at a definite area away from bonding interfaces, but near the melted zone borderline. Bigger pores at hundreds of microns are formed beyond $700 \mathrm{~W}$. The characteristics of pores also depend on the scanning speed. When the scanning speed is faster than or equal to $10 \mathrm{~mm} / \mathrm{s}$, porosity I appears as opposed to both porosity type I and II existing at less than or equal to the scanning speed of $8 \mathrm{~mm} / \mathrm{s}$. This is easily understood as the both laser power and scanning speed affect the heat input. Consequently, type I pores are only generated when the heat input is high than $77.8 \mathrm{~J} / \mathrm{mm}$, which is equivalent to the laser power of $700 \mathrm{~W}$ and scanning speed of $9 \mathrm{~mm} / \mathrm{s}$, whereas type II pores are formed in all heat inputs [126].

Porosity II has a typical characteristic with irregular shapes and rough surfaces due to thermal shrinkage, which can be explained by the volume contraction of CFRPs for the duration of solidification in the laser joining method. As metals have considerably larger thermal conductivity compared to that of CFRPs (i.e. $0.28 \mathrm{~W} / \mathrm{m} \mathrm{K}$ ), heat is conducted quickly by metals while CFRPs near the bonding interfaces are initially solidified. CFRPs in a melting zone boundary are solidified at the end. Thus, the contraction of CFRP gives rise to the generation of porosity II at the final region of solidification [126].

During the laser welding process, metal surfaces are exposed to an argon gas stream to avoid the oxidation of metal surface due to atmospheric exposure, which could in turn prevent the formation of strong and durable bonds. Different lap joints between a variety of metals (304 stainless steel, Zn-coated steel or A5052 aluminium alloy) and CFRP sheets could be formed by irradiating a disk laser. The formation of high strength bonded composites are attributed to three factors comprising anchor/pull effect, Van der Waals forces and chemical bonding [125]. With respect to CFRPs, fibre type in long, short or endless formations, fibre orientation, fibre volume fraction and types of matrix materials are major factors to significantly influence the final characteristics. The main single factor affecting joint strength is the interfacial reaction taking place between metal alloys and reinforced phases. Microstructures of this region show the presence of brittle reaction products, resulting in decreased mechanical properties of matrices. In addition, Al 6061 alloys contains very small proportion of magnesium with high weldability. As such, weldability can be improved further by increasing the silicon content artificially. However, this makes it more susceptible to cracking at high temperatures, and can be reduced by lowering the amount of heat applied in the system using a variation of laser beam conduction welding including temporal laser pulse shaping/welding [129]. 


\subsection{Friction spot welding}

\subsubsection{Method and mechanism}

Frictional heat in friction spot welding is generated by a non-consumable tool consisting of a clamping ring, sleeve and pin, which are assembled coaxially and move independently relative to each other. The clamping ring holds the parts to be joined together. The pin and sleeve can rotate independently and produce the required heat as a result of the friction between these parts and the workpieces $[130,131]$. The rotating sleeve plunges into the metallic sheet to a pre-defined depth while the pin retracts upwards. The friction between the sleeve and the metal causes the increasing temperature to locally soften and plasticize the alloys. The plasticized alloys flow in the reservoir left behind by the retraction of the pin. The frictional heat is also conducted to composite interfaces from metal alloys and generates a thin layer of molten polymer throughout the overlap region. The pin then pushes the softened metal and refill the key-hole in the metallic sheet. Finally, the tool is retracted and the joint is consolidated under pressure. The molten layer is then consolidated under pressure and induces the adhesion and interlocking between metals and composites. The tool plunges into the metal part to a shallow depth that does not reach the composite interface to avoid any damage to the load-bearing network of fibres [130,132, 133]. In contrast to friction stir welding, the tool plunges the maximum $40 \%$ of metal thickness and does not reach composites in friction spot welding, which prevents the excessive degradation of the polymer and the network of load-bearing fibres. Adhesion force is the main bonding factor in friction spot welding where huge physicochemical differences of metal and polymer partners prevent materials from mixing, further leading to sharp interfaces [132].

Metal cleaning is essential in this method by abrasives such as $\mathrm{SiC}$ and $\mathrm{Al}_{2} \mathrm{O}_{3}$ using abrasive paper or sand blasting. Both metal and composite samples were then cleaned by acetone in an ultrasonic bath and pressurized, and finally left in dry air [132]. The joining partners were placed in the overlap configuration against a backing bar. The samples were clamped together during and after the joining process to ensure firm contact between them, as well as to avoid the separation due to large differences in the coefficient of thermal expansion between these two materials. An extended consolidation time is required for polymer consolidation to warrant the absence of differential contraction [130, 133]. The peak temperature at the interfaces of composite/aluminium specimens at a rotational speed of $1900 \mathrm{rpm}$ is around $345^{\circ} \mathrm{C}$, which is

sufficient to melt a thin layer of polyphenylene sulphide (PPS)matrices (melting temperature 
$\left.T_{\mathrm{m}}=280^{\circ} \mathrm{C}\right)$. Nevertheless, it is far below the reported extensive thermal degradation range of this polymer starting at approximately $500{ }^{\circ} \mathrm{C}[134,135]$. The cross section of a typical joint between AA2024-T3 and PPS/CF composites at rotational speed of 1900 rpm, plunge depth of $0.5 \mathrm{~mm}$, joining time of $4.8 \mathrm{~s}$ and joining force of $8.5 \mathrm{kN}$ shows deformed aluminium feature. Metallic nub increases the shear strength by inducing mechanical interlocking owing to the insertion into composites of the joint [139].

As a result of the texture changes through plastic deformation [136] and the surface pretreatment, pores and crevices were formed on the aluminium surface in contact with composites. The molten PPS matrices fill these pores/crevices, which, after consolidation, increases the micro-mechanical interlocking and the global shear strength of the joint [131]. Furthermore, another important phenomenon is observed: a portion of carbon fibres are entrapped by the plasticized aluminium, thereby creating a micro-mechanical interlocking. During the course of the joining process, the molten PPS matrices are squeezed out of the nub and partially displaced by the softened aluminium. Due to the applied axial force by the sleeve and the pin, the plasticized aluminium penetrates into the first plies of composites and either individual fibres or fibre bundles become embedded into the aluminium. It is believed that these two phenomena of pore filling by molten PPS and fibre enclosure by the aluminium are largely responsible for the shear strength of the joints [132, 133].

\subsubsection{Properties}

It was reported that the tool rotational speed is the parameter with the greatest influence on the lap shear strength of the joints (34.77\%), followed by the joining time (32.37\%), plunge depth (20.70\%) and joining force (12.15\%) [130, 133]. The increase of rotational speed (while keeping the other joining parameters constant) enhances the ultimate lap shear force as the higher rotational speed of the tool generates a higher and bigger joining area. For instance, the increase of rotational speed from 1900 to $2900 \mathrm{rpm}$ results in a 70\% increase in the joining area. The larger the joining area, the more intimate contact between PPS matrices and carbon fibres with aluminium. Hence higher load is achieved from $950.6 \pm 43.8 \mathrm{~N}$ at $1900 \mathrm{rpm}$ to1254.1 $\pm 41.6 \mathrm{~N}$ at $2900 \mathrm{rpm}$. The displacement at the peak load exhibits a similar behaviour. For example, the changes in the displacement are not very pronounced up to the tool rotational speed of $1900 \mathrm{rpm}$. However, a sharp increase in the displacement was observed (0.6 mm for $1900 \mathrm{rpm} ; 1.0 \pm$ 0,1 mm for $2900 \mathrm{rpm}$ ) above $1900 \mathrm{rpm}$. A similar trend is also noted when tool plunge depth and the joining time increase as evidenced by $762.6 \pm 182.7 \mathrm{~N} / 0.45 \pm 0.08$ 
$\mathrm{mm}$ and $1276 \pm 181.5 \mathrm{~N} / 0.65 \pm 0.05 \mathrm{~mm}$ for a plunge depth of 0.5 and $0.8 \mathrm{~mm}$, respectively. This trend is associated with the generation of a more pronounced 'nub' and the increased intimate contact at the interface of composites/aluminium, which can increase the adhesion forces by micromechanical interlocking. The fracture surfaces of those two specimens with respective plunge depths of 0.5 and $0.8 \mathrm{~mm}$ indicate that more fibres remain attached to the specimen with $0.8 \mathrm{~mm}$. Plunge depth plays an important role in macro-mechanical interlocking mechanisms at the metal-composite interface controlling the formation of metallic nub. The higher the plunge depth, the more pronounced the metallic nub. Therefore larger heat inputs as a result of elevated joining times and optimized rotational speeds as well as plunge depth can lead to stronger joints. The increases of rotational speed above a certain limit induces tool slippage and a decrease in heat generation. However, the plunge depth has a limitation since too large plunge depths can cause the rupture of aluminium plates within the spot joint area [130]. The joint between AA2024 alclad alloy and CFRPs shows higher strength compared to that between AA2024-bare alloys and CFRPs due to the higher ductility of cladded layer, which deforms more easily during the process and embeds a higher volume of polymer matrices relative to bare specimens. The elongation of alclad samples $(0.9 \mathrm{~mm})$ is larger when compared to bare specimens $(0.6 \mathrm{~mm})$. This larger elongation could be attributed to the larger joint area and the increased amount of polymer matrices attached to the aluminium surface. However, some local changes can occur, such as the changes in the polymer crystallization state and chain re-orientation, which influences the strength and ductility of the joints [137]. Both bare and alclad specimens display a pronounced increase in the lap shear force and displacement when sand blasting is performed on aluminium. The sand blasted bare specimens exhibited an average lap shear force of almost twice of that of the mechanically ground specimens. The sand blasted specimens gave rise to a larger displacement at the peak load as opposed to mechanically ground samples. Sand blasting clearly creates more pores/crevices and distributes them more homogeneously on the aluminium surface. Furthermore, the deeper indentions created by sand blasting can better accommodate the molten polymer and increase the micromechanical interlocking. The larger displacement of sand blasted specimens is most likely due to the improved interlocking of polymer into aluminium pores and crevices, thereby retarding final failure.

Goushegir et al. [132] defined the bonded area into three regions where the outer region is called the adhesion zone, a transition zone is next to the internal border of the consolidated layer, and the plastically deformed zone is at the centre. These three zones are not 
homogeneously distributed around the nub due to inhomogeneous heat distribution in the specimens. The joints fail by having the cracks initiate at the periphery of the adhesion zone and propagate along the interface between this layer and the aluminium or composite surface in a plane parallel with the applied load direction. Should the cracks reach the beginning of the transition zone, their path can shift from the interface into composites and propagate in the plastically deformed zone within a volume close to the metallic nub, being in the first plies of composites. This crack propagation is associated with a more cohesive failure in a plastically deformed zone, in which a larger amount of polymer matrices and carbon fibres remain attached to the aluminium surface [131, 132]. The tool rotational speed and joining time significantly influence the plastically deformed zone by controlling the heat input in the joints, and in turn the viscosity of molten polymer matrices. Higher rotational speed and longer joining time facilitate the flow of the molten polymer matrices to spread in the bonding area. Higher joining pressure generally increases the lateral flow of molten matrices. The interaction of the plunge depth and joining time was significant on the plastically deformed zone despite the insignificant effect of plunge depth. Shorter joining time requires higher plunge depth to increase the axial force, and thus facilitates the lateral flow of molten polymer matrices though the effect of plunge depth is less pronounced when joining time is longer [133].

\subsection{Friction lap joining}

\subsubsection{Method and mechanism}

The friction lap joining uses the similar mechanism, which can be carried out using a friction stir welding apparatus [138, 139], and the heat energy generated by friction between the rotating tool and metal surface. A reusable rotating tool is pressed into the surface of the metal plate and dragged along the overlap region. The tool not only heats the materials to be joined but also applies the pressure at the joint interface [140]. The appearance of a friction lap joint is similar to that of a friction stir weld joint. The tool in friction stir weld incorporates a stirring probe to assist material flow, which is not the case for the tool in friction lap joining [141]. Conductive heat transfer from the heated metal to the plastic component produces a narrow melted region in the plastic material near the interface. Joining of the metal and the plastic is complete after the melted plastic is solidified under pressure produced by the contact with the metal substrate. Given these advantages, friction lap joining has the potential to generate interfaces with strong joint strengths without any damage to base materials, high-cost apparatus, or design limitations imposed on the joint geometry. In addition, there are 
significantly fewer joining parameters such as tool dimension, rotation speed, plunge depth, and joining speed required to be controlled. It is an energy-saving and environmentally friendly process that would further expand the applications for plastic materials, including thermoplastic matrices based on CFRPs, combined with metals [141]. In this case, thermoplastic matrices of CFRPs and A5052 alloys are joined via an oxide layer consisting of MgO. CFRPs and A5052 were joined via an MgO oxide layer. The grinding of A5052 surface generated the hydroxide $\mathrm{Al}(\mathrm{OH})_{3}$, and the tensile shear strength of the friction lap joint increased from 1.0 to $2.9 \mathrm{kN}$ with this surface treatment where the area of surface was constant [141].

\subsubsection{Properties}

Almost all the joints fractured near the A5052/CFRP interface regardless of surface treatment. Traces of matrix material melting are noticed on the macrographs of the CFRP side from interfacial fractures. The presence of CFRP was not noted on the A5052 for the ungroundA5052/CFRP joints where a smooth and bright surface was observed together with the smooth surface of the CFRP side. This indicates that the unground-A5052/CFRP joint fractured only at the interface of those two materials. On the other hand, for the ground-A5052/CFRP joint, residual CFRTP adhered to the A5052 was present on the fractured surface of the A5052 though a smooth and bright zone without the residual CFRP was also noted. The crack in the ground-A5052/CFRP joint partially propagated through the CFRP, including both the matrices and carbon fibres. The unground-A5052/CFRP joints possessed weak interfacial strengths, and therefore the fracture mainly occurred at the interface. Grinding of A5052 increased the joint strength, and fracture occurred at least partially in CFRPs [141].

The tensile shear strength increased with the joining speed up to a certain value, and then decreased. The joint tensile shear strength decreased regardless of the size of the joined area, with decreasing joining speed. The maximum tensile strength of tensile-fractured CFRP joints was lower than those of the as-injected CFRP counterparts due to firstly the generation of voids in CFRPs, secondly the reorganization of orientations of carbon fibres, and finally the deterioration of polymer matrices [141].

\section{Effect of CFRP properties on mechanical fastening joint}

The common failure modes such as tension, shear, bearing, cleavage and pull-through in mechanically fastened joints in composite laminates are associated with the material 
constitution and reinforcing structure [142, 143]. The schematics of the different types of failures are presented in Fig. 39.

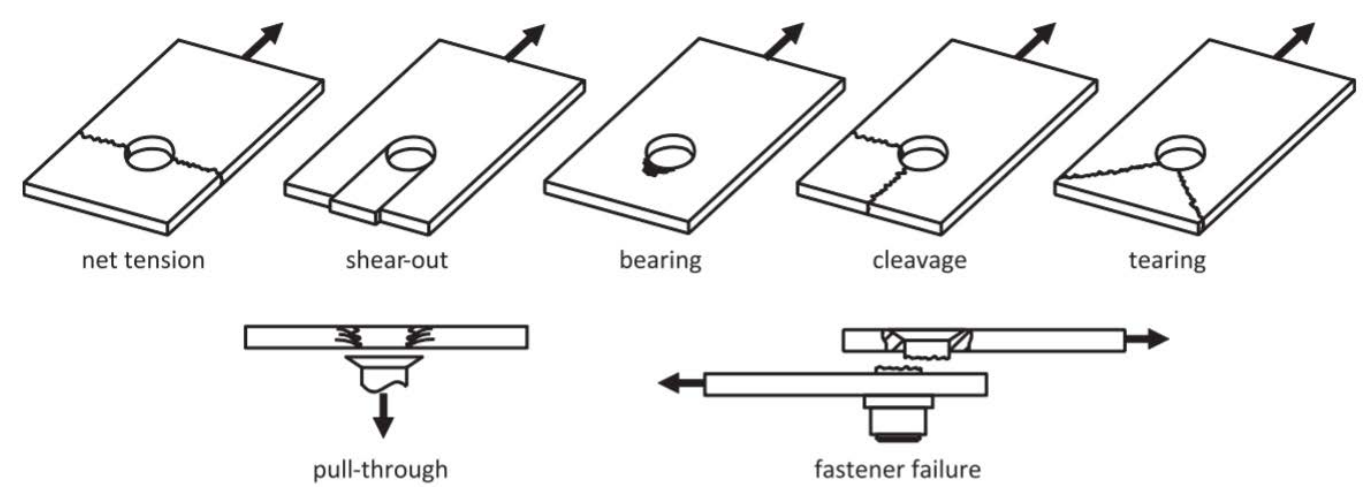

Fig. 39 Schematics of different failure modes of mechanically fastened CFRP joints [143]

Tension and bearing failures take place when the hole diameter is large with smaller fractions of plate width,. This fraction depends on types of material and lay-up. The bearing failure leads to a hole elongation. A special case of bearing failure is the shear-out failure taking place at very large end distances for highly orthotropic laminates. Inadequate end distance and transverse plies boost the cleavage failure. Pull-through failure occurs mainly with countersunk fasteners or when the ratio between plate thickness and bolt diameter is high enough to precipitate failure [144]. Therefore, width $(w)$, end distance $(e)$, hole diameter $(d)$ and laminate thickness $(t)$ are very important on the joint strength of composites [144-151]. The mode of failure changes from bearing to tension for glass fibre reinforced plastics (GFRPs) and carbon fibre-reinforced plastics (CFRPs) when the specimen width is reduced to a certain value [145]. Similarly, the bearing failure mode changes to that of shear out with the reduction of end distance to a certain value. The load carrying capacity of joint is reduced in both cases. The change failure mode changed from tension to bearing occurs because the delamination near the hole reduces the stress concentration factor in this region. The larger holes undergo proportionally less stress concentration relief before failure, which decreases the strength of larger holes. This suggests that the use of softening strips near the hole increases the stress concentration relief due to the greater delamination associated with fibres [145]. The small values of end distance result in shear-out failure and small values of width causes tensile failure in Kevlar fibre-reinforced plastics (KFFW) as also seen in CFRPs and GFRPs [148]. Correlations can be established between joint strength and ratios of geometric parameters(e.g. $w / d, e / d$ and $t / d$ ), which depends on the lay-up of CFRPs where higher values of $w / d$ and $e / d$ yield the higher strength [146, 150]. However, the joint structural efficiency increases with the 
increase in $w / d$, until an optimum value is achieved [144, 147]. No significant influence of laminate thickness on bearing strength is noticed when the compression over the washer contact area through plate thickness is at least $22 \mathrm{MN} / \mathrm{m}^{2}$. The bearing strength of CFRPs could be improved by increasing the through-thickness compressive stress around the loaded hole by changing the fibre orientations. Improvements of $60 \%$ to $170 \%$ was achieved with constraint pressures of up to $22 \mathrm{MN} / \mathrm{m}^{2}$ for $\left(0^{\circ} / \pm 45^{0}\right)$ laminate composites based on the hole size. At higher constraint pressures, little further improvement appeared. The lack of through-thickness compression at the contact zone could lead to premature in-plane compressive failure occurring due to the initiation of shear cracks at the hole edge and the subsequent propagation to the edge of clamped regions [146].

The tensile strength of a single-hole joint depends on the ply orientation [145] where the bearing strength of CFRP in $\left(0^{0} / \pm \alpha^{0}\right)$ laminates is based on the ratio of $0^{0}$ plies to $\pm \alpha^{0}$ plies, and the effect of these plies relies on the type of failure [146]. The addition of $\pm 45^{\circ}$ plies to a $0^{0}$ or $90^{\circ}$ laminate increases the bearing strength until the $\pm 45^{\circ}$ plies account for approximately $75 \%$ of the total laminate thickness, which is ascribed to the reduced stress concentration. The addition of either $0^{0}$ or $\pm 45^{\circ}$ to a $90^{\circ}$ laminates produces a similar change in the variation of bearing strength [149]. The minimum values of $w / d$ and $e / d$ to achieve full strength depend on the lay-up used where high values of $w / d$ and $e / d$ give full strengths in $\left( \pm 45^{\circ}\right)$ and $\left(0^{0} / 90^{\circ}\right)$ laminates, respectively. The shear-out failures are prevalent for fibre patterns that are both rich in $0^{\circ}$ and deficient in $90^{\circ}$ plies. The same strength and failure modes were achieved in joints with $50 \%$ of $0^{\circ}$ plies and $50 \%$ of $\pm 45^{\circ}$ plies for $e / d=2$ and $e / d=22$. The shear-out and bearing strengths are maximised for quasi-isotropic laminates. The fibres in any one of basic laminate directions, namely $\pm 45^{\circ}, 0^{0}$ and $90^{\circ}$, should be within $1 / 8$ to $3[144,147]$. For $\left(0^{\circ} \pm 45^{\circ}\right)$ laminates improvements from $60 \%$ to $170 \%$ according to hole size were achieved with constraint pressures up to $22 \mathrm{MN} / \mathrm{m}^{2}$. At higher constraint pressures, further minor improvement was achieved. It was considered that the lack of through-thickness compression at the contact zone could lead to premature in-plane compressive failure, which is believed to occur by the initiation of shear cracks at the hole edge and the subsequent propagation to the edge of the clamped region. The shear cracks cannot propagate under compression when the laminate is restrained laterally [145]. Therefore the lateral expansion is spread into a wider area that lies outside the washer boundary. For high values of clamping pressure the bearing strength-clamping pressure relation was almost constant, suggesting the existence of an optimum value of pressure that should be applied to avoid unnecessary damage in the laminate. 
A through-thickness restrain by the fastener affects the joint strength where a plain pin can give the lowest bearing strength, and a fully tightened bolt leads to the highest bearing strength. The bearing strength obtained using a riveted joint would fall between these two extremes [142]. The joint strength depends not only on the amount of bolt clamping pressure, but also on the area over which it is applied. The influence of clamp-up for the other failure modes is not as pronounced as it is for bearing failure [144, 147].

The stacking sequences of laminates also affect the joint strength because of the throughthickness normal and shear stresses at the hole boundary. It is suggested that placing a $90^{\circ}$ layer at the surface increases the bearing strength due to the generation of normal compressive through-thickness stress that can inhibit the delamination [152]. Less homogeneous stacking sequences display lower bearing strengths, arising from the occurrence of high inter-laminar shear stresses in such laminates [145].

Multi-row fasteners are used in most of the joints used in practice [153]. It was possible to predict the total load carried by multi-hole joints using single-hole data when pitches are large enough to avoid the interference of stress fields around the holes [146, 151]. However, a multihole joint does not offer a considerable enhancement over a single-hole joint. The decrease in bearing stress and diameter to pitch ratio $(p / d)$ increases the joint strength above the optimum tension failure strength of single bolt. Two bolts could improve the strength of an optimally proportioned single-bolt joint by about $10 \%$, whereas a line of eight or ten bolts would be necessary to achieve a $25 \%$ improvement. The strongest joint for bearing failure contains only one row of bolts. Joints with multi-row bolts have lower bearing stress and tend to undergo tension failure [144, 147].

\section{Discussions}

Carbon fibres are used as the reinforcement for both thermosetting and thermoplastic composites [154]. It is well known that the primary physical difference between these two types of matrices is that thermoplastics can be remelted back into a liquid, whereas thermoset plastics always remain in a permanent solid state. This is due to the presence of polymers in thermosets with a cross-linking feature during the curing process to form irreversible chemical bonds. On the other hand, no such chemical reaction occurs during the curing process of thermoplastic matrices, which allows thermoplastics to be remoulded and 
recycled without negatively disturbing their physical properties. Therefore, all joining methods are valid for carbon fibre reinforced thermosetting as well as thermoplastic composites. However, the joining methods that require softening or melting of matrix materials such as welding and thermo-clinching [81] processes, are only valid for thermoplastic composites.

The bolted joint and the clinching joint require drilled holes on CFRPs. The drilling process influences the joint strength badly. The deformed metal holds the drilled surface in the clinched joint, which minimises the effect of drilling process. Similarly, the melted matrices rebinds torn fibres during the thermal-clinching and minimises the generated defects during the hole formation. CFRPs, owing to their anisotropy and abrasive nature of defects of carbon fibres are inclined to making the drilling process complex [155]. In addition, a relatively high sensitivity to heat damage and weakness in the thickness direction further complicates drilled composites [156, 157]. The smoothness of the drilled surface and tool wear are equally important in real applications though the defect-free drilled hole is prioritized over the tool wear [158]. Challenges in drilling CFRPs are excessive tool wear and workpiece materialrelated problems such as surface irregularities and defects [155, 159-161]. Composites are very susceptible to surface splintering generally occurring at the entrance and exit of drilled holes [156]. The peeling force grabs the top plies at the entry, but the punching forces induces peeling on the bottom surface plies. The top surface splintering is encountered due to a very high feed rate, whereas exit surface splintering occurs towing to a very high feed force $[162,163]$. Plate bulging, spall opening and spall tearing/twisting mainly contribute to the delamination [164]. A bulge is the start of fracture due to the action of chisel edge onto the laminates. Pieces or spalls from the laminate surface start to break off due to the advancement of the chisel edge to open spalls. The plunging push stimulates cracking via an opening mode of fracture. The drill torque twists and tears the spall because of the downward thrust force and the rake angle along cutting lips. The action of flutes on the spalls propagates the crack even further $[164,165]$. The CFRPs are constantly sheared and smeared into the gaps among the fibres at low feeds, but at higher feeds, the compression induced rupture normal to fibres and shear fracture along the fibre/matrix interfaces occur due to the bending effect [166]. The tool geometry related damages are attributed to the angle between fibres orientation and cutting edge. The temperature related damages appear due to the friction between the drill and the hole wall [157, 167]. 
There are a number of methods available to join aluminium alloys with CFRPs though the performances and mechanisms of those are quite different. The facts behind establishing bonding among workpieces are (a) to resist the sliding along length and width (movement along $\mathrm{X}$ and $\mathrm{Y}$ as shown in Fig. 40) and (b) to stop falling apart along the normal direction (movement along $\mathrm{Z}$ as shown in Fig. 40) of bonded surfaces. All bonding methods address these two facts in different ways and the capabilities of addressing these two facts are known as the strength of joints. Fig. 40 shows a typical joining arrangement and interaction at joining interfaces. In a service condition, joints are subjected to different types of loads, such as $F_{x}, F_{y}$ and $F_{z}$ (Fig. 40), which tries to separate the joining parts and use joining mechanisms to resist this effort by generating reactions such as, $R_{x}, R_{y}$ and $R_{z}$ through adhesives, rivets, bolts etc. In case of adhesive bonding, a layer of adhesive remains between adherent surfaces. Therefore the interactions of adhesives with joining surfaces are the main factors in order to control the joint performance. Bonding strength is constant for a given system of adherent surfaces and adhesives. Thus the maximum loads under shear and T-peel tests are very similar despite different failure behaviours. The failure happens progressively during T-peel tests as the displacement increases with decreasing the load leading to until it becomes zero for final failure. This is associated with the stress concentration at interfaces as small areas in the bond endures peel test loading. On the other hand, whole joint interfaces endure the load during shear testing and complete fracture occurs after certain plastic deformation at a load level very close to the maximum shear load.

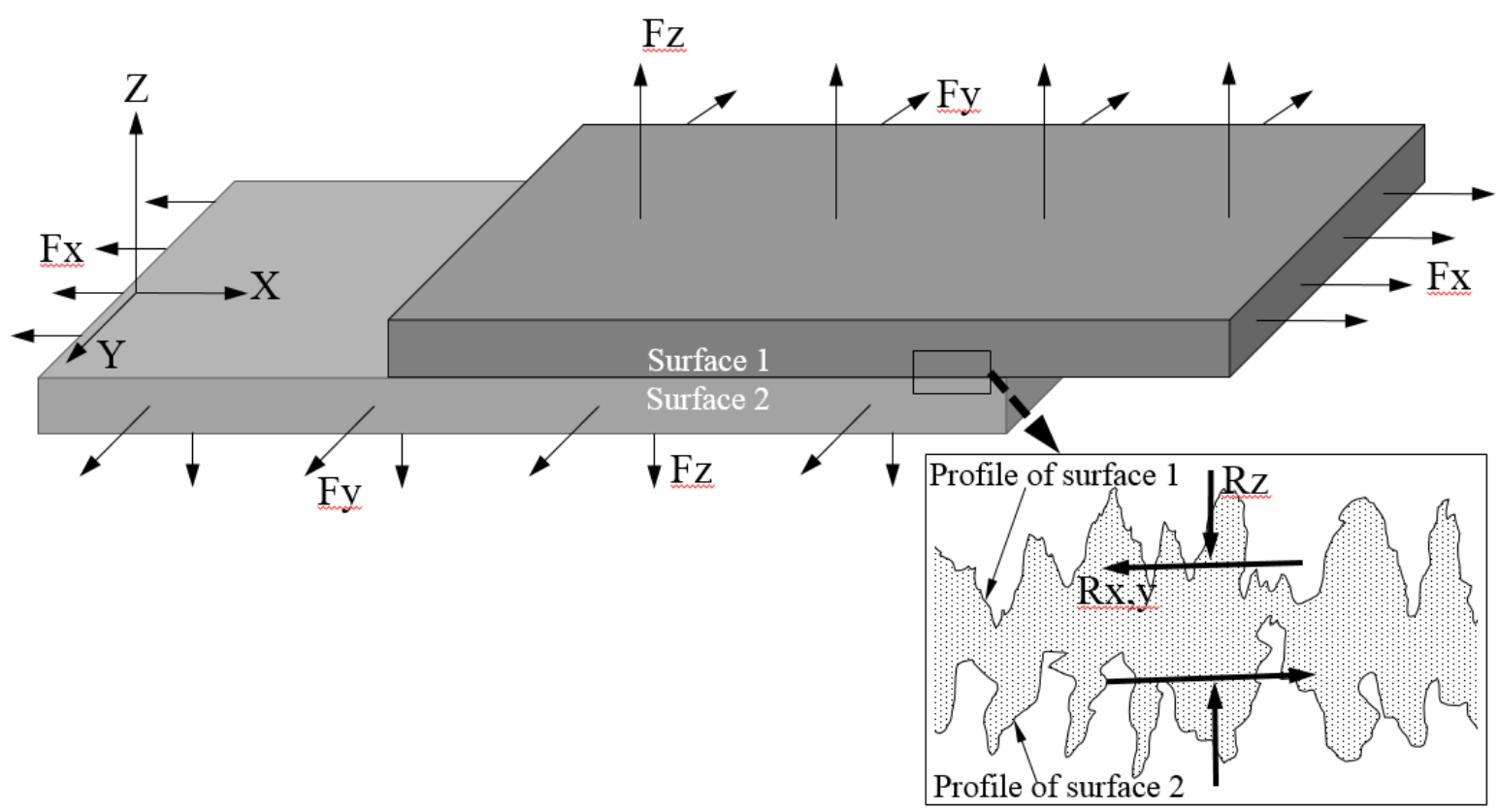

Fig. 40: Typical joining arrangement and interaction of forces at joining interfaces. 
SPRs hold the adherents by applying a compressive force through rivets. The compressive force $\left(R_{\mathrm{z}}\right.$ shown in Fig. 40) cannot be varied for a given riveting system. The initial resistance to sliding at interfaces between two adherents is constant, which comes from the interlocking of surface profiles. Additional resistance against sliding stems from shear strength of rivets that are inserted into workpieces without drilling a hole, and thus lock the bottom adherents by creating a flare inside it. Theoretically, no gap exists between rivets and joining parts and the joint acts as a single workpiece until it fails. Thus, load-displacement curves for self-piercing riveting joints do not have noticeable steps or slope changes Bolted joints have a similarity to self-piercing riveting joints in that both of these methods use external metallic parts for holding joining components. However, a pre-drilled hole is required for bolted joints and compressing a load on joints can be varied by tightening and loosening the nut depending on the requirements. In general, a certain amount of clearance exists between bolts and drilled holes. The compressive force, which can be adjusted by an applied torque, controls interlocking between mating surfaces and an increase of torque increases interlocking and resistance of sliding in $X$ and $Y$ directions (Fig. 40). Shearing of interlocking in mating surfaces takes place initially when the joint is under load in $X$ or $Y$ directions. In this case, interlocking fails due to the clearance in between holes and bolt. Bolts start to carry the load suddenly, and thus gives rise to steps in load-displacement curves for a bolted joint. These steps continue to generate with a load increase due to the progressive bearing failure of reinforcements in CFRPs with respect to rigid bolts. Adhesives are added to reinforce interlocking strength of mating surfaces in self-piercing riveting and bolted joints, known as hybrid joints. Trends of load-displacement curves of hybrid joints are identical to those of corresponding self-piercing riveting and bolted joints despite the significant increase in load-bearing capacity. In case of clinching process, aluminium alloys deform locally and are punched through pre-drilled holes in CFRPs in the bottom. This makes flat head look like button due to the presence of a die at the end and the parts in joints are in complete contact in the bonding region. This joint mainly fails due to button separation and cracks in CFRPs. Hence load-displacement curves contain some steps and complete failure occurs at zero load in most cases. Bonding between aluminium alloys and CFRPs by welding is very similar to that of adhesive bonding. Melted CFRPs act as adhesives in the joint regions. They fail in the way similar to that of adhesive joints though plastic deformation was not evident due to the brittle behaviour of solidified plastics at interfaces. In addition, the bubble formation in CFRPs, close to interfaces, affects the bonding performance. 
The surface preparation, joining mechanism and failure mechanism of different joining techniques are presented in the table 1.

Table 1. Different joining techniques between aluminium alloy and CFRP

\begin{tabular}{|c|c|c|c|}
\hline $\begin{array}{c}\text { Joining } \\
\text { techniques }\end{array}$ & $\begin{array}{c}\text { Surface } \\
\text { preparation }\end{array}$ & mechanism & chanism \\
\hline $\begin{array}{l}\text { Adhesive } \\
\text { bonding }\end{array}$ & $\begin{array}{l}\text { Mechanical } \\
\text { polishing and } \\
\text { wipe cloths to } \\
\text { remove any } \\
\text { contamination. } \\
\text { Etching Al alloy } \\
\text { by hydrochloric } \\
\text { acid and water } \\
\text { (20 to } 80 \%) \\
\text { works. Radio } \\
\text { frequency } \\
\text { treatment of } \\
\text { polymers by } \\
\text { plasma in air, } \\
\text { oxygen, } \\
\text { nitrogen, argon } \\
\text { and helium } \\
\text { shows improved } \\
\text { wettability for } \\
\text { adhesive } \\
\text { bonding. }\end{array}$ & $\begin{array}{l}\text { Inter-atomic and inter- } \\
\text { molecular forces at } \\
\text { interface, and inter- } \\
\text { diffusion of molecules } \\
\text { through interface } \\
\text { enable adhesion } \\
\text { process self-healing } \\
\text { and welding. } \\
\text { Mechanical keying } \\
\text { allows adhesive to wet } \\
\text { cavities, pores and } \\
\text { asperities of adherent } \\
\text { surfaces and thus } \\
\text { contributes to adhesive } \\
\text { strength significantly } \\
\text { after curing. }\end{array}$ & $\begin{array}{l}\text { Adhesive fails when the strength } \\
\text { of the adhesive materials } \\
\text { becomes weaker than adherents } \\
\text { for a perfectly bonded adhesive } \\
\text { joint; otherwise adherents fail. } \\
\text { Cracks start around entrenched } \\
\text { adherend corner (under the } \\
\text { overlap) at middle of the joint } \\
\text { (along the width). With time, } \\
\text { these cracks spread out } \\
\text { depending on brittle/ductile } \\
\text { nature of an adhesive. Gradual } \\
\text { variation of adhesive properties } \\
\text { due to the change of temperature } \\
\text { is the prime concern for applying } \\
\text { adhesives in environments where } \\
\text { temperature } \\
\text { considerably. }\end{array}$ \\
\hline $\begin{array}{l}\text { Diffusion } \\
\text { bonding }\end{array}$ & \multicolumn{3}{|c|}{$\begin{array}{l}\text { There is no study on direct diffusion bonding between aluminium alloy and } \\
\text { CFRP, though researchers have used wires (titanium), foils (titanium) and } \\
\text { fibres (glass fibre), between aluminium and CFRP as transition elements, on } \\
\text { course of diffusion bonding }\end{array}$} \\
\hline $\begin{array}{l}\text { Self- } \\
\text { piercing }\end{array}$ & $\begin{array}{l}\text { No surface } \\
\text { preparation }\end{array}$ & $\begin{array}{l}\text { Plastic deformation of } \\
\text { joint components tie-up }\end{array}$ & $\begin{array}{l}\text { Failure occurs only in top } \\
\text { element, the normal stresses near }\end{array}$ \\
\hline
\end{tabular}




\begin{tabular}{|c|c|c|c|}
\hline $\begin{array}{l}\text { rivet } \\
\text { technique }\end{array}$ & $\begin{array}{l}\text { required. Thus } \\
\text { there is also no } \\
\text { need of exact } \\
\text { alignment among } \\
\text { components and } \\
\text { rivet setting } \\
\text { apparatus. }\end{array}$ & $\begin{array}{l}\text { two or more material } \\
\text { panels with the help of } \\
\text { semi-tubular rivet. The } \\
\text { compression by rivet } \\
\text { head and flare of shank } \\
\text { generates a mechanical } \\
\text { interlock. }\end{array}$ & $\begin{array}{l}\text { rivet (high stress concentration } \\
\text { because of hole) cause failure of } \\
\text { the joints for cross-ply laminates. } \\
\text { In contrast, rivets are pulled-out } \\
\text { for angle-ply laminate. The rivet } \\
\text { head damages fibres near the } \\
\text { hole and contributes to the partial } \\
\text { failure of laminate. For hybrid } \\
\text { joints, minute fibre damage with } \\
\text { rivet pull-out occurred for joints } \\
\text { with cross-ply laminate CFRP } \\
\text { after adhesive failure due to } \\
\text { breakage of CFRP laminate close } \\
\text { to rivet. Angle-ply CFRP are } \\
\text { categorized by high pull-out of } \\
\text { rivet with compression and } \\
\text { successive folding of composite } \\
\text { material at the back of rivet. The } \\
\text { failure occurs as a result of de- } \\
\text { bonding of composite materials } \\
\text { as rivet holes add discontinuity in } \\
\text { joints. }\end{array}$ \\
\hline $\begin{array}{l}\text { Bolted } \\
\text { joints }\end{array}$ & $\begin{array}{l}\text { Pre-drilled } \\
\text { uniaxial common } \\
\text { hole through } \\
\text { components to } \\
\text { be joined. The } \\
\text { hole diameter is } \\
\text { smaller than the } \\
\text { bolt diameter. }\end{array}$ & $\begin{array}{l}\text { Bolts are screwed into } \\
\text { the nuts on other side. } \\
\text { The bolt head and nut } \\
\text { act as flanges to hold } \\
\text { the joint components } \\
\text { tightly. Bolts don't } \\
\text { deform plastically and } \\
\text { the diameter and } \\
\text { material of bolt } \\
\text { determine the strength } \\
\text { of bolted joints when }\end{array}$ & $\begin{array}{l}\text { Bearing mode failure occur due } \\
\text { to damage build up though four } \\
\text { phases: damage onset, damage } \\
\text { growth, local fracture and final } \\
\text { structural fracture. Severe } \\
\text { damage occurs on contact } \\
\text { surfaces between bolt and hole } \\
\text { though this is not the main } \\
\text { incident in bearing failure. } \\
\text { Destruction in inside-washer } \\
\text { section is damage build up routes }\end{array}$ \\
\hline
\end{tabular}




\begin{tabular}{|c|c|c|c|}
\hline & & $\begin{array}{l}\text { other components of the } \\
\text { joint are stronger. }\end{array}$ & $\begin{array}{l}\text { for example, fibre kink bands of } \\
\text { 0-plies, which encourage shear } \\
\text { cracks and delamination in } \\
\text { surrounding } \pm 45 \text {-plies. } \\
\text { Compressive damage grows } \\
\text { along in-plane direction in stage- } \\
\text { by-stage fashion. Extensive } \\
\text { delamination takes place under } \\
\text { washer area and rapidly reduces } \\
\text { the response of joint when the } \\
\text { damage of inside-washer } \\
\text { progressively saturates. Spread } \\
\text { of delamination corresponds to } \\
\text { fibre orientation or splitting } \\
\text { direction of the ply contacting } \\
\text { aluminium adherent. As not all } \\
\text { the bolts break at a time, stress } \\
\text { declines step-by-step with } \\
\text { signature mark in the load- } \\
\text { displacement curve. }\end{array}$ \\
\hline Clinching & $\begin{array}{l}\text { No surface } \\
\text { preparation } \\
\text { except produce } \\
\text { holes of certain } \\
\text { diameter in the } \\
\text { CFRP sheets for } \\
\text { the joint. }\end{array}$ & $\begin{array}{l}\text { Al } 6061 \text { sheets are } \\
\text { bulged initially and } \\
\text { compressed with punch } \\
\text { and die, and interlocked } \\
\text { with CFRP with a } \\
\text { variable amount of } \\
\text { deformation between } \\
\text { the sheets. The die } \\
\text { cavity consists of a ring } \\
\text { groove that supports the } \\
\text { interlock formation and } \\
\text { sheets forced into die } \\
\text { cavity form the required }\end{array}$ & $\begin{array}{l}\text { Failure occurs due to button } \\
\text { separation as a result of } \\
\text { insufficient undercut and CFRP } \\
\text { fracture around the hole-clinched } \\
\text { area. A peel load which causes } \\
\text { fracture to CFRP laminates, is } \\
\text { prompted during single lap shear } \\
\text { test. Delamination due to } \\
\text { dragging weakens the CFRP } \\
\text { around clinched area and } \\
\text { accelerates CFRP fracture. Thus, } \\
\text { unexpected button separation } \\
\text { failure occurred at clinched joint }\end{array}$ \\
\hline
\end{tabular}




\begin{tabular}{|c|c|c|c|}
\hline & & $\begin{array}{l}\text { undercut. The final } \\
\text { joint does not need any } \\
\text { additional finishing } \\
\text { after this process. }\end{array}$ & $\begin{array}{l}\text { for CFRP thicknesses of } 1.0 \mathrm{~mm} \\
\text { and } 1.2 \mathrm{~mm} \text {. An increase in } \\
\text { clinched joint diameter improves } \\
\text { joint strength. For specimens } \\
\text { with CFRP thicknesses of } 1.4 \\
\text { mm and } 1.6 \mathrm{~mm} \text {, necking } \\
\text { fracture was observed in upper } \\
\text { sheet at } 2.75 \text { and } 3.34 \mathrm{kN} \\
\text { respectively. }\end{array}$ \\
\hline $\begin{array}{l}\text { Laser } \\
\text { assisted } \\
\text { welding }\end{array}$ & $\begin{array}{l}\text { General cleaning } \\
\text { of both materials } \\
\text { and sandblasting } \\
\text { of aluminium } \\
\text { alloy to increase } \\
\text { laser beam } \\
\text { absorptivity. }\end{array}$ & $\begin{array}{l}\text { The weld is formed due } \\
\text { to melting of mating } \\
\text { parts. The laser rapidly } \\
\text { heats material which } \\
\text { facilitates an interfacial } \\
\text { region reaction at very } \\
\text { high temperatures } \\
\text { which suggests that the } \\
\text { joint was produced by } \\
\text { bonding CFRP with } \\
\text { oxide film covering } \\
\text { total surface area of the } \\
\text { metal. }\end{array}$ & $\begin{array}{l}\text { Two kinds of porosities are } \\
\text { reported in literature: Porosity I } \\
\text { and Porosity II. Porosity I is deep } \\
\text { with a smooth inner wall where } \\
\text { carbon fibres are detected inside } \\
\text { the porosity. In case of porosity } \\
\text { II, a relatively rough inner wall } \\
\text { with minor pores, grooves and } \\
\text { cracks, without any noticeable } \\
\text { bare carbon. It is likely that these } \\
\text { defects generate cracks and } \\
\text { finally the joint fails. }\end{array}$ \\
\hline $\begin{array}{l}\text { Friction } \\
\text { spot } \\
\text { welding }\end{array}$ & $\begin{array}{l}\text { Metal is cleaned } \\
\text { by } \mathrm{SiC} \text { and } \mathrm{Al}_{2} \mathrm{O}_{3} \\
\text { abrasive paper or } \\
\text { sand blasting. } \\
\text { Both the metal } \\
\text { and the } \\
\text { composite } \\
\text { samples are } \\
\text { cleaned by } \\
\text { acetone in an } \\
\text { ultrasonic and }\end{array}$ & $\begin{array}{l}\text { Frictional heat is } \\
\text { generated by a tool } \\
\text { consists of a clamping } \\
\text { ring, sleeve and pin. } \\
\text { The friction between } \\
\text { the sleeve and the metal } \\
\text { soften and plasticize the } \\
\text { alloy locally. The heat } \\
\text { conducts to composite } \\
\text { interface from the metal } \\
\text { alloy and generate a }\end{array}$ & $\begin{array}{l}\text { The joints fail by having the } \\
\text { cracks initiate at the periphery of } \\
\text { the adhesion zone and propagate } \\
\text { along the interface between } \\
\text { aluminium and composite } \\
\text { surface in a plane parallel with } \\
\text { the applied load direction. } \\
\text { Should the cracks reach the } \\
\text { beginning of the transition zone, } \\
\text { their path can shift from the } \\
\text { interface into the composite and }\end{array}$ \\
\hline
\end{tabular}




\begin{tabular}{|c|c|c|c|}
\hline & $\begin{array}{l}\text { pressurized bath, } \\
\text { and finally in dry } \\
\text { air. }\end{array}$ & $\begin{array}{l}\text { thin layer of the molten } \\
\text { polymer throughout the } \\
\text { overlap region. Molten } \\
\text { layers consolidates } \\
\text { under pressure and } \\
\text { induces adhesion and } \\
\text { interlock between the } \\
\text { metal and composite. }\end{array}$ & $\begin{array}{l}\text { propagate in the plastically } \\
\text { deformed zone within a volume } \\
\text { close to the metallic nub, in the } \\
\text { first plies of the composite. This } \\
\text { crack propagation is associated } \\
\text { with a more cohesive failure in } \\
\text { plastically deformed zone. }\end{array}$ \\
\hline $\begin{array}{l}\text { Friction } \\
\text { lap joining }\end{array}$ & $\begin{array}{l}\text { General cleaning } \\
\text { of both materials. } \\
\text { Grinding of } \\
\text { metallic } \\
\text { component } \\
\text { improve the } \\
\text { joint. }\end{array}$ & $\begin{array}{l}\text { Heat generated by } \\
\text { friction between a } \\
\text { reusable rotating tool } \\
\text { and metal surface. The } \\
\text { tool presses the surface } \\
\text { of the metal plate and } \\
\text { moves along the } \\
\text { overlap region. It is } \\
\text { similar to a friction stir } \\
\text { welding without a } \\
\text { stirring probe. Heat } \\
\text { transferred from the } \\
\text { heated metal to the } \\
\text { plastic layer produces a } \\
\text { narrow melted region at } \\
\text { the interface. Adhesion } \\
\text { and interlocking joins } \\
\text { materials after merging } \\
\text { under pressure. }\end{array}$ & $\begin{array}{l}\text { Almost all the joints fractured } \\
\text { near the joint interface regardless } \\
\text { of surface treatment. The CFRP } \\
\text { may be present on the metallic } \\
\text { component depending on the } \\
\text { surface treatment. } \\
\text { unground-A5052/CFRP joint } \\
\text { fractured only at the interface but } \\
\text { the fracture in the ground- } \\
\text { A5052/CFRP joint partially } \\
\text { propagate through the CFRP, } \\
\text { including both the matrix and the } \\
\text { carbon fibres. }\end{array}$ \\
\hline
\end{tabular}

\section{Future work}

Traditional joining methods such as adhesive, riveting and joining by means of loop connections are well-known for manufacturing of continuous fibre reinforced composites with thermosetting matrices. The adhesives are flexible for material arrangements, but frequently 
involves broad surface pre-treatments of adherents. These kinds of joints are mainly utilized in aerospace industries [168]. The bolted and riveted methods are frequently used for trusted joints in aviation, according to their high reproducibility and fast joining processes $[169,170]$. Since the holes which are needed for these methods, fibre reinforcements are locally broken up and the structures are weakened in those areas [171]. The additional joining elements increase the weight of bolted and riveted joints. The self-piercing riveting method does not require any pre-treatments such as surface treatments or hole drilling and significantly reduces the process time. Nevertheless, this process interrupts the fibre reinforcement unpredictably [118]. The incorporation of special joining zones for loop connections during composite processing is very labour intensive [71, 72].

Despite many research interests in this field, many research challenges are still encountered. New techniques are being developed, and the existing processes require a comprehensive understanding of the improvements of product and process properties such as strength, robustness, performance, productivity, sustainability, life expectance and flexible automation, etc. [172]. We anticipate to identify some key research areas required for the future development to achieve desired products and processes as follows:

- Model development to predict the performance of different joining techniques.

- Reference guidelines for the fair assessment and performance comparison of different joining techniques side by side.

- Developments of hybrid joining methods by combining several joining techniques so that the weakness of individual techniques is reduced and the strength of individual techniques are super positioned to enhance the performance of hybrid joints.

\section{Conclusions}

There are many methods for joining dissimilar materials. This review only investigated available methods to join CFRPs and aluminium alloys. Though joining mechanisms and properties are different in each method, all joints generally have the capacity to carry loads. A side by side comparison of performances for different joining methods is very difficult due to geometric and configuration variations. Thermo-clinching, laser assisted welding, friction spot welding, friction lap joining are still in the early stage of development. These methods have a very high potential in this area, and further research is required to completely exploit these 
methods in practical applications. Based on systematic analyses and facts presented in this review, the following key points can be summarized:

- Other than adhesion and welding, all joining methods modify adherent parts in a way that original parts become weak and stress concentration can be introduced. The CFRPs must be made of thermoplastic matrices to be joined through welding and thermoclinching processes.

- Depending on the adherents, intensive surface preparation by air blast, abrasive paper, plasma and liquid cleaning agents are necessary for better bonding between adherents. This improves the wetting, surface energy and contact angle of joining surfaces.

- Direct diffusion bonding between CFRPs and 6061 aluminium alloys is not possible with the further foreseen research in this field. The incorporation of distinct joining zones of CFRPs for loop connections or metallic inserts is very labour intensive. Prefabricated holes are required only in CFRPs required to be in the bottom during clinching. Aluminium layer penetrates through the holes of CFRPs and locks the CFRP layer by making a flat head at exit with the help of a die. This deformation of aluminium layer induces additional defects in CFRPs. However, an opposite process is followed in thermo-clinching joints where pre-fabricated hole is required in metal parts and the locally softened CFRPs (with two straight cuts across the hole centre)are pushed by a tapered pin. The passed-through material is compressed and forms lock head when cooled. Bolted joints also require pre-fabricated holes in both CFRP and aluminium alloy layers. Friction is the first stage of resistance to this bonding, which can be controlled by tightening bolt torques. The clearances exists in between drilled surfaces and bolts, causing the steps in load-displacement curves.

- Riveted joints are very similar to bolted joints though rivets pierce through CFRPs and partly to aluminium alloys in the bottom and flare inside aluminium alloys with the help of a die to generate the bonding. Clearances do not exist between pierced surfaces and rivets with the step absence in load-displacement curves.

- Applications of rivets, clinches or bolts on adhesive joints improve the joint performance significantly, which is commonly known as hybrid joints. 


\section{REFERENCES}

1. Johnson, T. History of Composites 20142014 May 22,2014]; The Evolution of Lightweight Composite Materials]. Available from: http://composite.about.com/od/aboutcompositesplastics/a/HistoryofComposites.htm.

2. Proctor, B.A. Composite Materials. 1990 [cited 201415 April 2014]; Available from: http://www.rsc.org/Education/Teachers/Resources/Inspirational/resources/4.3.1.pdf.

3. Pramanik, A., Developments in the non-traditional machining of particle reinforced metal matrix composites. International Journal of Machine Tools and Manufacture, 2014. 86: p. 4461.

4. Krishnaraj, V.Z., R.; Collombet, F., Comprehensive review on drilling of multi material stacks. Journal of Machining and Forming Technologies, 2010. 2(3-4): p. 1-32.

5. Campbell, F.C., Chapter 11 - Structural Assembly, in Manufacturing Technology for Aerospace Structural Materials, F.C. Campbell, Editor. 2006, Elsevier Science: Oxford. p. 495-537.

6. Sadowski, T., M. Kneć, and P. Golewski, Experimental investigations and numerical modelling of steel adhesive joints reinforced by rivets. International Journal of Adhesion and Adhesives, 2010. 30(5): p. 338-346.

7. Groche, P., et al., Joining by forming -A review on joint mechanisms, applications and future trends. Journal of Materials Processing Technology, 2014. 214(10): p. 1972-1994.

8. Matsuzaki, R., M. Shibata, and A. Todoroki, Improving performance of GFRP/aluminum single lap joints using bolted/co-cured hybrid method. Composites Part A: Applied Science and Manufacturing, 2008. 39(2): p. 154-163.

9. Grant, L.D.R., R.D. Adams, and L.F.M. da Silva, Experimental and numerical analysis of singlelap joints for the automotive industry. International Journal of Adhesion and Adhesives, 2009. 29(4): p. 405-413.

10. Belingardi, G. and G. Chiandussi, Stress flow in thin-walled box beams obtained by adhesive bonding joining technology. International Journal of Adhesion and Adhesives, 2004. 24(5): $p$. 423-439.

11. Goglio, L., M. Rossetto, and E. Dragoni, Design of adhesive joints based on peak elastic stresses. International Journal of Adhesion and Adhesives, 2008. 28(8): p. 427-435.

12. de Morais, A.B., et al., Strength of epoxy adhesive-bonded stainless-steel joints. International Journal of Adhesion and Adhesives, 2007. 27(8): p. 679-686.

13. Rudawska, A., Adhesive joint strength of hybrid assemblies: Titanium sheet-composites and aluminium sheet-composites-Experimental and numerical verification. International Journal of Adhesion and Adhesives, 2010. 30(7): p. 574-582.

14. Brockmann, W., et al., Adhesion in bonded aluminium joints for aircraft construction. International journal of adhesion and adhesives, 1986. 6(3): p. 115-IN1.

15. da Silva, L.F., A. Öchsner, and R.D. Adams, Introduction to Adhesive Bonding Technology. Handbook of Adhesion Technology, 2011: p. 1-7.

16. Dillard, D., Advances in structural adhesive bonding. 2010: Elsevier.

17. Pramanik, A. and A. Basak, Stainless Steel: Microstructure, Mechanical Properties and Methods of Application. 2015.

18. Kim, G. and F. Ajersch, Surface energy and chemical characteristics of interfaces of adhesively bonded aluminium joints. Journal of materials science, 1994. 29(3): p. 676-681.

19. Gouldstone, C., Adhesive joining of curved metal and composite structures. 2002, Massachusetts Institute of Technology.

20. Saleema, N., et al., A simple surface treatment and characterization of $A A 6061$ aluminum alloy surface for adhesive bonding applications. Applied Surface Science, 2012. 261(0): p. 742748. 
21. Rhee, K.Y. and J.-H. Yang, A study on the peel and shear strength of aluminum/CFRP composites surface-treated by plasma and ion assisted reaction method. Composites Science and Technology, 2003. 63(1): p. 33-40.

22. Ebnesajjad, S., Chapter 7 - Surface Preparation of Metals, in Surface Treatment of Materials for Adhesive Bonding (Second Edition), S. Ebnesajjad, Editor. 2014, William Andrew Publishing: Oxford. p. 139-183.

23. Del Real, J., et al., Influence of surface preparation on the fracture behavior of acrylic adhesive/CFRP composite joints. The Journal of Adhesion, 2011. 87(4): p. 366-381.

24. Meyer, M., et al., Surface eatchingof 3-dimesional carbon-fiber reinforced plastics in a dualfrequency mode plasma (40khz and $2.45 \mathrm{ghz}$ ). Surface \& Coatings Technology, 1993. 59(1-3): p. 297-300.

25. Huang, Y.D., et al., The uniform treatment of carbon fiber surface in three-directional orthogonal fabric by oxygen-plasma. Journal of Materials Science, 2003. 38(4): p. 759-766.

26. Menningen, M. and $\mathrm{H}$. Weiss, Application of fracture mechanics to the adhesion of metal coatings on CFRP. Surface and Coatings Technology, 1995. 76: p. 835-840.

27. Zia, A.W., Y.Q. Wang, and S. Lee, Effect of Physical and Chemical Plasma Etching on Surface Wettability of Carbon Fiber-Reinforced Polymer Composites for Bone Plate Applications. Advances in Polymer Technology, 2015. 34(1).

28. Lee, S., et al., Ar and O-2 linear ion beam PET treatments using an anode layer ion source. Current Applied Physics, 2014. 14: p. S180-S182.

29. Gomathi, N., A. Sureshkumar, and S. Neogi, RF plasma-treated polymers for biomedical applications. CURRENT SCIENCE-BANGALORE-, 2008. 94(11): p. 1478.

30. Chung, H., et al., Effect of oxygen plasma treatment on the bonding strength of CFRP/aluminum foam composite. Journal of Alloys and Compounds, 2009. 481(1): p. 214-219.

31. Rhee, K., et al., Effect of oxygen plasma-treated carbon fibers on the tribological behavior of oil-absorbed carbon/epoxy woven composites. Composites Part B: Engineering, 2012. 43(5): p. 2395-2399.

32. Pizzi, A. and K.L. Mittal, Handbook of adhesive technology, revised and expanded. 2003: CRC Press.

33. Bikerman, J., The Science of Adhesive Joints Academic. New York, 1961.

34. Bascom, W.D., C.O. Timmons, and R.L. Jones, Apparent interfacial failure in mixed-mode adhesive fracture. Journal of Materials Science, 1975. 10(6): p. 1037-1048.

35. Good, R.J., Theory of "cohesive" vs "adhesive" separation in an adhering system. The Journal of Adhesion, 1972. 4(2): p. 133-154.

36. Schultz, J., Effect of orientation and organization of polymers at interfaces on adhesive strength. The Journal of Adhesion, 1992. 37(1-3): p. 73-81.

37. Sharpe, L. and H. Schonhorn, Theory gives direction to adhesion work. Chemical and Engineering News, 1963. 41(15): p. 67-68.

38. Derjagin, B., N. Krotova, and V. Smilga, Adhesion of solids. Studies in soviet cience: physical sciences. 1978, Plenum Publishing Corporation, New York.

39. Derjaguin, B. and V. Smilga, Adhesion: Fundamentals and Practice. McLaren, London, 1969.

40. Voiutskii, S.S., Autohesion and adhesion of high polymers. 1963.

41. Plueddemann, E.P., Silane coupling agents. 2013: Springer Science \& Business Media.

42. Gent, A. and J. Schultz, Effect of wetting liquids on the strength of adhesion of viscoelastic material. The Journal of Adhesion, 1972. 3(4): p. 281-294.

43. Wake, W.C., Adhesion and the Formulation of Adhesives. 1976.

44. Evans, J. and D. Packham, Polymer oxidation and surface topography in the adhesion of polyethylene to copper. 1977.

45. Ladizesky, N.H. and I.M. Ward, A study of the adhesion of drawn polyethylene fibre/polymeric resin systems. Journal of Materials Science, 1983. 18(2): p. 533-544. 
46. Nardin, M. and I.M. Ward, INFLUENCE OF SURFACE TREATMENT ON ADHESION OF POLYETHYLENE FIBRES. Materials Science and Technology, 1987. 3(10): p. 814-826.

47. Ladizesky, N.H. and I.M. Ward, The adhesion behaviour of high modulus polyethylene fibres following plasma and chemical treatment. Journal of Materials Science, 1989. 24(10): p. 37633773.

48. Packham, D.E., Theories of fundamental adhesion, in Handbook of Adhesion Technology. 2011, Springer. p. 9-38.

49. Baker, A. and R. Chester, Minimum surface treatments for adhesively bonded repairs. International journal of adhesion and adhesives, 1992. 12(2): p. 73-78.

50. Schubbe, J. and S. Mall, Investigation of a cracked thick aluminum panel repaired with a bonded composite patch. Engineering Fracture Mechanics, 1999. 63(3): p. 305-323.

51. Rhee, K.Y., N.-S. Choi, and S.-J. Park, Effect of plasma treatment of aluminum on the bonding characteristics of aluminum-CFRP composite joints. Journal of adhesion science and technology, 2002. 16(11): p. 1487-1500.

52. Rhee, K.Y., et al., Treatment of CFRP by IAR method and its effect on the fracture behavior of adhesive bonded CFRP/aluminum composites. Materials Science and Engineering: A, 2003. 357(1-2): p. 270-276.

53. Karachalios, E., R. Adams, and L.F. da Silva, Single lap joints loaded in tension with high strength steel adherends. International Journal of Adhesion and Adhesives, 2013. 43: p. 8195.

54. Marannano, G. and B. Zuccarello, Numerical experimental analysis of hybrid double lap aluminum-CFRP joints. Composites Part B: Engineering, 2015. 71: p. 28-39.

55. Roulin-Moloney, A.C., Fractography and failure mechanisms of polymers and composites. 1989: Elsevier applied science.

56. Adams, R. and V. Mallick, The effect of temperature on the strength of adhesively-bonded composite-aluminium joints. The Journal of Adhesion, 1993. 43(1-2): p. 17-33.

57. Grant, L., R. Adams, and L.F. da Silva, Effect of the temperature on the strength of adhesively bonded single lap and $T$ joints for the automotive industry. International journal of adhesion and adhesives, 2009. 29(5): p. 535-542.

58. Apalak, M.K., et al., Steady-state thermal and geometrical non-linear stress analysis of an adhesively bonded tee joint with double support. International journal of adhesion and adhesives, 2003. 23(2): p. 115-130.

59. Harris, J. and P. Fay, Fatigue life evaluation of structural adhesives for automative applications. International journal of adhesion and adhesives, 1992. 12(1): p. 9-18.

60. Chen, Z., R. Adams, and L.F. Da Silva, Prediction of crack initiation and propagation of adhesive lap joints using an energy failure criterion. Engineering Fracture Mechanics, 2011. 78(6): p. 990-1007.

61. Da Silva, L.F. and R. Adams, Joint strength predictions for adhesive joints to be used over a wide temperature range. International Journal of Adhesion and Adhesives, 2007. 27(5): p. 362-379.

62. García, J., et al., Characterization and material model definition of toughened adhesives for finite element analysis. International Journal of Adhesion and Adhesives, 2011. 31(4): p. 182192.

63. Apalak, M.K., R. Gunes, and S. Eroglu, Thermal residual stresses in an adhesively bonded functionally graded tubular single lap joint. International journal of adhesion and adhesives, 2007. 27(1): p. 26-48.

64. Zhang, K., Z. Yang, and Y. Li, A method for predicting the curing residual stress for CFRP/Al adhesive single-lap joints. International Journal of Adhesion and Adhesives, 2013. 46: p. 7-13.

65. Daverschot, D., A. Vlot, and H. Woerden, Thermal residual stresses in bonded repairs. Applied Composite Materials, 2002. 9(3): p. 179-197.

66. Jumbo, F., et al., Thermal residual stress analysis of epoxy bi-material laminates and bonded joints. International Journal of Adhesion and Adhesives, 2010. 30(7): p. 523-538. 
67. Schimanski, K., A. von Hehl, and F. Syassen, Diffusion bonding of transition structures for integral aluminium - fibre reinforced polymer (FRP) compounds. Materialwissenschaft und Werkstofftechnik, 2012. 43(4): p. 293-301.

68. Schimanski, K., A. von Hehl, and H.-W. Zoch, Failure behavior of diffusion bonded transition structures for integral FRP-Aluminum compounds. Procedia Materials Science, 2013. 2: p. 189196.

69. Schumacher, J., H. Bomas, and H.-W. Zoch, Failure behaviour of advanced seam structures for CFRP-aluminium connections. Procedia Materials Science, 2013. 2: p. 227-233.

70. Woizeschke, P. and V. Wottschel, Recent developments for laser beam joining of CFRPaluminum structures. Procedia Materials Science, 2013. 2: p. 250-258.

71. Möller, F., et al., Novel method for joining CFRP to aluminium. Physics Procedia, 2010. 5: p. 3745.

72. Schiebel, P., et al., Connections between a monolithic metal component and a continuous-fiber reinforced laminate component, and method for production of the same. 2014, Google Patents.

73. Pickin, C.G., K. Young, and I. Tuersley, Joining of lightweight sandwich sheets to aluminium using self-pierce riveting. Materials \& Design, 2007. 28(8): p. 2361-2365.

74. Hoang, N.H., et al., Self-piercing riveting connections using aluminium rivets. International Journal of Solids and Structures, 2010. 47(3-4): p. 427-439.

75. Hoang, N.H., et al., The effect of the riveting process and aging on the mechanical behaviour of an aluminium self-piercing riveted connection. European Journal of Mechanics - A/Solids, 2011. 30(5): p. 619-630.

76. Mori, K., 7 - Assessing the suitability of materials for self-piercing riveting (SPR), in Self-Piercing Riveting, A. Chrysanthou and X. Sun, Editors. 2014, Woodhead Publishing. p. 111-123.

77. Di Franco, G., L. Fratini, and A. Pasta, Analysis of the mechanical performance of hybrid (SPR/bonded) single-lap joints between CFRP panels and aluminum blanks. International Journal of Adhesion and Adhesives, 2013. 41(0): p. 24-32.

78. Porcaro, R., et al., The behaviour of a self-piercing riveted connection under quasi-static loading conditions. International Journal of Solids and Structures, 2006. 43(17): p. 5110-5131.

79. Voelkner, W., Present and future developments of metal forming: selected examples. Journal of Materials Processing Technology, 2000. 106(1-3): p. 236-242.

80. He, X., I. Pearson, and K. Young, Self-pierce riveting for sheet materials: state of the art. Journal of materials processing technology, 2008. 199(1): p. 27-36.

81. Gude, M., et al., Development of novel form-locked joints for textile reinforced thermoplastices and metallic components. Journal of Materials Processing Technology, 2015. 216: p. 140-145.

82. Hou, W., et al. Characterization for quality monitoring of a self-piercing riveting process. in AWS Sheet Metal Welding Conference XI, Paper. 2004.

83. King, R.P., Analysis and quality monitoring of a self-pierce riveting process. 1997, University of Herfordshire.

84. Di Franco, G., L. Fratini, and A. Pasta, Influence of the distance between rivets in self-piercing riveting bonded joints made of carbon fiber panels and AA2024 blanks. Materials \& Design, 2012. 35(0): p. 342-349.

85. Barnes, T.A. and I.R. Pashby, Joining techniques for aluminium spaceframes used in automobiles: Part II - adhesive bonding and mechanical fasteners. Journal of Materials Processing Technology, 2000. 99(1-3): p. 72-79.

86. He, X., A review of finite element analysis of adhesively bonded joints. International Journal of Adhesion and Adhesives, 2011. 31(4): p. 248-264.

87. He, X., F. Gu, and A. Ball, Recent development in finite element analysis of self-piercing riveted joints. The International Journal of Advanced Manufacturing Technology, 2012. 58(5-8): p. 643-649. 
88. Booth, G., et al., Self-piercing riveted joints and resistance spot welded joints in steel and aluminium. 2000, SAE Technical Paper.

89. Chen, Y., et al., Fretting wear in self-piercing riveted aluminium alloy sheet. Wear, 2003. 255(7): p. 1463-1470.

90. Zhang, J. and S. Yang, Self-piercing riveting of aluminum alloy and thermoplastic composites. Journal of Composite Materials, 2014: p. 0021998314535456.

91. Xing, B., et al., Mechanical properties of self-piercing riveted joints in aluminum alloy 5052. The International Journal of Advanced Manufacturing Technology, 2014. 75(1-4): p. 351-361.

92. Settineri, L., E. Atzeni, and R. Ippolito, Self piercing riveting for metal-polymer joints. International Journal of Material Forming, 2010. 3(1): p. 995-998.

93. Cai, W., P. Wang, and W. Yang, Assembly dimensional prediction for self-piercing riveted aluminum panels. International Journal of Machine Tools and Manufacture, 2005. 45(6): p. 695-704.

94. Fratini, L. and V.F. Ruisi, Self-piercing riveting for aluminium alloys-composites hybrid joints. The International Journal of Advanced Manufacturing Technology, 2009. 43(1-2): p. 61-66.

95. Chrysanthou, A., 3 - Fatigue behaviour of self-piercing riveted joints, in Self-Piercing Riveting, A. Chrysanthou and X. Sun, Editors. 2014, Woodhead Publishing. p. 33-40.

96. Han, L., A. Chrysanthou, and J.M. O'Sullivan, Fretting behaviour of self-piercing riveted aluminium alloy joints under different interfacial conditions. Materials \& Design, 2006. 27(3): p. 200-208.

97. Kweon, J.-H., et al., Failure of carbon composite-to-aluminum joints with combined mechanical fastening and adhesive bonding. Composite structures, 2006. 75(1): p. 192-198.

98. Xiao, Y. and T. Ishikawa, Bearing strength and failure behavior of bolted composite joints (part I: Experimental investigation). Composites Science and Technology, 2005. 65(7): p. 1022-1031.

99. Di Franco, G. and B. Zuccarello, Analysis and optimization of hybrid double lap aluminum-GFRP joints. Composite Structures, 2014. 116: p. 682-693.

100. Barut, A. and E. Madenci, Analysis of bolted-bonded composite single-lap joints under combined in-plane and transverse loading. Composite Structures, 2009. 88(4): p. 579-594.

101. Fu, M. and P. Mallick, Fatigue of hybrid (adhesive/bolted) joints in SRIM composites. International journal of adhesion and adhesives, 2001. 21(2): p. 145-159.

102. Lee, C.-J., et al., Design of mechanical clinching tools for joining of aluminium alloy sheets. Materials \& Design, 2010. 31(4): p. 1854-1861.

103. Association, E.A. The Aluminium Automotive Manual. 2002 [cited 2014; Available from: http://www.alueurope.eu/wp-content/uploads/2012/01/AAM-Joining-5-Mechanicaljoining.pdf.

104. Oudjene, M. and L. Ben-Ayed, On the parametrical study of clinch joining of metallic sheets using the Taguchi method. Engineering Structures, 2008. 30(6): p. 1782-1788.

105. Oudjene, M., et al., Shape optimization of clinching tools using the response surface methodology with Moving Least-Square approximation. Journal of Materials Processing Technology, 2009. 209(1): p. 289-296.

106. Varis, J., The suitability of clinching as a joining method for high-strength structural steel. Journal of Materials Processing Technology, 2003. 132(1): p. 242-249.

107. Abe, Y., T. Kato, and K. Mori. Joining of aluminium alloy and mild steel sheets using mechanical clinching. in Materials Science Forum. 2007. Trans Tech Publ.

108. Abe, Y., et al., Joining of hot-dip coated high-strength steel sheets by mechanical clinching. Steel Research International, 2010. 81(9): p. 1128-1131.

109. Abe, Y., K. Mori, and T. Kato, Joining of high strength steel and aluminium alloy sheets by mechanical clinching with dies for control of metal flow. Journal of Materials Processing Technology, 2012. 212(4): p. 884-889.

110. Su, Z.-M., et al., Fatigue Analyses of Self-Piercing Rivets and Clinch Joints in Lap-Shear Specimens of Aluminum Sheets. International Journal of Fatigue, 2014. 
111. Mori, K., Y. Abe, and T. Kato, Mechanism of superiority of fatigue strength for aluminium alloy sheets joined by mechanical clinching and self-pierce riveting. Journal of Materials Processing Technology, 2012. 212(9): p. 1900-1905.

112. Mucha, J., The analysis of lock forming mechanism in the clinching joint. Materials \& Design, 2011. 32(10): p. 4943-4954.

113. Carle, D. and G. Blount, The suitability of aluminium as an alternative material for car bodies. Materials \& Design, 1999. 20(5): p. 267-272.

114. Gao, S. and L. Budde, Mechanism of mechanical press joining. International Journal of Machine Tools and Manufacture, 1994. 34(5): p. 641-657.

115. Mori, K.-i., et al., Joining by plastic deformation. CIRP Annals - Manufacturing Technology, 2013. 62(2): p. 673-694.

116. Lee, C.-J., et al., Design of hole-clinching process for joining of dissimilar materials -Al6061-T4 alloy with DP780 steel, hot-pressed 22MnB5 steel, and carbon fiber reinforced plastic. Journal of Materials Processing Technology, 2014. 214(10): p. 2169-2178.

117. Lee, C.-J., et al., Design of hole-clinching process for joining CFRP and aluminum alloy sheet. International Journal of Precision Engineering and Manufacturing, 2014. 15(6): p. 1151-1157.

118. Ueda, M., et al., Instantaneous mechanical fastening of quasi-isotropic CFRP laminates by a self-piercing rivet. Composite Structures, 2012. 94(11): p. 3388-3393.

119. de Paula, A.A., et al., Finite element simulations of the clinch joining of metallic sheets. Journal of Materials Processing Technology, 2007. 182(1-3): p. 352-357.

120. Kim, J., et al., Effect of shape parameters of tool on improvement of joining strength in clinching. Trans Mater Process, 2009. 18: p. 392-399.

121. Mucha, J., L. KaŠČÁK, and E. SpiŠÁK, Joining the car-body sheets using clinching process with various thickness and mechanical property arrangements. Archives of Civil and Mechanical Engineering, 2011. 11(1): p. 135-148.

122. Davies, P., et al., Joining and repair of a carbon fibre-reinforced thermoplastic. Composites, 1991. 22(6): p. 425-431.

123. Wise, R., New technique for joining dissimilar materials. Welding Review International, 1993. 2: p. 40-42.

124. Assuncao, D., et al. Conduction mode: broadening the range of applications for laser welding. in 63rd Annual Assembly \& International Conference of the International Institute of Welding. 2010. Istanbul, Turkey.

125. Katayama, S., Y. Kawahito, and M. Mizutani, Latest progress in performance and understanding of laser welding. Physics Procedia, 2012. 39: p. 8-16.

126. Tan, X., et al., Characteristics and formation mechanism of porosities in CFRP during laser joining of CFRP and steel. Composites Part B: Engineering, 2015. 70: p. 35-43.

127. Xianghu, T., S. Jiguo, and R. Jialie, Effects of $\mathrm{Cr}$ plating layer on shear strength and interface bonding characteristics of mild steel/CFRP joint by laser heating. Acta Metall Sin, 2013. 49(6): p. 751-756.

128. Katayama, S. and Y. Kawahito, Laser direct joining of metal and plastic. Scripta Materialia, 2008. 59(12): p. 1247-1250.

129. Rohde, M., C. Markert, and W. Pfleging, Laser micro-welding of aluminum alloys: experimental studies and numerical modeling. The International Journal of Advanced Manufacturing Technology, 2010. 50(1-4): p. 207-215.

130. Esteves, J., et al., Friction spot joining of aluminum AA6181-T4 and carbon fiber-reinforced poly (phenylene sulfide): effects of process parameters on the microstructure and mechanical strength. Materials \& Design, 2015. 66: p. 437-445.

131. André, N.M., et al., Friction Spot Joining of aluminum alloy 2024-T3 and carbon-fiberreinforced poly (phenylene sulfide) laminate with additional PPS film interlayer: Microstructure, mechanical strength and failure mechanisms. Composites Part B: Engineering, 2016. 94: p. 197-208. 
132. Goushegir, S., J. Dos Santos, and S. Amancio-Filho, Friction spot joining of aluminum AA2024/carbon-fiber reinforced poly (phenylene sulfide) composite single lap joints: microstructure and mechanical performance. Materials \& Design, 2014. 54: p. 196-206.

133. Goushegir, S., J. dos Santos, and S. Amancio-Filho, Influence of process parameters on mechanical performance and bonding area of AA2024/carbon-fiber-reinforced poly (phenylene sulfide) friction spot single lap joints. Materials \& Design, 2015. 83: p. 431-442.

134. Ma, C.c.M., et al., Thermal and rheological properties of poly (phenylene sulfide) and poly (ether etherketone) resins and composites. Polymer composites, 1987. 8(4): p. 256-264.

135. Li, X.G., et al., High - resolution thermogravimetry of polyphenylene sulfide film under four atmospheres. Journal of applied polymer science, 2002. 83(10): p. 2053-2059.

136. Wouters, O., et al., On the evolution of surface roughness during deformation of polycrystalline aluminum alloys. Acta materialia, 2005. 53(15): p. 4043-4050.

137. Lampman, S., Characterization and failure analysis of plastics. 2003, Ohio: ASM International.

138. Thomas, W. and E. Nicholas, Friction stir welding for the transportation industries. Materials \& Design, 1997. 18(4): p. 269-273.

139. Chen, Y. and K. Nakata, Friction stir lap joining aluminum and magnesium alloys. Scripta Materialia, 2008. 58(6): p. 433-436.

140. Liu, F., J. Liao, and K. Nakata, Joining of metal to plastic using friction lap welding. Materials \& Design (1980-2015), 2014. 54: p. 236-244.

141. Nagatsuka, K., et al., Direct joining of carbon-fiber-reinforced plastic to an aluminum alloy using friction lap joining. Composites Part B: Engineering, 2015. 73: p. 82-88.

142. Camanho, P.P. and F. Matthews, Stress analysis and strength prediction of mechanically fastened joints in FRP: a review. Composites Part A: Applied Science and Manufacturing, 1997. 28(6): p. 529-547.

143. Heimbs, S., et al., Static and dynamic failure behaviour of bolted joints in carbon fibre composites. Composites Part A: Applied Science and Manufacturing, 2013. 47: p. 91-101.

144. Hart-Smith, L., Mechanically-fastened joints for advanced composites-phenomenological considerations and simple analyses, in Fibrous composites in structural design. 1980, Springer. p. 543-574.

145. Kretsis, G. and F. Matthews, The strength of bolted joints in glass fibre/epoxy laminates. Composites, 1985. 16(2): p. 92-102.

146. Collings, T., The strength of bolted joints in multi-directional CFRP laminates. Composites, 1977. 8(1): p. 43-55.

147. Hart-Smith, L., Design and analysis of bolted and riveted joints in fibrous composite structures, in Recent advances in structural joints and repairs for composite materials. 2003, Springer. p. 211-254.

148. Hodgkinson, J., D. de Beer, and F. Matthews, The strength of bolted joints in Kevlar RP. ESA SP, 1986. 243: p. 53-61.

149. Collings, T., On the bearing strengths of CFRP laminates. Composites, 1982. 13(3): p. 241-252.

150. Ozen, M. and O. Sayman, Failure loads of mechanical fastened pinned and bolted composite joints with two serial holes. Composites Part B: Engineering, 2011. 42(2): p. 264-274.

151. Karakuzu, R., et al., Failure behavior of laminated composite plates with two serial pin-loaded holes. Composite structures, 2008. 82(2): p. 225-234.

152. Quinn, W. and F. Matthews, The effect of stacking sequence on the pin-bearing strength in glass fibre reinforced plastic. Journal of Composite Materials, 1977. 11(2): p. 139-145.

153. Karakuzu, R., et al., Effects of geometric parameters on failure behavior in laminated composite plates with two parallel pin-loaded holes. Composite structures, 2008. 85(1): p. 19.

154. Blackketter, D.M., et al., Evaluation of fiber surfaces treatment and sizing on the shear and transverse tensile strengths of carbon fiber - reinforced thermoset and thermoplastic matrix composites. Polymer composites, 1993. 14(5): p. 430-436. 
155. Faraz, A., D. Biermann, and K. Weinert, Cutting edge rounding: An innovative tool wear criterion in drilling CFRP composite laminates. International Journal of Machine Tools and Manufacture, 2009. 49(15): p. 1185-1196.

156. Astrom, B.T., Manufacturing of polymer composites. 1997: CRC Press.

157. Merino-Pérez, J., et al., On the temperatures developed in CFRP drilling using uncoated WC-Co tools Part I: Workpiece constituents, cutting speed and heat dissipation. Composite Structures, 2015. 123: p. 161-168.

158. Dharan, C. and M. Won, Machining parameters for an intelligent machining system for composite laminates. International Journal of Machine Tools and Manufacture, 2000. 40(3): p. 415-426.

159. Enemuoh, E.U., A.S. El-Gizawy, and A.C. Okafor, An approach for development of damage-free drilling of carbon fiber reinforced thermosets. International Journal of Machine Tools and Manufacture, 2001. 41(12): p. 1795-1814.

160. Langella, A., L. Nele, and A. Maio, A torque and thrust prediction model for drilling of composite materials. Composites Part A: Applied Science and Manufacturing, 2005. 36(1): p. 83-93.

161. Çelik, A., et al., Wear on SiAION ceramic tools in drilling of aerospace grade CFRP composites. Wear, 2015. 338: p. 11-21.

162. Paleen, M. and J. Kilwin, Hole drilling in polymer-matrix composites. Materials Park, OH: ASM International, 2001., 2001: p. 646-650.

163. Celik, A., et al., Investigation on the performance of SiAION ceramic drills on aerospace grade CFRP composites. Journal of Materials Processing Technology, 2015. 223: p. 39-47.

164. DiPaolo, G., S.G. Kapoor, and R. E.DeVor, An experimental investigation of the crack growth phenomenon for drilling of fibre-reinforced composite materials. Trans. ASME J. Eng. Ind. , 1996. 118: p. 104-110.

165. Bonnet, C., et al., CFRP drilling: Fundamental study of local feed force and consequences on hole exit damage. International Journal of Machine Tools and Manufacture, 2015. 94: p. 5764.

166. Kim, D., M. Ramulu, and W. Pedersen, Machinability of titanium/graphite hybrid composites in drilling. Trans. NAMRI/SME, 2005. 33: p. 445-452.

167. Abrao, A., et al., Drilling of fiber reinforced plastics: A review. Journal of Materials Processing Technology, 2007. 186(1): p. 1-7.

168. Bishopp, J., Surface pretreatment for structural bonding. Handbook of Adhesives and Sealants, 2005. 1: p. 163-214.

169. Higashi, A. and M. Lima, Occurrence of defects in laser beam welded Al-CU-Li sheets with Tjoint configuration. Journal of Aerospace Technology and Management, 2012. 4: p. 421-429.

170. Wilson, R., et al., A preliminary structural design procedure for laser beam welded airframe stiffened panels. Thin-Walled Structures, 2012. 55: p. 37-50.

171. Thoppul, S.D., J. Finegan, and R.F. Gibson, Mechanics of mechanically fastened joints in polymer-matrix composite structures-a review. Composites Science and Technology, 2009. 69(3): p. 301-329.

172. Martinsen, K., S. Hu, and B. Carlson, Joining of dissimilar materials. CIRP Annals-Manufacturing Technology, 2015. 64(2): p. 679-699. 